\title{
Phylogeny and Systematic Position of Opiliones: A Combined Analysis of Chelicerate Relationships Using Morphological and Molecular Data ${ }^{1}$
}

\author{
Gonzalo Giribet, ${ }^{*}$ Gregory D. Edgecombe,$\uparrow$ Ward C. Wheeler, $\ddagger$ and \\ Courtney Babbitt $\ddagger$ \\ *Department of Organismic and Evolutionary Biology, Harvard University, 16 Divinity Avenue, \\ Cambridge, Massachusetts 02138; †Centre for Evolutionary Research, Australian Museum, 6 College Street, \\ Sydney, New South Wales 2010, Australia; and $¥$ Division of Invertebrate Zoology, American Museum of \\ Natural History, Central Park West at 79th Street, New York, New York 10024
}

Accepted August 15, 2001

The ordinal level phylogeny of the Arachnida and the suprafamilial level phylogeny of the Opiliones were studied on the basis of a combined analysis of 253 morphological characters, the complete sequence of the 185 rRNA gene, and the D3 region of the 28S rRNA gene. Molecular data were collected for 63 terminal taxa. Morphological data were collected for 35 exemplar taxa of Opiliones, but groundplans were applied to some of the remaining chelicerate groups. Six extinct terminals, including Paleozoic scorpions, are scored for morphological characters. The data were analyzed using strict parsimony for the morphological data matrix and via direct optimization for the molecular and combined data matrices. A sensitivity analysis of 15 parameter sets was undertaken, and character congruence was used as the optimality criterion to choose among competing hypotheses. The results obtained are unstable for the high-level chelicerate relationships (except for Tetrapulmonata, Pedipalpi, and Camarostomata), and the sister group of the Opiliones is not clearly established, although the monophyly of Dromopoda is supported under many parameter

${ }^{1}$ Communicated by J. Muona. sets. However, the internal phylogeny of the Opiliones is robust to parameter choice and allows the discarding of previous hypotheses of opilionid phylogeny such as the "Cyphopalpatores" or "Palpatores." The topology obtained is congruent with the previous hypothesis of "Palpatores" paraphyly as follows: (Cyphophthalmi (Eupnoi (Dyspnoi + Laniatores))). Resolution within the Eupnoi, Dyspnoi, and Laniatores (the latter two united as Dyspnolaniatores nov.) is also stable to the superfamily level, permitting a new classification system for the Opiliones. @ 2002 The Willi Hennig Sociely

Key Words: Arthropoda; Chelicerata; Opiliones; Eupnoi; Dyspnoi; fossils; cladistics; morphology; molecular; phylogeny; 18S rRNA; $28 S$ rRNA.

\section{INTRODUCTION}

The relationships of the extant chelicerate orders have been vigorously debated for over a century (i.e., Thorell, 1877; Lankester, 1881; Pocock, 1893; Börner, 1902; Petrunkevitch, 1955; Sharov, 1966; Savory, 1971; 
Firstman, 1973; Yoshikura, 1975; van der Hammen, 1977a,b, 1979, 1982, 1985, 1986; Grasshoff, 1978; see a summary of these hypotheses in Wheeler and Hayashi, 1998) using nonnumerical methods of character analysis. The most recent studies have used more quantitative methodologies for the analysis of morphological (Weygoldt and Paulus, 1979a,b; Shultz, 1990; Wheeler and Hayashi, 1998) and molecular data (Turbeville et al., 1991; Wheeler and Hayashi, 1998), although agreement in the proposed phylogenies has not been reached.

One of the most challenging matters in arachnid systematics is the phylogenetic position of the Opiliones (i.e., Pocock, 1893; Savory, 1971; Grasshoff, 1978; van der Hammen, 1985, 1986). Based on cladistic analyses of morphological data, Weygoldt and Paulus (1979a,b) placed the Opiliones as sister group to (Ricinulei + Acari), with the three of them as a sister group to Haplocnemata (Fig. 1A). However, the morphological parsimony-based analysis of Shultz (1990), and the combined parsimony analysis of morphological and molecular data by Wheeler and Hayashi (1998), placed the Opiliones as the sister group of a clade containing Scorpiones, Solifugae, and Pseudoscorpiones (Figs. 1B and 1C), constituting the Dromopoda. These are two radically different hypotheses, and new data are needed to test these possibilities.

The order Opiliones has generally been divided into three principal clades, with the rank of suborders: $\mathrm{Cy}$ phophthalmi, Palpatores, and Laniatores (Hansen and Sørensen, 1904; Roewer, 1923; Shear, 1982; Hennig,
1986; Shultz, 1998). Hansen and Sørensen (1904) also recognized two tribes of "Palpatores," namely Eupnoi and Dyspnoi, which were raised to a subordinal rank by Silhavhý (1961). In contrast to this, Martens and co-workers (Martens, 1976, 1980, 1986; Martens et al., 1981), based primarily on genital characters, proposed a new clade, "Cyphopalpatores," containing the $\mathrm{Cy}$ phophthalmi nested within a paraphyletic "Palpatores" (Fig. 2A). However, Martens' hypothesis relied on a priori assumptions of character evolution and lacked a numerical treatment of data.

Because of the necessity for a numerical treatment of opilionid internal relationships, Shultz (1998) undertook parsimony analyses of morphological data. His conclusion, based on a parsimony analysis of 26 morphological characters for 17 terminal taxa, was consistent with the classical hypothesis that considered "Palpatores" to be monophyletic (sensu Hansen and Sørensen, 1904) (Fig. 2B). However, although Shultz's analysis included all opilionid superfamilies, it was biased toward a larger representation of Dyspnoi (six taxa), while including only two Eupnoi and a single representative of the Cyphophthalmi. Certainly, if the relationships among these three groups are problematic, more expansive taxonomic sampling should be expected to better resolve this situation. Giribet $e t$ al. [1999c (this study was part of an unpublished thesis by Giribet, 1997); see also Giribet and Wheeler, 1999] analyzed a data matrix of 45 morphological characters extracted primarily from the literature and DNA sequence data from the $18 \mathrm{~S}$ rRNA gene (ca. $1800 \mathrm{bp}$ ) and
A

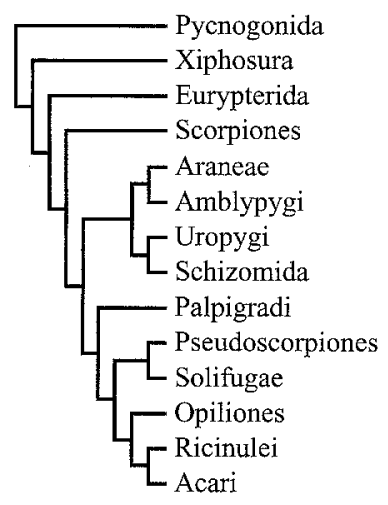

B

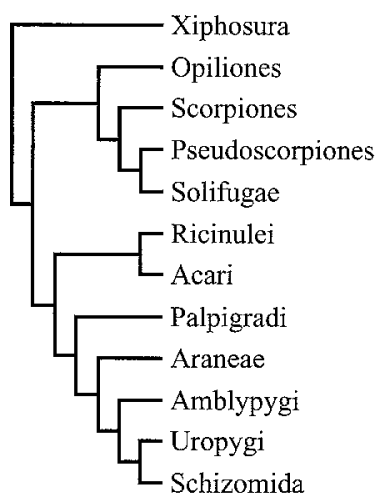

C

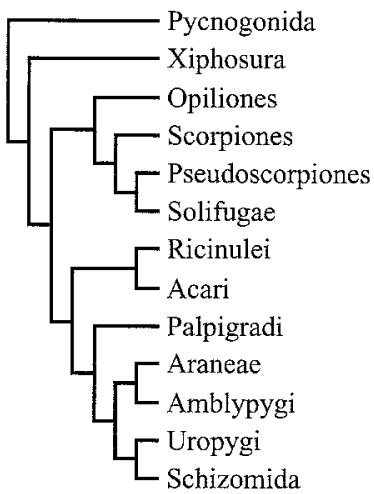

FIG. 1. Cladistic hypotheses for the relationships among chelicerate orders of (A) Weygoldt and Paulus (1979a,b) (based on morphology), (B) Shultz (1990) (based on morphology), and (C) Wheeler and Hayashi (1998) (based on morphology and ribosomal sequence data). 
A

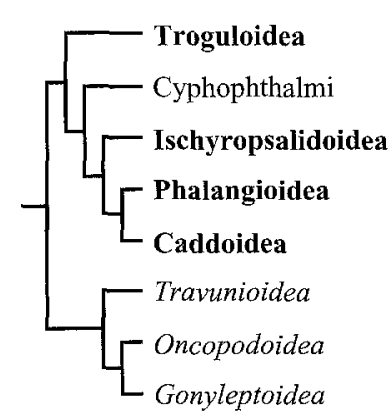

B

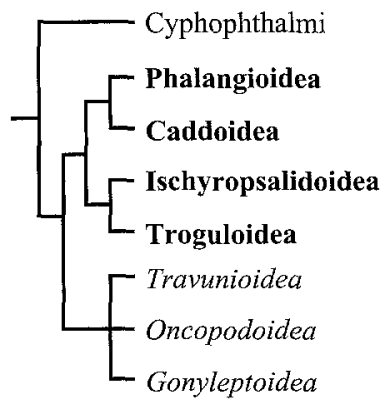

C

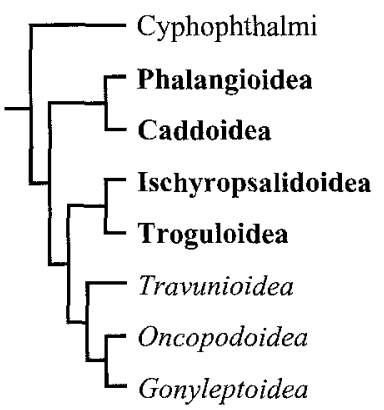

FIG. 2. Cladistic hypotheses for the relationships among the opilionid superfamilies. Cyphophthalmi are in regular font, "Palpatores" [both Eupnoi (Phalangioidea and Caddoidea) and Dyspnoi (Ischyropsalidoidea and Troguloidea)] in bold, and Laniatores in italic. (A) "Cyphopalpatores" hypothesis of Martens (1976, 1980, 1986; Martens et al., 1981). (B) "Classical" hypothesis of Shultz (1998) with monophyly of "Palpatores." (C) Hypothesis of Giribet et al. (1999c) with paraphyly of "Palpatores."

the D3 region of the $28 \mathrm{~S}$ rRNA gene (ca. $350 \mathrm{bp}$ ). Both morphological and molecular data were consistent with Silhavhy's (1961) hypothesis considering the Eupnoi and Dyspnoi as independent groups (Fig. 2C). The classical hypothesis, however, was also obtained in some analyses when molecular characters were equally weighted. All the superfamilies of opilionid taxa were represented, but only three Cyphophthalmi, three Eupnoi, and three Dyspnoi were used in that analysis.

In summary, the hypotheses of relationships proposed by the three groups of authors (Martens, Giribet, and Shultz) differ in the status (monophyletic, paraphyletic, or polyphyletic) of the so-called "Palpatores" (Phalangioidea, Caddoidea, Ischyropsalidoidea, and Troguloidea). Martens (1976, 1980, 1986; Martens et al., 1981) considered the "Palpatores" as including the Sironoidea, making them paraphyletic, (Troguloidea (Sironoidea (Ischyropsalidoidea (Caddoidea + Phalangioidea)) )), and renamed this clade "Cyphopalpatores" (Fig. 2A). Alternatively, Shultz (1998) and Giribet et al. (1999c) placed the root of the Opiliones tree on the branch that separates the Cyphophthalmi from the Phalangida (= "Palpatores" plus Laniatores). However, Shultz (1998) considered the "Palpatores" to be monophyletic (Fig. 2B), whereas Giribet et al. (1999c) considered the "Palpatores" to be paraphyletic with respect to the Laniatores (Fig. 2C).

The objectives of this study are twofold. First, we want to revisit internal opilionid relationships. Second, due to the necessity of defining the sister group relationships of the order Opiliones, we undertake a study of ordinal arachnid relationships. These objectives should determine a more exact position of the Opiliones within the chelicerate tree, as well as permitting a new internal system of classification for the order Opiliones. This contribution presents a much more exhaustive taxon sampling than has been undertaken in previous molecular work for both Chelicerata and Opiliones. Compared to the 25 chelicerate partial 185 rRNA sequences considered by Wheeler and Hayashi (1998), and the 15 opilionid sequences considered by Giribet et al. (1999c), we use a total of 63 chelicerate complete $18 \mathrm{~S}$ rRNA sequences (including 35 opilionid sequences) and 57 sequences of the $\mathrm{D} 3$ region of the $28 \mathrm{~S}$ rRNA gene (including 32 opilionid sequences). We include the first molecular data for the order Palpigradi. All orders of chelicerates (except Palpigradi and Uropygi) and superfamilies of Opiliones (except Caddoidea) are represented by more than one terminal taxon. In addition, we have assembled new morphological data for the same set of terminal taxa used in the molecular analyses (see details about the characters in Appendix 1 and character codings in Appendix 2) and included fossils for the morphology codings. The expanded taxonomic sample together with the combined analysis of the morphological and molecular data sets is designed to contribute to a clearer understanding of arachnid and opilionid relationships.

\section{Controversies in Chelicerate Phylogeny}

Many contentious issues about the internal phylogeny of the chelicerates have been treated elsewhere (see reviews in Weygoldt, 1998; Wheeler and Hayashi, 
1998), and thus we focus here on just a few problems. Table 1 summarizes nomenclature used for supraordinal chelicerate relationships.

The choice of an outgroup and the phylogenetic position of the Pycnogonida. The Pycnogonida was placed incertae sedis at the base of the Chelicerata by Weygoldt and Paulus (1979a,b). Later, in his cladistic analysis of arthropod relationships, Weygoldt (1986) placed pycnogonids as the sister group to the Chelicerata (Xiphosura + Arachnida), a position corroborated by brain studies (Strausfeld, 1998) and in subsequent morphological, molecular, and combined analyses of morphological data (Wheeler et al., 1993;

TABLE 1

Some Proposed Nomenclature for Chelicerate Orders Used in This Article

Acaromorpha Dubinin, 1957 (= Acarinomorpha Weygoldt and Paulus, 1979)

Ricinulei + Acari

Arachnida Lamarck, 1801

Araneae + Amblypygi + Uropygi + Schizomida + Palpigradi

+ Ricinulei + Acari + Pseudoscorpiones + Solifugae + Opiliones + Scorpiones

Camarostomata Petrunkevitch, 1949

Uropygi + Schizomida

Dromopoda Shultz, 1990

Scorpiones + Pseudoscorpiones + Solifugae + Opiliones

Haplocnemata Börner, 1904

Pseudoscorpiones + Solifugae

Labellata Petrunkevich, 1949

Araneae + Amblypygi

Lipoctena Pocock, 1893

Araneae + Amblypygi + Uropygi + Schizomida + Palpigradi

+ Ricinuclei + Acari + Pseudoscorpiones + Solifugae

+ Opiliones

Megoperculata Börner, 1902

Araneae + Amblypygi + Uropygi + Schizomida + Palpigradi

Merostomata Dana, 1852

Xiphosura + Eurypterida

Micrura Hansen and Srrensen, 1904

Araneae + Amblypygi + Uropygi + Schizomida + Palpigradi + Ricinulei + Acari

Novogenuata Shultz, 1990

Scorpiones + Pseudoscorpiones + Solifugae

Pedipalpi Latreille, 1810

Amblypygi + Uropygi + Schizomida

Tetrapulmonata Shultz, 1990

Araneae + Amblypygi + Uropygi + Schizomida

Phalangioidea Thorell, 1876

Eupnoi + Dyspnoi + Laniatores

Palpatores Thorell, 1876

Eupnoi + Dyspnoi

Dyspnolaniatores New clade

Dyspnoi + Laniatores
Wheeler, 1995, 1998a,b; Wheeler and Hayashi, 1998; Giribet and Ribera, 1998; Edgecombe et al., 2000). However, an alternative possibility has been proposed, with Pycnogonida as the sister group to the remaining Arthropoda, with the scheme (Pycnogonida (Chelicerata + Mandibulata)), making "Chelicerata s. lat." a paraphyletic group ${ }^{1}$ (Zrzavý et al., 1998; morphological analysis of Edgecombe et al., 2000; see also Giribet and Ribera, 2000). Giribet et al. (1999b) discussed both hypotheses and stated that the addition of fossil taxa, especially the Devonian pantopod Palaeoisopus (Bergström et al., 1980), which possesses certain chelicerate synapomorphies not present in extant pycnogonids, could definitely resolve this issue.

In this study, we employ Pycnogonida and Trilobita as outgroups for the internal phylogeny of the Chelicerata because this is the best corroborated hypothesis (the one obtained with the largest amount of data in combined analyses). Moreover, irrespective of whether Pycnogonida is actually sister group to Chelicerata (e.g., Wheeler and Hayashi, 1998; Edgecombe et al., 2000) or sister group to the remaining Arthropoda (e.g., Zrzavý et al., 1998; morphological analysis of Edgecombe et al., 2000), it still represents an appropriate outgroup choice for examining internal chelicerate phylogeny.

The status of the Pedipalpi. The Pedipalpi is a taxon named by Latreille (1810), which originally included the orders Amblypygi, Uropygi, and Schizomida, although Börner (1902) expanded the taxon to include Palpigradi. Other authors, however, consider the Amblypygi to be more closely related to Araneae than to Camarostomata (Platnick and Gertsch, 1976; Weygoldt and Paulus, 1979a,b). Shultz (1990) found morphological support for the Pedipalpi and listed six putative synapomorphies for the group. However, Wheeler and Hayashi (1998), although recognizing the grouping Pedipalpi in $65 \%$ of the combined analyses performed, did not find support for Pedipalpi in the analyses that optimized congruence between morphological and molecular data (their optimality criterion). In a recent paper, Shultz (1999) studied in detail the muscular anatomy of one amblypygid and listed 31 putative synapomorphies that support

\footnotetext{
'This is the reason we apply the classical term "Chelicerata s. str." to the "Euchelicerata" and will refer to Pycnogonida + Chelicerata as "Chelicerata s. lat."
} 
the monophyly of Pedipalpi. The addition of new molecular data, and the expansion of the chelicerate morphological data set, should help to resolve this issue.

The position of the Opiliones. As mentioned above, the phylogenetic position of the Opiliones is one of the most challenging matters in arachnid systematics. For many authors "opilionids are evidently closest to some groups of mites ..." (Shear, 1982, p. 105), although other hypotheses exist. In this study, we attempt to definitively position the Opiliones with respect to the other chelicerate orders by considering as much evidence as possible, although recognizing that this contentious issue might be hard to resolve due to the numerous apomorphic morphological features present in the Opiliones, such as the genital organs.

Fossil terminals. Certain extinct clades that are known from well-preserved fossils have figured prominently in considerations of arachnid phylogeny. Foremost among these is the Eurypterida. The traditional classification of Eurypterida and Xiphosura in the taxon Merostomata (e.g., Størmer, 1955) has generally been rejected as a paraphyletic group; Weygoldt and Paulus (1979a,b), Shultz (1990), and Dunlop and Selden (1998) considered eurypterids to be the sister group of Arachnida. Several recent studies, however, have endorsed closest relations between Eurypterida and Scorpiones (Dunlop and Webster, 1999; Braddy et al., 1999; Dunlop, 1999). These studies have concluded that an "arachnid" clade that includes scorpions is a polyphyletic group. In order to evaluate this hypothesis, we have coded Eurypterida as a terminal taxon and also considered fossil representatives of the Scorpiones.

As reviewed by Jeram (1998) and Weygoldt (1998), the phylogenetic significance of Paleozoic scorpions is controversial. Weygoldt (1998) continued to question. paleontological arguments that the early scorpions were aquatic. Jeram (1998), however, presented sedimentological as well as morphological data in support of aquatic habits for the earliest Scorpiones and reiterated the argument that terrestriality occurred independently in scorpions and arachnids. As noted in the following character discussions, the earliest fossil scorpions lack several characters of terrestrial arachnids, such as trichobothria, stomotheca in a preoral chamber, paired claws, and ocelli. In order to incorporate data from early, aquatic scorpions we have coded representatives of Protoscorpiones and Palaeoscorpiones sensu
Stockwell (1989; see Jeram, 1994b, Fig. 1, Table 1). Stockwell (1989) construed Protoscorpiones as a monophyletic group of Silurian-Devonian taxa, sister group to all other scorpions, and Jeram (1994b) tentatively accepted this view. More recently, though, Jeram (1998) removed the Early Devonian marine Palaeoscorpius from this group, resolving it as sister group to all other scorpions. The remaining genera of Protoscorpiones sensu Stockwell are retained by Jeram (1998) as a clade; this group is composed of the Silurian Dolichophonus, Palaeophonus, and Allopalaeophonus. Jeram's reweighted phylogeny (1998, Fig. 2) resolves "Protoscorpiones" as a grade consisting of the basal two lineages of scorpions. We code the palaeophonid clade based on the well-preserved Palaeophonus and Allopalaeophonus (revised by Kjellsvig-Waering, 1986). The Silurian Proscorpius is the most completely coded representative of Palaeoscorpiones sensu Stockwell in Jeram's (1998) analysis and is thus selected as a palaeoscorpion exemplar.

The Silurian-Permian clade Trigonotarbida has been considered in recent cladistic analyses of arachnid orders and is known from exquisitely-preserved fossils that permit relatively complete character coding (Shear et al., 1987). Trigonotarbids have been considered either a sister group to Tetrapulmonata (Shear et al., 1987; Selden et al., 1991) or a sister group to Ricinulei (Dunlop, 1996b). The combination of (putatively apomorphic) characters implied by these rival schemes justifies inclusion of Trigonotarbida as a terminal taxon.

Fossil taxa are particularly relevant to the problem of rooting for Chelicerata. The chelicerate stem group is sampled from a vast diversity of extinct representatives of the Arachnata. Trilobites serve as probably the best understood of these extinct lineages (Edgecombe and Ramsköld, 1999). Consideration of morphological characters for trilobites permits the relationships of Chelicerata s. str. to be appraised with reference to a taxon in addition to the highly autapomorphic Pycnogonida. Fossil arachnates demonstrate that many characters of pycnogonids (e.g., absence of respiratory lamellae, lateral facetted eyes, pleural folds, and toothed gnathobases) may not be plesiomorphic for Chelicerata. The Devonian pantopod Palaeoisopus (revised by Bergström et al., 1980) displays some apparent plesiomorphies (e.g., segmented abdomen and styliform postanal telson) and is coded as a terminal. 


\section{Controversies in Internal Opilionid Phylogeny}

The monophyly of the Opiliones. Although the monophyly of the Opiliones is not a controversial issue in the current literature, we applied the strictest test of monophyly by adding all the putative sister taxa (including Opilioacarida) or all the taxa that have been postulated to "break" opilionid monophyly. An exam ple is Ricinulei, since Savory (1977) proposed the Cyphophthalmi to be a new order of arachnids from which evolved the Phalangida and the Ricinulei. Implicitly, Savory considered the Opiliones to be paraphyletic with respect to the Ricinulei.

The root of the opilionid tree. The placement of the root in the phylogenetic tree of the Opiliones is ambiguous, and two options have been proposed: (1) root between the "Cyphopalpatores" and the Laniatores (Martens, 1976, 1986; Martens et al., 1981) or (2) root between the Cyphophthalmi and the Phalangida (classical hypotheses and the phylogenetic analyses of Shultz, 1998; Giribet et al., 1999c). This disagreement is most likely due to the observation that the characters used for internal opilionid phylogeny lack homologous structures in the remaining arachnid orders. This is also the reason why Giribet et al. (1999c) used only molecular data to place the root in the opilionid tree. Consequently, we wanted to test both hypotheses again by including the molecular data together with an expanded morphological data set that includes data for the remaining groups of chelicerates.

The "Palpatores" problem. The conflict existing regarding the monophyly or the paraphyly of the "Palpatores" (Eupnoi and Dyspnoi) has been discussed by Giribet et al. (1999c). A reanalysis of these data by Giribet and Wheeler (1999), using character congruence as the optimality criterion to choose among competing hypotheses, seemed to reaffirm the data presented by Giribet $e t$ al. about "Palpatores" paraphyly. However, a recent morphological analysis (Shultz, 1998) supported "Palpatores" as a monophyletic group, as in the classical hypothesis. Compared to the 3 Eupnoi and 3 Dyspnoi taxa used in the analyses of Giribet et al. (1999c), and from the 2 Eupnoi and 6 Dyspnoi taxa used by Shultz (1998), we have increased the sampling to 9 Eupnoi and 11 Dyspnoi, representing the four superfamilies of "Palpatores." This expanded taxonomic sample should help to establish the status of Eupnoi and Dyspnoi, as well as testing the "Cyphopalpatores" hypothesis of Martens and co-workers (Martens, 1976, 1980, 1986; Martens et al., 1981).

The phylogeny of Laniatores. The higher phylogeny of the Laniatores has received little attention in the recent literature except for a few studies of Gonyleptoidea (Kury, 1993). The Laniatores is a well-supported monophyletic group that was divided into two groups by Šilhavý (1961): Oncopodomorphi and Gonyleptomorphi. Later on, Martens (1976) presented his phylogenetic tree with the Laniatores divided into three superfamilies, (Travunioidea (Oncopodoidea + Gonyleptoidea)), although certain authors have said that the Gonyleptoidea could be paraphyletic with respect to the Oncopodoidea, constituting a clade informally named Grassatores by Kury. The relationship proposed by Martens for the Laniatores was also obtained by Giribet et al. (1999c), although alternative topologies were presented by Giribet and Wheeler (1999), for example ((Travunioidea + Oncopodoidea) Gonyleptoidea). With the aim of resolving these controversial issues of the internal phylogeny of the Laniatores, we have expanded the sampling for the three recognized laniatorid superfamilies.

\section{MATERIALS AND METHODS}

\section{Classification Adopted}

The classification system for the Opiliones that we have adopted a priori recognizes four main groups: Cyphophthalmi, Eupnoi, Dyspnoi, and Laniatores (sensu Hansen and Sørensen, 1904; Silhavhý, 1961; Giribet $e t$ al., 1999c). For the internal structure of the Cyphophthalmi, we follow Shear (1980); for the Eupnoi we follow Shear (1975b); for the Dyspnoi and the Laniatores we follow Martens (1976).

Cyphophthalmi. The Cyphophthalmi are small, mite-like opilionids, heavily sclerotized, characterized by several synapomorphies (Shear, 1980; Giribet, 2000). Hansen and Sørensen (1904) recognized a single family of cyphophthalmids, Sironidae, divided into two subfamilies, Sironinae and Stylocellinae. In his cladistic analysis of the Cyphophthalmi, Shear (1980) recognized five families, namely Stylocellidae, Ogoveidae, Neogoveidae, Sironidae, and Pettalidae, later adding 
a sixth family, the Troglosironidae (Shear, 1993c). The Cyphophthalmi constitutes a well-supported monophyletic group that comprises the superfamilies Sironoidea, Stylocelloidea, and Ogoveoidea. Two families belonging to the Sironoidea and Stylocelloidea are sampled here (Sironidae and Stylocellidae).

Martens et al. (1981) based their characterization of the ovipositor of the Sironoidea on original observations of Siro duricorius and Siro rubens, but Martens (1986) synthesized information from many species to describe male genitalia. The somatic characters used by Shultz (1998) were based on Siro acaroides and other Siro species. Giribet et al. (1999c) employed two sironids (Siro rubens and Parasiro coiffaiti) and one stylocellid [Stylocellus sp. (here named StylocellusBL, from Bukit Larut; see Appendix 3)]. In the present study, we included S. rubens, P. coiffaiti, and two Stylocellus species [an undescribed species from Bukit Larut (Taiping, Malaysia) and an unidentified species from Jeram Pasu (Pasu Waterfall, south of Kota Baharu, Kelantan, Malaysia)].

Eupnoi: Caddoidea. The superfamily Caddoidea includes several genera from North America, Chile, New Zealand, Australia, Japan, and South Africa that resemble small phalangioids with large eye tubercles and raptorial palps (Gruber, 1974; Shear, 1975a, 1982, 1996). Some authors consider the Caddoidea to include two families, Caddidae and Acropsopilionidae (e.g., Cokendolpher and Maury, 1990), although Shear recognized a single family, Caddidae, with two subfamilies: Caddinae and Acropsopilionae.

Martens et al. (1981) based their assessment of characters of the ovipositor of the Caddoidea on one species, Caddo agilis. Martens (1986) apparently used the penis of the same species, described in Gruber (1974). This is the same species included in the studies of Shultz (1998) and Giribet et al. (1999c). C. agilis is also the only representative that we have been able to include in our molecular analyses, and thus, no conclusions will be drawn about internal relationships within the Caddoidea.

Eupnoi: Phalangioidea. The superfamily Phalangioidea includes the typical opilionid species that receive the name "daddy-long-legs" or "harvestmen." Phalangioid monophyly has been defined by a single synapomorphy [presence of tibial spiracles (character 82); Hansen and Sørensen, 1904; Shultz, 1998], although the presence of two rows of denticles on the ocularium (character 9) could represent a second synapomorphy for the group. The superfamily comprises several often poorly delimited families with representatives in all continents except Antarctica (Shultz, 1998): Neopilionidae, Monoscutidae, Sclerosomatidae, Phalangiidae, and other members of uncertain position, such as the Protolophinae and Dicranopalpus (Crawford, 1992; Cokendolpher and Lee, 1993).

Martens et al. (1981) studied the ovipositor of Phalangium opilio, Lacinius ephippiatus, and three species of the genus Opilio, which all had very similar ovipositor organs. Shultz (1998) included a single species of this group, the phalangiid Ph. opilio. Giribet et al. (1999c) used in their work representatives of the families Phalangiidae (Odiellus troguloides), and Sclerosomatidae, (Nelima silvatica). Here, we have expanded the sampling within the superfamily to include a representative of the "Metopilio group" (Dalquestia formosa); representatives of the three subfamilies of Phalangiidae [Oligolophinae (O. troguloides), Phalangiinae (Ph. opilio), and Opilioninae (Opilio parietinus)]; and representatives of two subfamilies of Sclerosomatidae [Sclerosomatinae (Astrobunus grallator) and three species of Leiobuninae (N. silvatica, Hadrobunus maculosus, and Leiobunum sp.)]. Representatives of the families Neopilionidae and Megalopsalididae were not included.

Dyspnoi: Ischyropsalidoidea. The superfamily Ischyropsalidoidea comprises seven genera of opilionids with a generally Holarctic distribution. These genera are classified in three families: Ischyropsalididae (with the genus Ischyropsalis), Ceratolasmatidae (including the genera Acuclavella, Ceratolasma, Crosbycus, and Hesperonemastoma), and Sabaconidae [with the genera Sabacon (including "Tomicomerus") and Taracus]. The cladistic relationships between these genera have been analyzed by Shear (1986).

Martens et al. (1981) derived their model of the ovipositor of the Ischyropsalidoidea from Ischyropsalis luteipes, Sabacon viscayanum, and Hesperonemastoma kepharti. The penis characters were obtained from Martens (1986). Shultz (1998) included three genera in his analyses: Ischyropsalis (I. luteipes and I. hellwigi), Sabacon cavicolens, and Hesperonemastoma modestum. Giribet et al. (1999c) included a single species (I. luteipes). In the present study, we have included representatives of the three families of Ischyropsalidoidea and five of the 
genera (Ischyropsalididae, I. luteipes; Ceratolasmatidae, H. modestum and Ceratolasma tricantha; and Sabaconidae, S. cavicolens and Taracus sp.). This more complete taxon sampling within the superfamily allows the monophyly of the group and interfamilial relationships to be addressed.

Dyspnoi: Troguloidea. The superfamily Troguloidea consists of four families, namely Dicranolasmatidae, Nemastomatidae, Nipponopsalididae, and Trogulidae. Nipponopsalididae and Dicranolasmatidae include a single genus each, Nipponopsalis and Dicranolasma, respectively. Nemastomatidae and Trogulidae are more diverse families that group several genera. Nipponopsalis is found in Japan and Korea. The Nemastomatidae is primarily Holarctic. Dicranolasmatidae and Trogulidae are mainly found in Europe, North America, the Middle East, and North Africa.

Martens et al. (1981) based their description of the ovipositor of the Troguloidea on Paranemastoma quadripunctatum (Nemastomatidae), D. scabrum (Dicranolasmatidae), T. nepaeformis, and T. coriciformis (Trogulidae). Martens (1986) did not list the species used in the characterization of the troguloid penis, treating this character as a groundplan for the superfamily. Shultz (1998) used three species in his analysis of morphological characters: Paranemastoma sillii (Nemastomatidae), D. scabrum (Dicranolasmatidae), and T. nepaeformis (Trogulidae). Giribet et al. (1999c) used the species Dicranolasma soerenseni (Dicranolasmatidae) and Centetostoma dubium (Nemastomatidae). Here we have included representatives of the four families of troguloids: Dicranolasmatidae (D. soerenseni), Nemastomatidae (C. dubium, Nemastoma bimaculata, and Ortholasma sp.), Nipponopsalididae (Nipponopsalis abei), and Trogulidae (T. nepaeformis). The taxonomic sampling employed here should allow us to test for monophyly of the superfamily as well as for familial interrelationships.

Laniatores: Travunioidea. The Travunioidea includes four families (Triaenonychidae, Synthetonychidae, Travuniidae, and Cladonychiidae) distributed mainly in temperate regions. They are characterized by being the only laniatorids with internal musculature in the penis and by having triramous or multiramous claws in walking legs III and IV.
Martens et al. (1981) examined the ovipositors of Peltonychia clavigera, Holoscotolemon unicolor, and Theromaster brunnea, and Martens (1986) represented the penis of Peltonychia sp. and H. unicolor. Shultz (1998) used members of the families Travuniidae (Peltonychia) and Cladonychiidae (Holoscotolemon). Giribet et al. (1999c) included a representative of the family Triaenonychidae (Equitius doriae). Here we have represented three species of the family Triaenonychidae (E. doriae, Zuma acuta, and Triaenobunus sp.).

Laniatores: Oncopodoidea. The Oncopodoidea comprises a single family (Oncopodidae) of opilionids from South East Asia. The family includes five genera: Oncopus, Gnomulus (including Pelitnus), Caenoncopus, Palaeoncopus, and Biantoncopus (Martens and Schwendinger, 1998).

Martens et al. (1981) examined the ovipositor of Oncopus acanthochelis, and Martens (1986) based his model of the oncopodid penis on examination of Oncopus (and Pelitnus, which has recently been synonymized with Oncopus by Martens and Schwendinger, 1998). Shultz (1998) included the genus Oncopus. Giribet et al. (1999c) used Oncopus cfr. alticeps in their analyses. Here we have included the somatic characters of Oncopus cfr. alticeps and Gnomulus sp.

Laniatores: Gonyleptoidea. The Gonyleptoidea is one of the most diverse superfamilies of Opiliones, with about 20 families from temperate and tropical regions. Some authors consider the possibility of Gonyleptoidea being paraphyletic with respect to Oncopodoidea.

Martens et al. (1981) based their model of the gonyleptoid ovipositor on the species Bishopella laciniosa, Scotolemon lespesi, Vonones sayi, and an unspecified gonyleptid. Shultz (1998) used the species S. lespesi (Phalangodidae), Vonones ornata (Cosmetidae), and Gonyleptes spp. (Gonyleptidae). Giribet et al. (1999c) used two phalangodids (Maiorerus randoi and S. lespesi), one cosmetid (Gnidia holmbergi) and one gonyleptid (Pachyloides thorellii). In the present study, we have included representatives of the following families: Phalangodidae (M. randoi, S. lespesi, and B. laciniosa), Cosmetidae (G. holmbergi), Gonyleptidae (P. thorellii), and Stygnopsidae (Hoplobunus sp.).

\section{Taxon Sampling}

Exemplar species were chosen to represent all extant orders for the chelicerate analysis and to represent the 
maximum superfamilial diversity for the opilionid analysis. Molecular and morphological data were collected for the Pycnogonida (outgroup to Cheliceratas. str., according to the study of Wheeler and Hayashi, 1998), the Xiphosura, and all the orders of the Arachnida (including the first molecular data for Palpigradi). Every order, except for Palpigradi and Uropygi, was represented by at least two terminal taxa. Within the Opiliones, all the extant superfamilies were included in the analyses with at least two terminal taxa (except for the Caddoidea, for which only $C$. agilis was included). We included as many families as possible, the constraint being availability of molecular data. All the characters for the Opiliones, except for a few characters from internal anatomy, were coded for the exemplar species so as to avoid ground-plan assumptions. In cases in which ground-plan assumptions could not be avoided, this is specified in the character description. For the ordinal level, the most diverse orders (Araneae and Acari) were split into subordinal categories [e.g., Mesothelae, Mygalomorphae, and Araneomorphae for the order Araneae, represented by the species Liphistius bicoloripes (Liphistiidae), Aphonopelma sp. (Theraphosidae), and Nesticus cellulanus (Nesticidae), respectively]. In general, however, ordinal ground plans were assumed.

\section{Morphological Data-Coding Strategy}

Morphological data for Opiliones were obtained from direct study of specimens and, when material was not available, from literature sources, as indicated in the character description section. The morphological matrix comprises 253 characters. Nonindependent characters have been coded as binary, whenever possible. For example, character 9 [ocularium $(0=$ smooth; $1=$ with two rows of denticles)] and character 10 [denticles of the ocularium $(0=$ small; $1=$ well developed $)]$ are in some way dependent. Since the principal homology presence/absence of two rows of denticles is independent of the presence of small or well-developed denticles (there is no hypothesis of polarization a priori), we preferred to treat them as different characters. An alternative coding strategy could have been to code a single character with three states [ocularium $0=$ smooth; 1 = with two rows of small denticles; $2=$ with two rows of well-developed denticles)]. However, this coding would not account for the homology of having two rows of denticles, unless the character is polarized, which incorporates new assumptions in the coding (see Lee and Bryant, 1999).

In other cases, when "linked homology" is not implied, we preferred to combine different states into unordered multistate characters, such as in the case of character 8 [shape of the ocularium $(0=$ rounded; $1=$ with anteriorly projecting bilobed hood equipment with marginal fringe of cuticular projections; 2 = with an erect medial spine)]. In this case, the presence of state 1 is independent of the presence of state 2 , and thus we decided to combine these two features into a single character.

In very few cases, we have opted for polarizing certain characters for which order seems obvious. This is the case, for example, for character 60 [tibia and tarsus of the palp with two rows of long-spined tubercles $(0=$ absent; 1 = present; 2 = spines fused into a lateral flap)]. State 2 is found in a derived group of Opiliones nested within the group that contains state 1 , and thus the assumption may be made that state 2 derives from state 1. Two other characters (204 and 210) have also been treated as ordered. A detailed description of the morphological matrix is provided in Appendix 1.

\section{Molecular Data}

DNA isolation. Genomic DNA samples were obtained from fresh, frozen, or ethanol-preserved tissues by extraction in a solution of guanidinium thiocyanate homogenization buffer following a modified protocol for RNA extraction (Chirgwin et al., 1979). The tissues were homogenized in $1 \mathrm{vol}(400 \mu \mathrm{l})$ of $4 \mathrm{M}$ guanidinium thiocyanate and $0.1 \mathrm{M} \beta$-mercaptoethanol for $1 \mathrm{~h}$, followed by a standard protocol of phenol purification and $3 \mathrm{M}$ sodium acetate precipitation.

DNA amplification. The $18 \mathrm{~S}$ rRNA loci were PCRamplified in three overlapping fragments of about 950, 900 , and $850 \mathrm{bp}$ each, using primer pairs $1 \mathrm{~F}-5 \mathrm{R}, 3 \mathrm{~F}-$ $18 \mathrm{Sbi}$, and $5 \mathrm{~F}-9 \mathrm{R}$, respectively. Primers used in amplification and sequencing were described elsewhere (Giribet et al., 1996, 1999a). The 28S RNA D3 fragment was amplified and sequenced using primers $28 \mathrm{Sa}$ and 28Sb (Whiting et al., 1997).

Amplification was carried out in a $50-\mu 1$ volume reaction, with 1.25 units of AmpliTaq DNA polymerase (Perkin-Elmer), $200 \mu \mathrm{M}$ dNTPs and $1 \mu \mathrm{M}$ each primer. The PCR program consisted of an initial denaturing 
step at $94^{\circ} \mathrm{C}$ for $60 \mathrm{~s}, 35$ amplification cycles $\left(94^{\circ} \mathrm{C}\right.$ for $15 \mathrm{~s}, 49^{\circ} \mathrm{C}$ for $15 \mathrm{~s}, 72^{\circ} \mathrm{C}$ for $15 \mathrm{~s}$ ), and a final step at $72^{\circ} \mathrm{C}$ for $6 \mathrm{~min}$ in a GeneAmp PCR System 9700 (Perkin-Elmer).

DNA sequencing. PCR-amplified samples were purified with the GeneClean III kit (BIO 101, Inc.) and directly sequenced using an automated ABI Prism 377 DNA sequencer. Cycle-sequencing with AmpliTaq DNA polymerase, FS (Perkin-Elmer) using dye-labeled terminators (ABI Prism BigDye Terminator Cycle Sequencing Ready Reaction Kit) was performed in a GeneAmp PCR System 9700 (Perkin-Elmer). The sequencing reaction was carried out in a $10-\mu \mathrm{l}$ volume reaction: $4 \mu$ l of Terminator Ready Reaction Mix, 10-30 $\mathrm{ng} / \mathrm{ml}$ of PCR product, 5 pmol of primer, and $\mathrm{dH}_{2} \mathrm{O}$ to $10 \mu \mathrm{l}$. The cycle-sequencing program consisted of an initial step at $94^{\circ} \mathrm{C}$ for $3 \mathrm{~min}, 25$ sequencing cycles $\left(94^{\circ} \mathrm{C}\right.$ for $10 \mathrm{~s}, 50^{\circ} \mathrm{C}$ for $5 \mathrm{~s}, 60^{\circ} \mathrm{C}$ for $\left.4 \mathrm{~min}\right)$ and a rapid thermal ramp to $4^{\circ} \mathrm{C}$ and hold. The BigDye-labeled PCR products were isopropanol-precipitated following the manufacturer's protocol.

DNA editing. Chromatograms obtained from the automated sequencer were read and contigs made using the sequence editing software Sequencher 3.0. Complete sequences were edited in GDE. The external primers $1 \mathrm{~F}$ and $9 \mathrm{R}$ (for the $18 \mathrm{~S}$ rRNA loci) and 28Sa and $28 \mathrm{Sb}$ (for the $28 \mathrm{~S}$ fragment) were excluded from the analyses. All the new sequences have been deposited in GenBank (see accession codes in Table 2).

\section{Phylogenetic Analyses}

Homology concept in sequence data. While most molecular analyses use strict base-to-base correspondences (a fixed alignment) as their primary homology statement, this approach introduces ambiguity and may have difficulties accommodating sequences of substantially unequal length. In contrast, our first hypothesis of homology corresponds to secondary structural features (see below) followed by a dynamic baseto-base correspondence, as described by the "direct optimization" method (Wheeler, 1996). This has been done by dividing the ribosomal sequences into unambiguously recognizable homologous regions. The split was done first using internal primer regions and then by identifying secondary structural features (Giribet, 1999, 2001). The correspondences among these regions are viewed as primary hypotheses of homology in a
TABLE 2

Taxon Sampling for the Nonopilionid and Opilionid Chelicerates and Accession Codes to GenBank

$18 \mathrm{~S}$ rRNA $28 \mathrm{~S}$ rRNA

\begin{tabular}{|c|c|c|}
\hline (A) Nonop & & \\
\hline Class Pycnogonida & & \\
\hline F. Ammotheidae & & \\
\hline Achelia echinata & $\mathrm{AF} 005438$ & AF005459 \\
\hline F. Callipallenidae & & \\
\hline Callipallene sp. & AF005439 & AF005460 \\
\hline F. Endeidae & & \\
\hline Endeis laevis & AF005441 & AF005462 \\
\hline F. Colossendeidae & & \\
\hline Colossendeis sp. & AF005440 & AF005461 \\
\hline Class Chelicerata & & \\
\hline Order Xiphosura & & \\
\hline Limulus polyphemus & U91490 & U91492 \\
\hline Carcinoscorpius rotundicaudatus & U91491 & U91493 \\
\hline Subclass Arachnida & & \\
\hline Order Scorpiones & & \\
\hline Belisarius xambeui & $\mathrm{AF} 005442$ & AF124954 \\
\hline Androctonus australis & $X 77908^{*}$ & AF124955 \\
\hline Order Ricinulei & & \\
\hline Pseudocellus pearsei & U91489 & AF124956 \\
\hline Ricinoididae sp. & AF124930 & AF062988 \\
\hline Order Solifugae & & \\
\hline Gluvia dorsalis & AF007103 & AF124957 \\
\hline Eusimonia wunderlichi & U29492 & AF124958 \\
\hline Chanbria regalis & AF124931 & AF062983 \\
\hline Order Schizomida & & \\
\hline Stenochrus portoricensis & AF005444 & \\
\hline Hubbardia pentapeltis & AF124932 & AF062990 \\
\hline Order Uropygi & & \\
\hline Mastigoproctus giganteus & AF005446 & AF062989 \\
\hline Order Amblypygi & & \\
\hline Paraphrynus sp. & AF005445 & AF124959 \\
\hline Amblypygi sp. & AF124933 & AF062965 \\
\hline Order Palpigradi & & \\
\hline Eukoenenia n. sp. & AF207648 & AF207653 \\
\hline Order Araneae & & \\
\hline Liphistius bicoloripes & AF007104 & AF124960 \\
\hline Aphonopelma sp. & $\mathrm{X} 13457^{*}$ & $X 90464^{*}$ \\
\hline Nesticus celullanus & AF005447 & AF124961 \\
\hline Order Pseudoscorpiones & & \\
\hline Roncus pugnax & AF005443 & $\mathrm{AF} 124962$ \\
\hline Americhernes sp. & AF124934 & AF062982 \\
\hline Order Acari Acariformes & & \\
\hline Acarus siro & $\mathrm{AF} 022023^{*}$ & \\
\hline Allonothrus russeolus & $\mathrm{AF} 022025^{*}$ & \\
\hline Opilioacariformes & & \\
\hline Opilioacarus texanus & AF124935 & AF124963 \\
\hline Parasitiformes & & \\
\hline Rhipicephalus bursa & AJ003816 & \\
\hline Rhipicephalus sanguineus & & AF062986 \\
\hline
\end{tabular}


TABLE 2-Continued

\begin{tabular}{|c|c|c|}
\hline (B) Opili & & \\
\hline Cyphophthalmi & & \\
\hline Superfamily Sironoidea & & \\
\hline Family Sironidae & & \\
\hline Siro rubens & U36998 & U91494 \\
\hline Parasiro coiffaiti & U36999 & U91495 \\
\hline Family Stylocellidae & & \\
\hline Stylocellus sp. (Bukit Larut) & U91485 & U91496 \\
\hline Stylocellus sp. (Jeram Pasu) & AF173419 & AF173422 \\
\hline Eupnoi & & \\
\hline $\begin{array}{l}\text { Superfamily Phalangioidea } \\
\text { "Metopilio group" }\end{array}$ & & \\
\hline Dalquestia formosa & AF124936 & AF124964 \\
\hline Family Phalangiidae & & \\
\hline Subfamily Oligolophinae & & \\
\hline Odiellus troguloides & X81441 & U91500 \\
\hline Subfamily Phalangiinae & & \\
\hline Phalangium opilio & AF124937 & AF124965 \\
\hline Subfamily Opilioninae & & \\
\hline Opilio parietinus & AF124938 & AF124966 \\
\hline Family Sclerosomatidae & & \\
\hline Subfamily Sclerosomatinae & & \\
\hline Astrobunus grallator & AF124939 & AF124967 \\
\hline Subfamily Leiobunidae & & \\
\hline Nelima silvatica & U91486 & U91501 \\
\hline Leiobunum sp. & AF124940 & AF124968 \\
\hline Hadrobunus maculosus & AF124941 & AF124969 \\
\hline Superfamily Caddoidea & & \\
\hline Family Caddidae & & \\
\hline Caddo agilis & U91487 & U91502 \\
\hline Dyspnoi & & \\
\hline Superfamily & & \\
\hline Ischyropsalidoidea & & \\
\hline Family Ischyropsalidae & & \\
\hline Ischyropsalis luteipes & $\mathrm{U} 37000$ & U91497 \\
\hline Family Ceratolasmatidae & & \\
\hline Hesperonemastoma modestum & AF124942 & AF124970 \\
\hline Ceratolasma tricantha & AF124943 & AF124971 \\
\hline Family Sabaconidae & & \\
\hline Sabacon cavicolens & AF124944 & AF124972 \\
\hline Taracus sp. & AF124945 & $\mathrm{AF} 173423$ \\
\hline Superfamily Troguloidea & & \\
\hline Family Dicranolasmatidae & & \\
\hline Dicranolasma soerenseni & U37001 & U91498 \\
\hline Family Nemastomatidae & & \\
\hline Centetostoma dubium & U37002 & U91499 \\
\hline Ortholasma sp. & AF124946 & AF124973 \\
\hline Nemastoma bimaculatum & AF124947 & AF124974 \\
\hline Family Nipponopsalididae & & \\
\hline Nipponopsalis abei & AF124948 & AF124975 \\
\hline Family Trogulidae & & \\
\hline Trogulus nepaeformis & AF124949 & AF124976 \\
\hline Laniatores & & \\
\hline Superfamily Travunioidea & & \\
\hline Family Triaenonychidae & & \\
\hline Equitius doriae & U37003 & U91503 \\
\hline Triaenobunus sp. & AF124950 & AF124977 \\
\hline Zuma acuta & AF124951 & AF124978 \\
\hline
\end{tabular}

TABLE 2-Continued

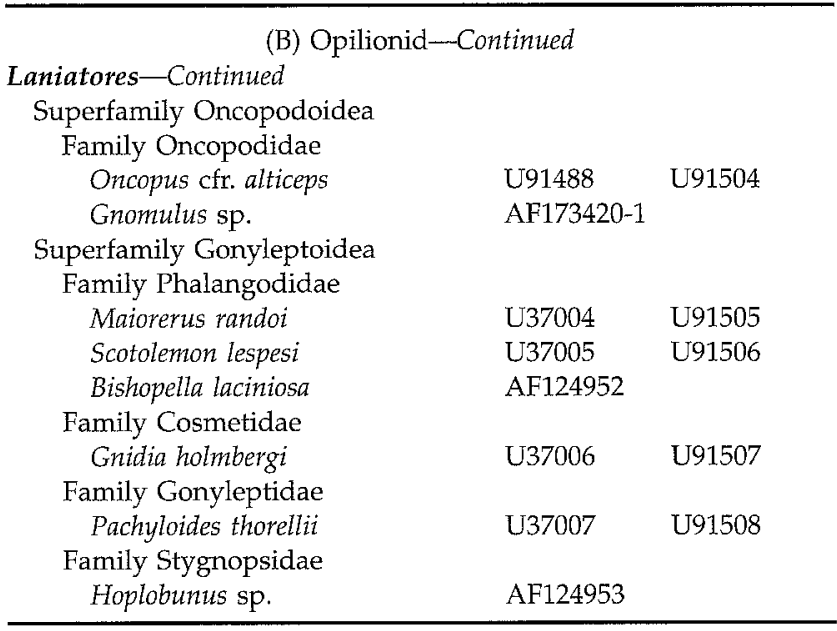

Note. Asterisks indicate sequences not obtained by the authors.

manner analogous to that of an investigator deciding primary homology in morphological features. Also, dividing the sequences into small putatively homologous pieces seems to save computation time without affecting tree length, at least for data sets without much length variation (Giribet, 2001).

In total, the $18 \mathrm{~S}$ rRNA molecule was divided into 10 fragments (excluding the external primers $1 \mathrm{~F}$ and 9R), and the 28S rRNA region was divided into four fragments (excluding external primers $28 \mathrm{Sa}$ and $28 \mathrm{Sb}$ ). The input files contained the unaligned sequences of all terminal taxa. All these sequence files, files containing the parameters used for the analyses, and batch files containing the executable lines of commands are available from http:/ / www.mcz.harvard.edu/Departments/InvertZoo/giribet_data.htm.

Sequence data analysis: Direct optimization. Sequence data were analyzed using the direct optimization method described by Wheeler (1996; see also Wheeler and Hayashi, 1998) and implemented in the computer program POY (Gladstein and Wheeler, 1997). This method directly assesses the number of DNA sequence transformations (evolutionary events) required by a phylogenetic topology without the use of multiple sequence alignment. This is accomplished through a generalization of existing character optimization procedures to include insertion and deletion events (indels) in addition to base substitutions. The crux of the model is the treatment of indels as processes, as opposed to the patterns implied by multiple sequence 
alignment. The results of this procedure are directly compatible with parsimony-based tree lengths and have been shown to generate more efficient (simpler) explanations of sequence variation than multiple alignment (Wheeler, 1996, 2000). The method, although computationally intense, is much less demanding than parsimony-based multiple sequence alignment algorithms. The method has also been demonstrated to yield more congruent results than multiple sequence alignments when using character congruence among partitions (Wheeler and Hayashi, 1998; Wheeler, 2000) or topological congruence (Wheeler, 1999) as a criterion.

Sensitivity analysis. Character transformations were weighted differentially to see how they affect phylogenetic conclusions (sensitivity analysis sensu Wheeler, 1995). A parameter space of two analytical variables was examined: insertion/deletion cost ratio and transversion/transition ratio (as in Wheeler, 1995). When the transversion/transition ratio was set at a value other than unity, the insertion/deletion cost was set according to the cost of transversions. In total, 15 combinations of parameters were employed in the analysis (insertion/deletion ratios of 1,2, and 4; transversion/transition ratios of $1,2,4,8$, and $\infty$ ). This is considered a way to explore the data and to discern between well-supported relationships (those supported throughout a wide range of parameters) and poorly supported relationships (those that appear only with particular parameter sets).

Molecular data analysis. The two molecular partitions were analyzed independently and combined directly, with all characters weighted equally without regard to source. These data sets are referred to hereafter as 18S (18S rRNA data set alone), 28S (28S rRNA data set alone), and molecular $(18 S+28 S)$.

The POY analyses were run in a cluster of 564 processors at 500 to $1000 \mathrm{MHz}$ (see descriptions at http:// clusters.top500.org/db/entry.php3?id = 168) connected in parallel using PVM software and the parallel version of POY (commands -parallel -jobspernode 2 in effect). Each analysis started from the best of 100 "quick" random addition sequence builds (-multibuild 100 -buildspr -buildtbr -approxbuild -buildmaxtrees 1), followed by spr and tbr branch swapping holding one cladogram per round of spr (-sprmaxtrees 1) and tbr (-tbrmaxtrees 1). Two rounds of tree fusing (Goloboff, 1999) (commands -treefuse -fuselimit 10 -fusemingroup 5 -fusemaxtrees 100), drifting (Goloboff, 1999) (commands -driftspr -numdriftchanges -numdriftspr 10 -drifttbr -numdrifttbr 10), ratcheting (Nixon, 1999) (commands -ratchetspr 5 -ratchettbr 5), and swapping on suboptimal cladograms (commands -slop 5 -checkslop 10) were used to make more aggressive searches, holding up to 50 cladograms per round (-maxtrees 50) and using the command -fitchtrees, which saves the most diverse cladograms that can be found for each island. This search strategy was repeated a minimum of 10 times and then up to 1000 times or until minimum cladogram-length was hit 3 times (commands -random 1000 -stopat 3 -minstop 10). The option -multirandom was in effect, which does random replicates in parallel using the 32 subclusters defined by the command controllers 32 . The use of controllers optimizes performance in achieving linearity by using groups of 32 processors (Janies and Wheeler, 2001).

Morphological data analysis. A parsimony analysis of the morphological data set was performed with the computer program NONA version 1.9 (Goloboff, 1998). The tree search strategy involved a heuristic algorithm with random addition-sequence (1000 replications) and tbr branch-swapping (hold10000;hold/10; mult*1000) with additional tbr branch-swapping to completion in all the stored trees (max*), followed by the command jump to search for additional islands of trees. All the morphological characters were equally weighted. Branch support (Bremer, 1988, 1994) up to three extra steps was calculated using a heuristic procedure and holding a maximum of 30,000 trees with NONA (Goloboff, 1998). The potential conflict of dealing with zero-length branches has been explored by doing the analyses under the options "amb-" and "amb $=$ " in NONA (see Coddington and Scharff, 1994).

Combined analysis. Morphological and molecular data (total) were combined directly and analyzed using the direct optimization method (Wheeler, 1996) for the same 15 parameters that were applied to each of the molecular data sets. The morphological transformations were weighted as equal to the highest of the molecular costs (= indels), to diminish the putative overwhelming effect of molecular data versus morphology. Bremer support values were estimated using a heuristic approach implemented in POY. 
Character congruence. Congruence among partitions (morphological and molecular) was measured by the ILD metrics (Mickevich and Farris, 1981; Farris et al., 1995) (see Table 3). This value is calculated by dividing the difference between the overall tree length and the sum of its data components:

$$
\mathrm{ILD}=\frac{\left(\text { length }_{\text {combined }}-\text { sum length }_{\text {individual sets }}\right)}{\text { length }_{\text {combined }}} .
$$

Character congruence is thus used as the optimality criterion to choose the best (most corroborated) tree: the tree that minimizes overall character conflict among the data. This is understood as an extension of parsimony (or any other minimizing criterion); in the same sense that parsimony tries to minimize the number of overall steps in a tree, the character congruence analysis tries to find the model that maximizes congruence for all the data sources.

\section{RESULTS}

\section{Morphological Data Analysis without Fossils}

The search strategy adopted yielded trees of minimum length [469 steps (435 steps removing autapomorphic changes); $\mathrm{CI}=0.59 ; \mathrm{RI}=0.84$ ] in each of 1000 replicates. In total, 70 trees were found after performing the heuristic search strategy adopted. No additional trees were found after tbr-swapping the original 70 trees to completion (the option $\mathbf{a m b}=$, which accommodates ambiguous support of nodes, yielded 288 trees, but does not change the topology of the strict consensus tree).

The strict consensus of the 70 trees (Fig. 3A) shows monophyly of Arachnida, which can be split into two clades. One clade contains an unresolved group with Scorpiones, Solifugae, and Pseudoscorpiones and its sister group, Opiliones $(\mathrm{bs}=3)$. The second clade contains the remaining arachnids, forming a polytomy of Palpigradi (Eukoenenia), Ricinulei, Acari, and Tetrapulmonata. Camarostomata, Pedipalpi, and Tetrapulmonata are the best supported supraordinal groups (bs $>3$ ).

The monophyly of Opiliones is also well supported (bs $>3$ ) and the internal pattern of the group reflects the following structure: (Cyphophthalmi (Eupnoi (Dyspnoi + Laniatores))). Monophyly of Cyphophthalmi is well supported (bs $>3$ ), as well as monophyly of Dyspnoi (bs = 3) and Laniatores (bs $>3$ ). On the contrary, the monophyly of Eupnoi (bs = 1) and Dyspnolaniatores nov. (bs $=1$ ) is supported by fewer characters.

Sironidae, Phalangioidea (= Eupnoi + Dyspnoi + Laniatores), Phalangiidae, Sclerosomatidae, Sabaconidae, Troguloidea, Oncopodidae, Triaenonychidae, and Cosmetidae + Gonyleptidae are among the monophyletic groups obtained. However, neither Stylocellidae, Leiobuninae, Ischyropsalidoidea, Ceratolasmatidae, Gonyleptoidea, nor Phalangodidae is resolved as monophyletic. Leiobuninae is paraphyletic with respect to Astrobunus. Not a single tree based on morphological characters obtains monophyly of the superfamily Ischyropsalidoidea (its monophyly requires a single extra step). Within the Laniatores, the major division is between the two oncopodids and the remaining laniatorids. Testing for tree length of the alternative hypotheses, the "classical" hypothesis of "Palpatores" being monophyletic requires 1 extra step, while the "Cyphopalpatores" hypothesis requires 10 extra steps.

\section{Morphological Data Analysis with Fossils}

The search strategy adopted yielded trees of minimum length [493 steps (465 steps removing autapomorphic changes); $\mathrm{CI}=0.57 ; \mathrm{RI}=0.84]$ in 545 of 1000 replicates. In total, 119 trees were found after performing the heuristic search strategy adopted. One additional tree (a total of 120) was found after tbr-swapping the original 119 trees to completion (the option $\mathrm{amb}=$ yielded 480 trees, without changing the topology of the strict consensus tree).

The strict consensus of the 120 shortest trees (Fig. 3B) leaves many aspects of the basal chelicerate phylogeny unresolved, such as the monophyly of Euchelicerata and the relationships between many arachnid groups. Arachnida is monophyletic, even after including the fossil scorpions. Other relationships supported by the data are the monophyly of Haplocnemata and the clade (Trigonotarbida + Palpigradi + (Ricinulei + Acari) + Tetrapulmonata). A unique relationship between scorpions and eurypterids is not endorsed.

Basal arachnid relationships are best summarized 
A

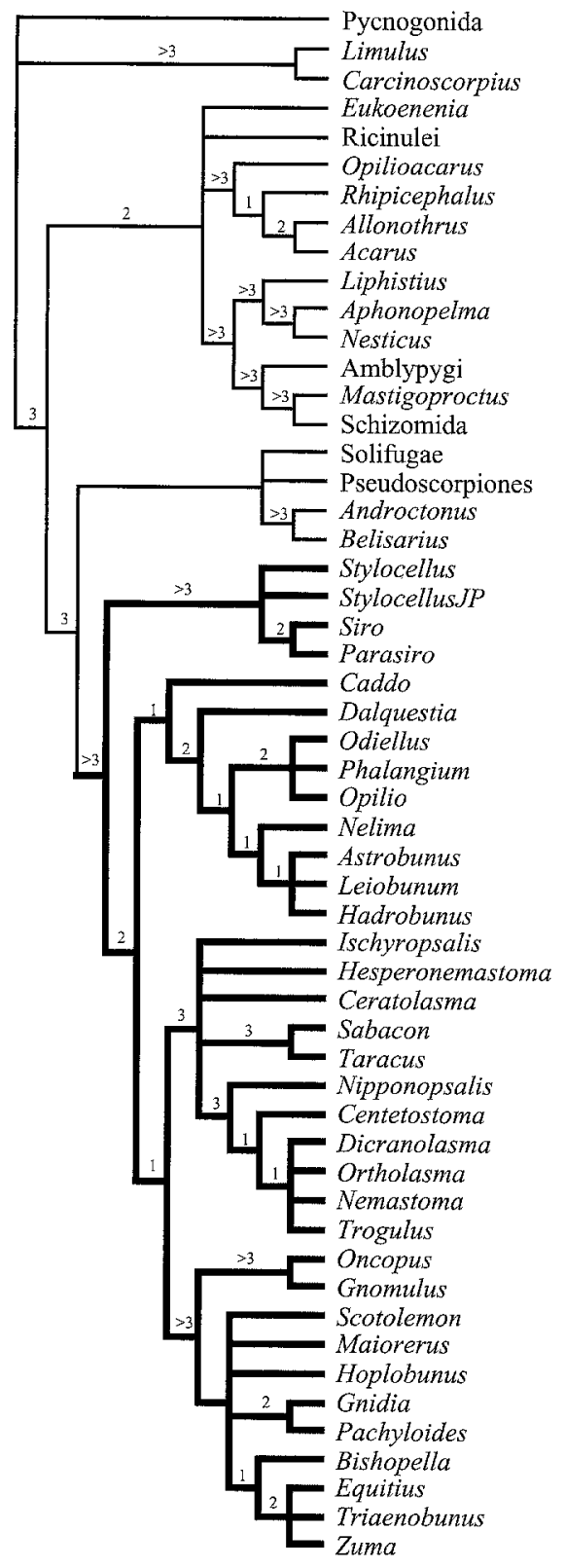

B

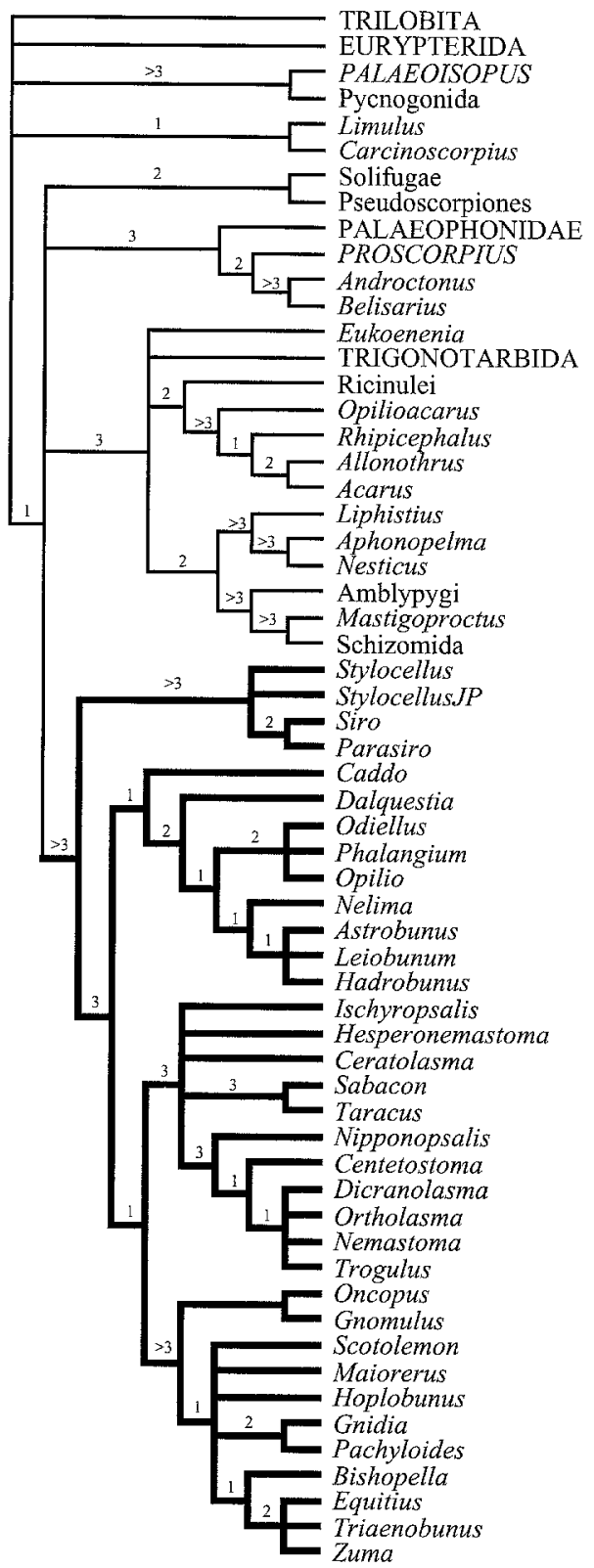

FIG. 3. (A) Strict consensus of 70 trees (469 steps; $C I=0.58$; RI $=0.84$ ) for the morphological data set including only extant taxa. (B) Strict consensus of 120 trees (493 steps; $C I=0.57$; RI $=0.84$ ) for the morphological data set when fossil taxa are included. Opiliones are represented by bold branches. Names of fossil taxa are represented in capitals. Stylocellus is Stylocellus sp. from Bukit Larut; StylocellusjP is Stylocellus sp. from Jeram Pasu. Numbers represent Bremer support values up to three steps; values higher than 3 are indicated by the symbol $>3$.

in a four-taxon tree in which the terminal nodes are Scorpiones (including the aquatic Paleozoic taxa), Opiliones, Haplocnemata, and the remaining arachnids (including Trigonotarbida). Scorpiones is either the sister group to the remaining arachnids or the sister group to Haplocnemata, these two taxa being sisters to Opiliones. This position of Haplocnemata conflicts with two alternatives, being sister group to Opiliones or to the remaining arachnids. A summary of these three alternative hypotheses is found in Fig. 4. 


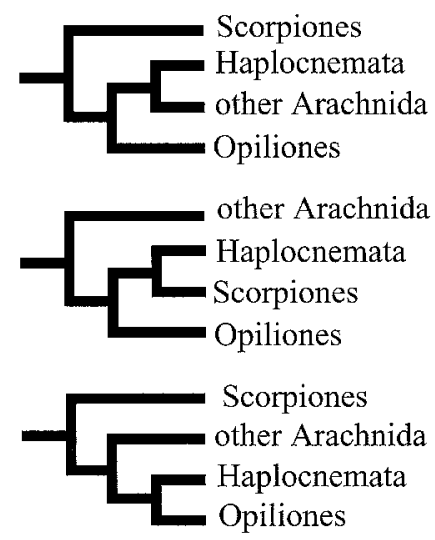

FIG. 4. Equally parsimonious hypotheses of basal arachnid relationships based on the morphological analysis including fossil taxa.

Pedipalpi and Camarostomata are the best supported supraordinal groups, showing bs $>3$. Arachnida, Haplocnemata, the clade containing (Trigonotarbida + Palpigradi + Ricinulei + Acari + Tetrapulmonata), Acaromorpha, and Tetrapulmonata have a Bremer support of 2 . The internal opilionid relationships are identical in both consensus trees, irrespective of whether the fossils are included.

\section{Combined Analysis without Fossils}

The results of the congruence analysis between the two molecular partitions and the morphological partition are shown in Table 3 . The ILD (overall incongruence) is minimized (ILD $=0.0234$ ) at a gap/change ratio of 2 and transversion/transition ratio of 2 [step matrix 221 (see Appendix 4)]. With this parameter set, we obtained two trees of 7999 weighted steps (Fig. 5). Immediate suboptimal parameters are 111 and 211 (ILDs of 0.0258 and 0.0261 , respectively), these being the only other values below 0.0270 .

The combined tree shows monophyly of all chelicerate orders represented by more than one terminal, although it shows nonmonophyly of arachnids, because the Xiphosura appears as an arachnid ingroup, sister to a monophyletic Dromopoda (Scorpiones, Pseudoscorpiones, Solifugae, and Opiliones). Within Dromopoda, Novogenuata and Haplocnemata are also monophyletic, as proposed by Shultz (1990). Palpigradi is sister group to Ricinulei + Tetrapulmonata, which includes a monophyletic Pedipalpi and Camarostomata. Acari appears as the first offshoot of the chelicerate tree.

Opiliones is monophyletic (bs $=40$ ), as are all its "suborders" [Cyphophthalmi (bs = 65), Eupnoi (bs = 23), Dyspnoi (bs = 89), and Laniatores (bs =91)] and "superfamilies" (see Fig. 5). Phalangida (bs $=21$ ) and Dyspnolaniatores are also monophyletic groups, although this last grouping shows lower support (bs =9), comparable to those of the family Sironidae, the superfamily Gonyleptoidea, or the supraordinal category Haplocnemata. Within the Cyphophthalmi, the two families Sironidae and Stylocellidae are well recognized. Within the Eupnoi, Caddo (Caddoidea, Caddidae) is sister to the Phalangioidea, which shows the structure (Dalquestia (Phalangiidae + Sclerosomatidae)).

The Dyspnoi is divided into two monophyletic groups: the superfamilies Ischyropsalidoidea $(b s=28)$ and Troguloidea ( $b s=59)$. Within the Ischyropsalidoidea, Hesperonemastoma (Ceratolasmatidae) is sister taxon to Taracus (Sabaconidae), this clade being sister to Sabacon (Sabaconidae), and Ceratolasma (Ceratolasmatidae) is sister to Ischyropsalis (Ischyropsalidae). If this topology is correct, the families Ceratolasmatidae and Sabaconidae are nonmonophyletic. Within the Troguloidea, Nipponopsalis (Nipponopsalididae) is sister to the remaining troguloids, with a clade containing (Dicranolasma + Trogulus) and another clade containing the three nemastomatids (Ortholasma (Centetostoma + Nemastoma)).

The Laniatores is divided into three monophyletic groups (Travunioidea (Oncopodoidea + Gonyleptoidea)). Within the Travunioidea, Equitius is sister taxon to Triaenobunus. Within the Gonyleptoidea, the three phalangodids are monophyletic and sister to the remaining taxa (Stygnopsidae (Cosmetidae + Gonyleptidae)). Bremer support values for the three superfamilies are moderately high (see Fig. 5).

\section{Combined Analysis with Fossils}

The results of the congruence analysis between the three partitions used are shown in Table 3. The ILD (overall incongruence) is minimized (ILD $=0.0213$ ) at a gap/change ratio of 2 and transversion/transition ratio of 2 [step matrix 221 (see Appendix 4)]. For this 
TABLE 3

Tree Length for the Individual (18S, $18 \mathrm{~S}$ rDNA; 28S, $28 \mathrm{~S}$ rDNA; Mor, Morphology without Fossils; Mor-f, Morphology with Fossils) and Combined (Mol, Molecular [18S + 28S]; Tot, Combined [18S + 28S + Mor]; Tot-f, Combined [18S + 28S + Mor-f] with Fossils) Data Sets at Different Parameter Values and ILDs for the Combined Analyses of All Data (with and without Fossils), at Parameter Sets 110 to 481

\begin{tabular}{|c|c|c|c|c|c|c|c|c|c|}
\hline & 185 & $28 S$ & Mol & Mor & Tot & ILD & Mor-f & Tot-f & ILD-f \\
\hline 110 & 1099 & 496 & 1634 & 469 & 2158 & 0.0436 & 493 & 2177 & 0.0409 \\
\hline 111 & 2460 & 1038 & 3548 & 469 & 4072 & 0.0258 & 493 & 4095 & 0.0254 \\
\hline 121 & 3607 & 1582 & 5249 & 938 & 6309 & 0.0288 & 986 & 6325 & 0.0237 \\
\hline 141 & 5831 & 2598 & 8582 & 1876 & 10622 & 0.0298 & 1972 & 10716 & 0.0294 \\
\hline 181 & 10261 & 4625 & 15189 & 3752 & 19246 & 0.0316 & 3944 & 19416 & 0.0302 \\
\hline 210 & 1308 & 626 & 1983 & 938 & 3008 & 0.0452 & 986 & 3048 & 0.0420 \\
\hline 221 & 4021 & 1915 & 6016 & 1876 & 7999 & 0.0234 & 1972 & 8080 & 0.0213 \\
\hline 241 & 6662 & 3239 & 10065 & 3752 & 14088 & 0.0309 & 3944 & 14251 & 0.0285 \\
\hline 281 & 11921 & 5835 & 18176 & 7504 & 26175 & 0.0350 & 7888 & 26480 & 0.0316 \\
\hline 410 & 1677 & 848 & 2598 & 1876 & 4603 & 0.0439 & 1972 & 4721 & 0.0474 \\
\hline 411 & 3060 & 1462 & 4618 & 1876 & 6606 & 0.0315 & 1972 & 6703 & 0.0312 \\
\hline 421 & 4755 & 2382 & 7337 & 3752 & 11304 & 0.0367 & 3944 & 11473 & 0.0342 \\
\hline 441 & 8137 & 4149 & 12728 & 7504 & 20600 & 0.0393 & 7888 & 20935 & 0.0364 \\
\hline
\end{tabular}

Note. ILD numbers in bold reflect the minimum incongruence among data sets.

parameter set we obtained two trees of equal cost $(8080$ weighted steps; strict consensus shown in Fig. 6). Both analyses, with and without fossils, minimize incongruence with the same parameter set.

The topology for chelicerate relationships is affected by the inclusion of fossil taxa. When the tree is rooted with Trilobita, Xiphosura and Eurypterida appear as successive sister groups to the remaining chelicerates, including Pycnogonida, nested within the Arachnida (see Discussion). Acari and Palpigradi cluster with the Pycnogonida, and the three groups appear as sister clade to (Tetrapulmonata + (Ricinulei + Trigonotarbida)). Dromopoda is sister group to the remaining arachnids, with the following structure: (Scorpiones ((Pseudoscorpiones + Solifugae) + Opiliones $))$. Therefore, Haplocnemata is resolved as the sister group to Opiliones, while in the analysis without fossils Novogenuata was resolved as the sister group to Opiliones.

Regarding the fossil taxa included in the analyses, Eurypterida appears as sister group to the nonxiphosuran chelicerates, as resolved by Weygoldt and Paulus (1979a,b); Trigonotarbida is sister to Ricinulei, as suggested by Dunlop (1996b); Proscorpius is sister to the extant scorpions and Palaeophonidae is sister to the scorpion crown-group; and Palaeoisopus is sister to the extant pycnogonids. The inclusion of fossil taxa does not change the internal topology of the opilionid tree, and only the Bremer support values show some variation.

\section{Molecular Analyses}

The molecular $(18 \mathrm{~S}+28 \mathrm{~S})$ analysis for the optimum parameter set (221) yielded two trees of 6016 weighted steps. The strict consensus of these two trees is shown in Fig. 7, in which arachnids are nonmonophyletic because the two acariform mites branch between the Pycnogonida and the Xiphosura. Acari is thus nonmonophyletic in this analysis, because the Opilioacariformes and Parasitiformes appear as sister group to the Pseudoscorpiones. The two clades within the Acari correspond to van der Hammen's (1989) Actinotrichida and Anactinotrichida. Following the Xiphosura we have a grade of clades as follows: (Ricinulei ((Palpigradi + Solifugae) ((Scorpiones (Pseudoscorpiones (Opilioacariformes + Parasitiformes))) (Amblypygi (Araneae (Uropygi + Schizomida)))) Opiliones)). Thus, except for the nonmonophyly of the Acari, all the other orders represented by more than one taxon are monophyletic. Neither Dromopoda, Novogenuata, nor Haplocnemata is monophyletic. On the other hand, 


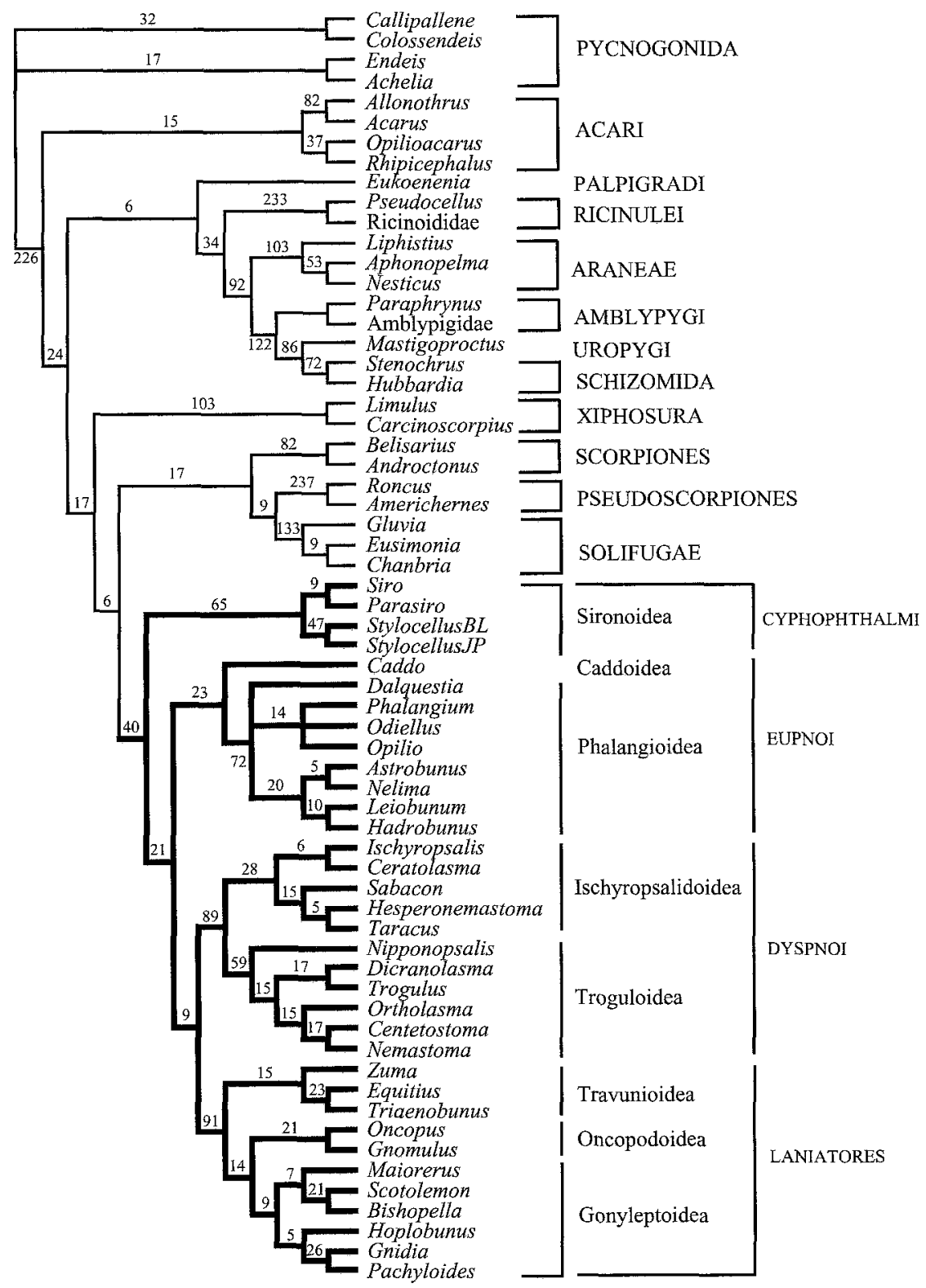

FIG. 5. Combined analysis of all the data for the extant chelicerates at the parameter set that maximizes character congruence (221; ILD = 0.0234), at 7999 weighted steps. Opiliones are represented by bold branches. StylocellusBL is Stylocellus sp. from Bukit Larut; StylocellusJP is Stylocellus sp. from Jeram Pasu. Numbers represent Bremer support values.

Tetrapulmonata is resolved as monophyletic, but not Pedipalpi, because the spiders are sister to Camarostomata. The internal relationship of the spiders is also inconsistent with morphological evidence, since Liphistius + Aphonopelma are monophyletic.

Within the Opiliones, the internal structure is basically identical to that shown in the morphological and combined analyses. Cyphophthalmi, Eupnoi, Dyspnoi, and Laniatores are all monophyletic, as are the suprasubordinal categories Phalangida and Dyspnolaniatores. The families Sironidae and Stylocellidae, and the superfamilies Phalangioidea, Ischyropsalidoidea, Troguloidea, and Gonyleptoidea, are also monophyletic. A few differences with the combined analyses are the position of Dalquestia (sister to the remaining Phalangioidea in the combined analyses and sister to 


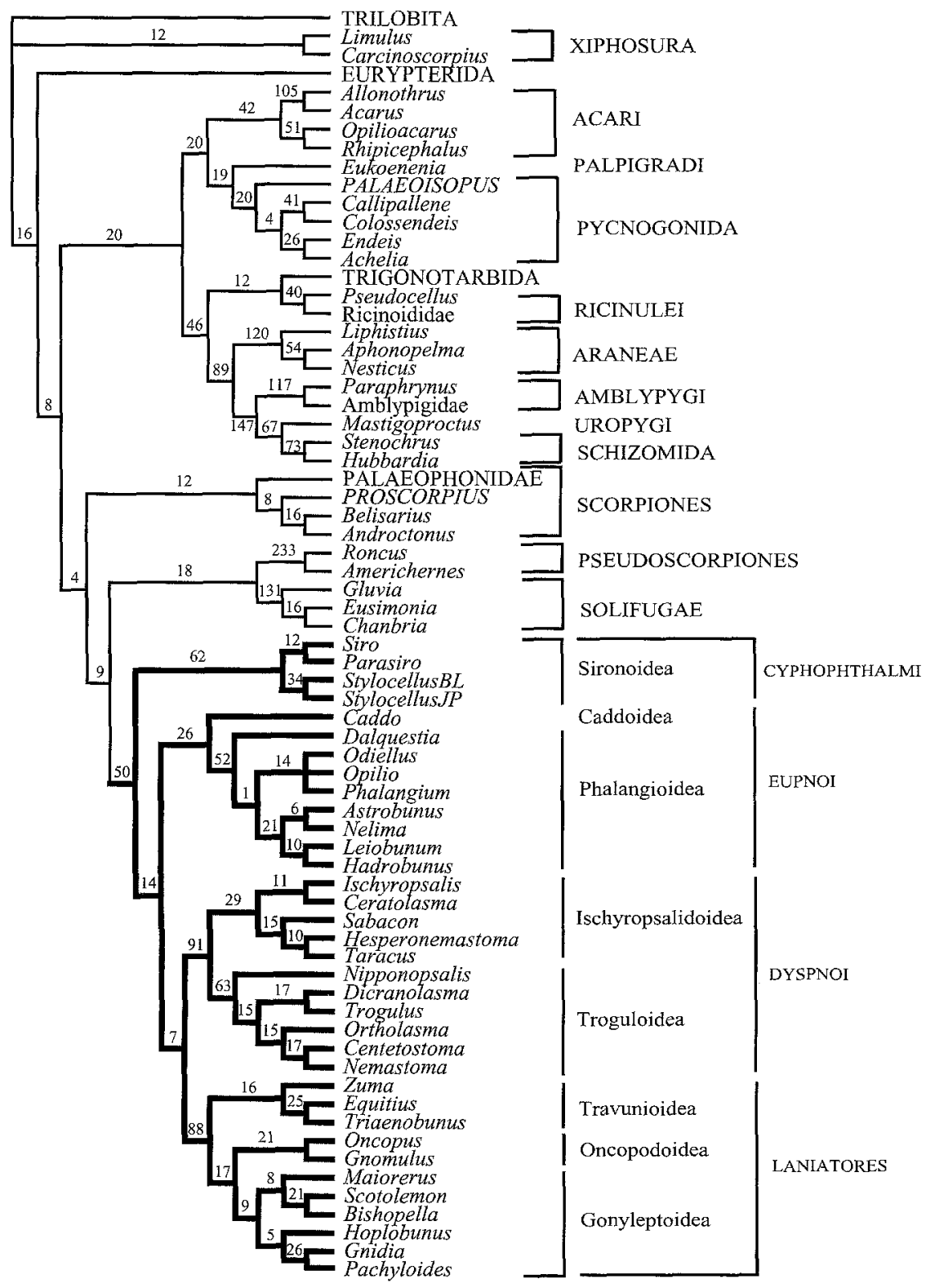

FIG. 6. Combined analysis of all the data for the extant and extinct chelicerates at the parameter set that maximizes character congruence $(221$; ILD $=0.0213)$, at 8080 weighted steps. Opiliones are represented by bold branches. Stylocellus species are abbreviated as in Fig. 5. Fossils are represented in capitals. Numbers represent Bremer support values.

Phalangiidae in the molecular analysis) and the internal structure of the Ischyropsalidoidea (Ischyropsalis (Sabacon (Ceratolasma (Hesperonemastoma + Taracus)))). Within the Laniatores, the American triaenonychid does not form a clade with the Australian ones, and some conflict bears on the monophyly of the two oncopodids, since they do not form a clade in one of the two shortest trees.

\section{Sensitivity Analysis}

Certain groups are obtained for all the 15 parameter sets here explored, including all the chelicerate orders represented by more than one species, with the exception of Acari, which is not monophyletic under certain parameter sets $(111,181,110,211)$. For the supraordinal relationships of chelicerates, only Tetrapulmonata, 


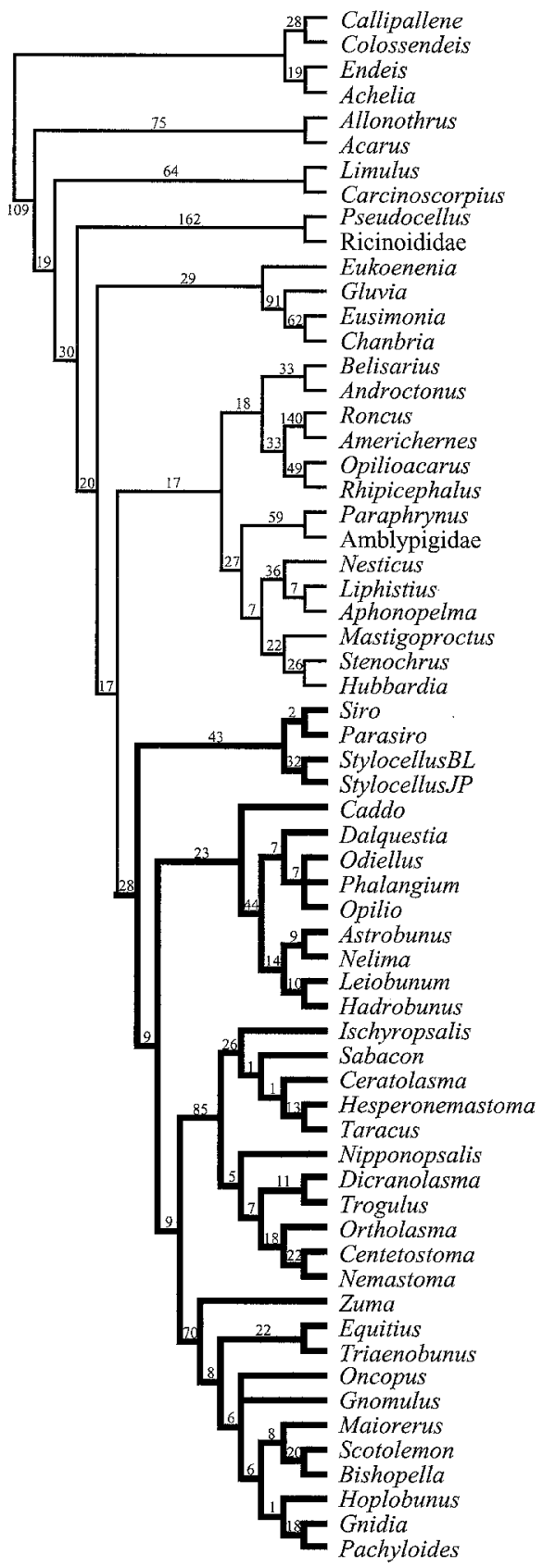

FIG. 7. Combined molecular tree $(18 \mathrm{~S}+28 \mathrm{~S})$ for the parameter set that minimizes overall incongruence (221), at 6016 weighted steps. Opiliones are represented by bold branches. Stylocellus species are abbreviated as in Fig. 5. Numbers represent Bremer support values.

Pedipalpi, and Camarostomata are obtained throughout the parameter space examined.

Some of the infraordinal relationships suggested by the data across the entire parameter space are the relationships among the two Acariformes and the relation- ship among Opilioacarus and the Parasitiformes. The extant scorpions are monophyletic, with the Silurian Proscorpius as their sister group, and the Palaeophonidae is sister to Proscorpius + the extant species. Within the Pantopoda, the fossil Palaeoisopus is sister to the extant pycnogonids. Among the extant species, Callipallene is invariably sister to Colossendeis, and Endeis is sister to Achelia.

Within the Opiliones, the following groups are monophyletic across the entire parameter space: $\mathrm{Cy}$ phophthalmi, Sironidae, Stylocellidae, Eupnoi, Phalangioidea, Phalangiidae, Sclerosomatidae, (Leiobunum + Hadrobunus), Dyspnoi, Ischyropsalidoidea, Troguloidea, Laniatores, (Equitius + Triaenobunus), Oncopodidae, (Scotolemon + Bishopella), and (Gnidia + Pachyloides). However, neither the monophyly of Dyspnolaniatores nor the monophyly of "Palpatores" is supported across the entire parameter space.

\section{DISCUSSION}

\section{Outgroups and Pycnogonid Relationships}

Inclusion of Trilobita in the outgroup has the effect of drawing Xiphosura and Eurypterida to the base of the Euchelicerata but repelling the Pycnogonida (see below). The optimal parameter set for combined analysis including fossils resolves the pycnogonids within the Arachnida. Extreme character conflict is added by the fossils with respect to the position of Pycnogonida, which is separated from the remaining chelicerates in the analysis without fossils by a branch with a Bremer support value of 226 weighted steps (Fig. 5). This number decreases to 20 weighted steps in the analysis that includes the fossils (Fig. 6).

As mentioned above, the internal pycnogonid relationships are stable to parameter change, and the extant pycnogonids constitute a monophyletic group with Callipallene as sister to Colossendeis and Endeis sister to Achelia. Relationships between the extant pycnogonid families are poorly understood, and only a few phylogenetic studies have been attempted, none of them using explicit cladistic analysis. Even though the sampling of pycnogonid families here represented is not optimal, the relationships obtained do not reflect the phylogenetic hypothesis proposed by Munilla (1999). 


\section{Chelicerate Relationships}

High-level relationships among the chelicerate groups are unstable to parameter change, and only a few supraordinal relationships are well supported by the data, such as the monophyly of Tetrapulmonata (bs = 89), Pedipalpi ( $b s=147$ ), and Camarostomata (bs = 67). Haplocnemata ( $b s=18$ ) is also a fairly wellsupported group although it is not found under most of the parameter sets here studied (Fig. 8). An alternative topology, the monophyly of (Scorpiones + Pseudoscorpiones), is found for 11 parameter sets, and the more inclusive group Novogenuata (Solifugae, Scorpiones, and Pseudoscorpiones) is also found in 9 suboptimal parameter sets.

One of the few widely accepted hypotheses of extant chelicerate phylogeny is the basal position of xiphosurids (Weygoldt and Paulus, 1979a,b; Shultz, 1990; Wheeler and Hayashi, 1998). Xiphosura is resolved basally within Euchelicerata in the optimum combined analysis including fossils (Fig. 6), but not in the analyses of extant taxa-only when molecular data are used. Half of the parameters explored yield monophyly of the Arachnida (Xiphosura as sister group of Arachnida). However, those parameters were not among the most congruent ones (see the specific parameters in Fig. 8 and the ILDs in Table 3). Not all morphological analyses that include fossils resolve Xiphosura as basal Euchelicerata. This result appears to be affected by character conflict between Trilobita and Pycnogonida in determining plesiomorphic states for chelicerates. That is, many of the characters regarded as plesiomorphic in Xiphosura, by comparison to trilobites (e.g., compound eyes, toothed gnathobasic coxae), are absent in pycnogonids. The traditional hypothesis of xiphosuran plesiomorphy has been questioned in some recent studies [witness Dunlop's (1999) query, "Are xiphosurans really primitive?"].

Most paleontological criticism of arachnid monophyly has centered on the possibility of a sister group relationship between eurypterids and scorpions (Braddy et al., 1999) and the implications of aquatic Paleozoic scorpions for traditional independent evolution of terrestrial characters in crown-group scorpions and other arachnids (Jeram, 1998; Dunlop and Webster,
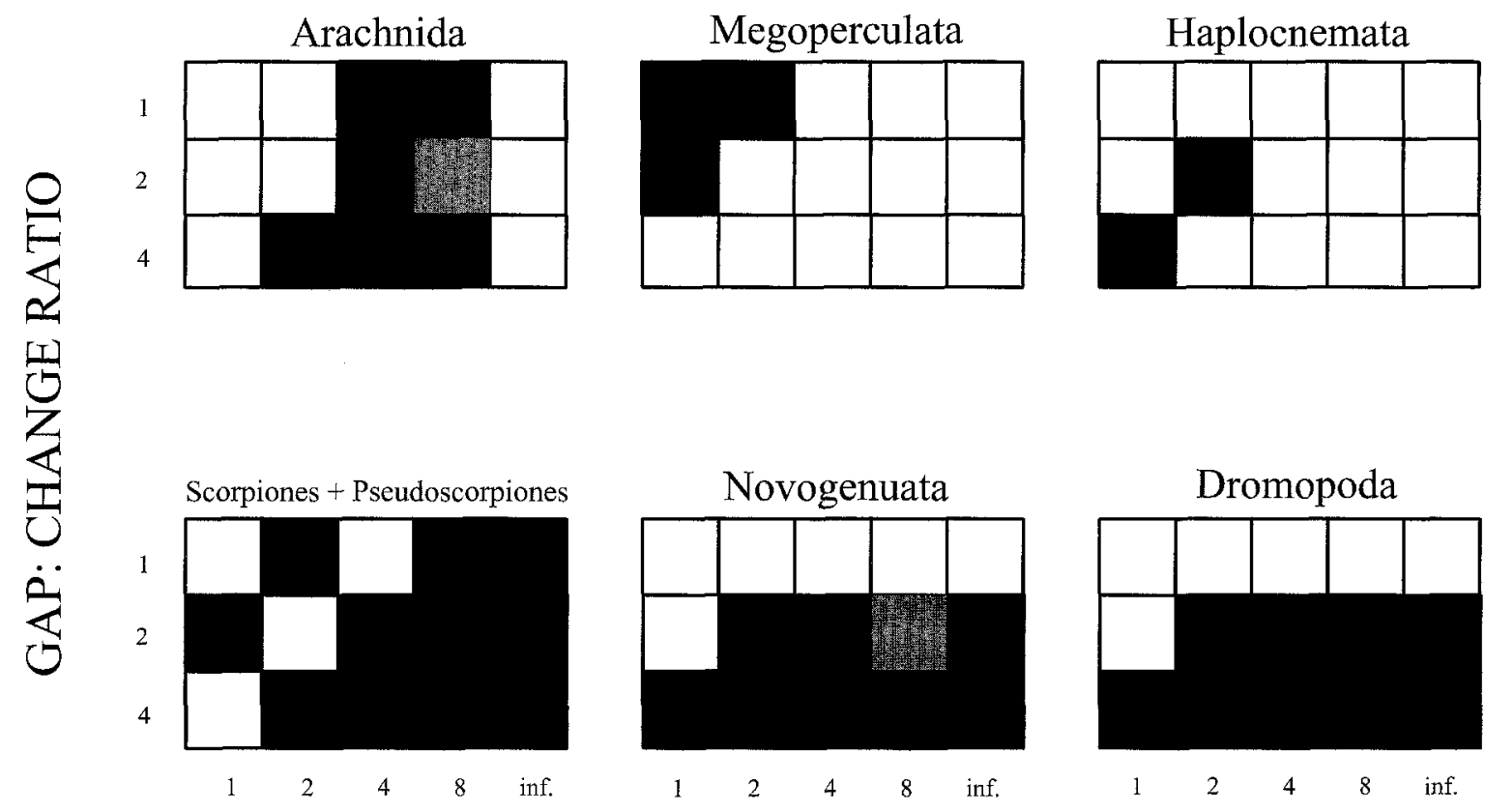

\section{TRANSVERSION:TRANSITION RATIO}

FIG. 8. Topological congruence plots of the combined analyses (extant taxa only) for several chelicerate higher groupings throughout the parameter space of 15 variables explored here.

(D) Monophyletic, (圈) some of the MPTs consistent with monophyly, ( $\square$ ) nonmonophyletic. 
1999). We have tested for these possibilities by including relevant fossil taxa (Eurypterida and two exemplars of aquatic scorpions), including all purported synapomorphies of eurypterids and scorpions, and including those characters that are considered to exclude scorpions from the Arachnida (Dunlop, 1999). We have not, however, excluded or down-weighted characters that are associated with terrestrialization because they may be prone to convergence nor excluded characters because they cannot be coded in fossils (e.g., many of the muscular characters cited as synapomorphies for Scorpiones within Dromopoda) (Shultz, 1990). The combined analysis with fossils (Fig. 6) agrees with Weygoldt and Paulus (1979a,b) and Shultz (1990) in a sister group relationship between eurypterids and arachnids, "merostome" paraphyly, and scorpions resolved within Arachnida. The data do not favor a eurypterid-scorpion clade.

The resolution of Xiphosura nested within the Arachnida in the combined analyses for extant taxa is affected by the interaction of characters that support two conflicting resolutions of scorpions: a set of characters that support scorpions within Dromopoda (Shultz, 1990) and a set that groups scorpions with eurypterids and xiphosurans (Dunlop, 1998, 1999) or at least outside a clade of the other arachnids (Lipoctena of Weygoldt and Paulus, 1979a,b). The resolution of some Acari at the base of the euchelicerates from the sequence data also contributes to a positioning of Xiphosura within the Arachnida in the combined analysis. The summation of the data thus recognizes Dromopoda based on Shultz's characters, but pulls Xiphosura "up-tree" based on characters shared by scorpions and "merostomes." In other words, neither set of characters for the scorpions is identified as homoplastic; rather, the "merostome"-scorpion characters are optimized as synapomorphies for a larger clade that includes Dromopoda.

The "unexpected" position of Xiphosura in analyses without fossils could be artifactual, appealing to the idea of rooting the chelicerate tree with an outgroup that is too distant. Rooting a tree based on distant outgroups has been demonstrated to be problematic (Wheeler, 1990). In the case presented here, the appropriateness of the pycnogonid outgroup is not in doubt in the context of the extant Arthropoda, as confirmed by several authors and several sources of information (Weygoldt, 1986; Wheeler et al., 1993; Wheeler, 1995, 1998a,b; Giribet and Ribera, 1998, 2000; Wheeler and Hayashi, 1998; but see a discussion in Giribet et al., 1999b). However, large amounts of morphological and molecular evolution in pycnogonids, together with rampant extinction in primitive chelicerates, could affect the analyses as if a too-distant outgroup were used. This is probably reflected in the large number of molecular autapomorphic changes shown by the pycnogonids, as seen in the large branch support value that separates them from the euchelicerates (bs $=109$ ) in the molecular tree (Fig. 7), although comparable values are also found for the Pseudoscorpiones (bs $=140$ ), Ricinulei $(b s=162)$, or Solifugae $(b s=91)$. How this might affect the analyses is hard to evaluate, especially after realizing that the support for Pycnogonida decreases considerably after the addition of the fossil taxa Trilobita and Palaeoisopus (bs = 20; Fig. 8).

The position of Scorpiones is problematic due to the character conflict created by the "merostomes," on one hand, and by the remaining dromopods on the other hand. Therefore, Scorpiones appear basal to the other arachnids in one parameter set (141), while grouping with the remaining dromopods in nine parameter sets (Fig. 8). In the remaining cases, as for example in the optimal tree including the fossil taxa (Fig. 6), scorpions are sister group of the remaining dromopods.

The position of Acari is highly unstable to parameter change, this group (1) tending to branch at the base of the chelicerates or (2) sister to a clade containing Palpigradi, Ricinulei, and Tetrapulmonata (parameter sets $241,281,421,441,481$ ) or (3) sister to Dromopoda (parameter sets 210, 411, 421), among other possibilities.

Tetrapulmonata is a well-supported group and stable to parameter change (found in every parameter set). This group has been previously recognized by other cladistic analyses of morphological and molecular data (Weygoldt and Paulus, 1979a,b; Shultz, 1990; Wheeler and Hayashi, 1998), and its monophyly has been widely accepted among arachnologists. However, the relationships within the Tetrapulmonata have remained contentious for a long period of time. Two hypotheses, the monophyly of Labellata (Petrunkevitch, 1955; Platnick and Gertsch, 1976; Weygoldt and Paulus, 1979a,b; Wheeler and Hayashi, 1998) or the alternative monophyly of Pedipalpi (Shear et al., 1987; Shultz, 1990, 1993, 1999), have been proposed. For example, Wheeler and Hayashi (1998) found Labellata 
in their favored tree (using character congruence as optimality criterion) but mentioned that the group was unstable to parameter change and that the support for the group was basically added by the molecular data. In the present study we added several putative synapomorphies for Pedipalpi described by Shultz (1999), resulting in a well-supported clade in the morphological analyses. This morphological support for the group stabilizes the clade even though the molecular data might not completely agree with the monophyly of Pedipalpi (see Fig. 7). Thus, the hypothesis here proposed for the monophyly of Pedipalpi is mainly derived from the morphological evidence marshaled by Shultz.

The relationship of tetrapulmonates to other arachnid orders is another contentious issue, and at least two phylogenetic hypotheses require discussion. Shultz (1990) proposed a sister group relationship between Palpigradi and Tetrapulmonata. This relationship, not surprisingly, was also resolved by Wheeler and Hayashi (1998), since they used most of Shultz's morphological characters, and molecular data for palpigrades were unavailable. In this study, the sequence data of palpigrades do not suggest a relationship with. the tetrapulmonates, and the morphological data are ambiguous, depending on whether fossil data are included. Only three suboptimal parameter sets suggest monophyly of Megoperculata, while several parameter sets suggest a relationship between the fossil Trigonotarbida and the Tetrapulmonata. Trigonotarbids uniquely share certain features with each of Tetrapulmonata and Ricinulei. The relationships proposed by Dunlop's (1996b) data showed palpigrades as the sister group to (Tetrapulmonata + (Ricinulei + Trigonotarbida)). A hypothesis similar to that presented by Dunlop (1996b) is shown in our morphological trees, although including the Acari within the clade (Fig. 3). However, the combined analysis for the best parameter set does not include the palpigrades within the clade containing tetrapulmonates, ricinuleids, and trigonotarbids. Ricinulei and Trigonotarbida are sister groups in the most congruent tree, although not in the morphological analyses. This difference in topologies of the relationships between Ricinulei and Trigonotarbida is interesting, since only morphological data are available for the fossils. However, congruence between morphological characters and the molecular hypothesis can overturn a relationship proposed by the morphological data alone, showing that the characters supporting a relationship between Acari and Ricinulei do not pass a stricter homology test. Palpigrades do not constitute the sister group of tetrapulmonates under any parameter set when the fossils are included, though they do when the fossils are not considered (see representation of Megoperculata in Fig. 8). On the contrary, a relationship between Trigonotarbida and Tetrapulmonata or a relationship between Trigonotarbida and Ricinulei is obtained under most parameters. The relationship obtained in the most congruent tree (Fig. 6) corresponds to the phylogenetic hypothesis of Dunlop (1996b), although its instability allows that further analyses might falsify this relationship.

\section{Opilionid Sister Group Relationships}

In the sensitivity analysis (excluding fossils) the sister group of Opiliones is not unambiguously defined. Scorpiones appear as sister group to Opiliones under one parameter set (111), as do Solifugae (141), but most parameter sets indicate a relationship with other dromopods (Fig. 8), in most cases as sister group to Novogenuata. This relationship of Novogenuata as the sister group of Opiliones, constituting the clade Dromopoda, was proposed by previous cladistic analyses of arachnid relationships (Shultz, 1990; Wheeler and Hayashi, 1998). Ricinulei never groups with the Opiliones, and thus we can conclude that the hypothesis of Savory (1977; Opiliones paraphyletic with respect to Ricinulei) or of Weygoldt and Paulus [1979a,b; Opiliones sister group to (Ricinulei + Acari)] can be rejected. Even though certain taxa are clearly discarded as putative sister groups of Opiliones, the data here presented are still unstable in defining their sister group relationships, because addition of fossils causes Haplocnemata instead of Novogenuata to be their sister taxon (Fig. 6). The morphological data are also indecisive in this respect when fossils are included. The data here analyzed support monophyly of Dromopoda, but are not decisive in establishing the sister group of the Opiliones, though the most probable candidates are Novogenuata or Haplocnemata.

\section{Opilionid Relationships}

Referring to the internal opilionid phylogeny, the main issue addressed here is whether the "Cyphopalpatores" (Martens, 1976, 1980, 1986; Martens et al., 
1981) would survive a numerical cladistic analysis and whether the "Palpatores" is monophyletic (Shultz, 1998) or paraphyletic (Giribet et al., 1999c; Giribet and Wheeler, 1999a). Clearly, the "Cyphopalpatores" hypothesis is not supported by any data set (morphological, molecular, or combined), and such a hypothesis requires numerous additional extra steps under any of the numerical analyses performed so far (Shultz, 1998; Giribet et al., 1999c; Giribet and Wheeler, 1999; this analysis). Thus the "Cyphopalpatores" hypothesis can clearly be rejected based on the available data.

The monophyly of "Palpatores" is a more contentious question. Previous analyses (Giribet et al., 1999c) showed conflict between the unweighted and the weighted parsimony analyses. Subsequently, this conflict was shown to be parameter dependent, but using character congruence among data sets as an optimality criterion, the paraphyletic "Palpatores" hypothesis was preferred (Giribet and Wheeler, 1999). On the contrary, Shultz (1998) presented a morphological parsimony analysis showing monophyly of "Palpatores" (Fig. 9A), while our hypothesis requires a single extra step in Shultz's data set. The monophyly of Palpatores in Shultz's study is supported by his characters 7, 13, and 14. Some disagreement exists in the way that Shultz coded some of his characters, such as considering absence of either one of the genital organs (0) multiple times (characters 16 to 26), instead of coding for
A

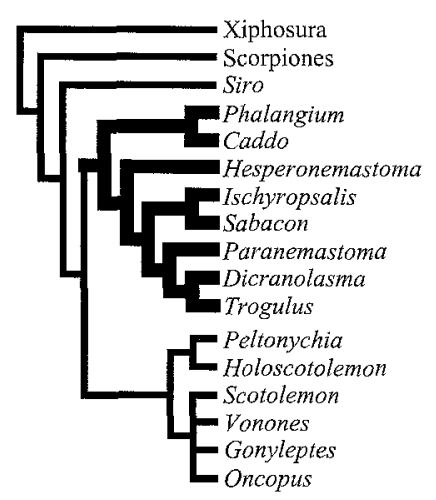

B

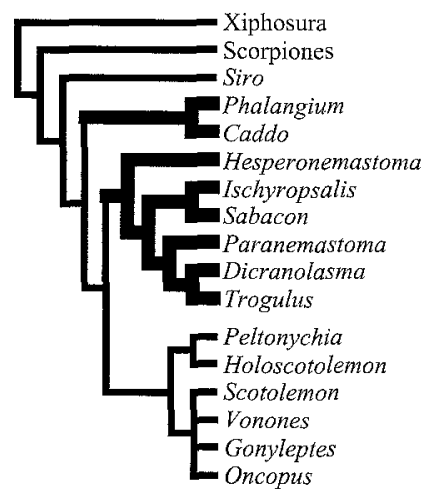

FIG. 9. Two of the four possible trees (62 steps; CI $=0.81 ; \mathrm{RI}=$ 0.89 ) obtained after analyzing a modified version (recoding a state for Phalangium) of the opilionid matrix presented by Shultz (1998). (A) Tree showing monophyly of "Palpatores" (as proposed by Shultz, 1998); (B) equally costly tree showing paraphyly of "Palpatores" (as proposed in this study and in the previous studies of Giribet et al., 1999c; Giribet and Wheeler, 1999). "Palpatores" branches are represented in bold. inapplicability. There is also some disagreement in the way that certain characters were coded in Giribet et al. (1999c). These differences are obviously reflected in our new morphological data matrix. In addition to these possibilities of coding characters in a different way, we identify a miscoding in Shultz's (1998) data set, which reverses his topology to the topology obtained here. Phalangium was coded as having plumose palpal setae by Shultz (1998), though this is not the case. All Phalangioidea examined here (Dalquestia, Astrobunus, Nelima, Leiobunum, Hadrobunus, Odiellus, Phalangium, Opilio, Nemastoma, and Centetostoma) present simple palpal setae (character 52). Recoding this state for Phalangium in Shultz's matrix yields four optimal trees that do not distinguish between the monophyly or the paraphyly of "Palpatores" (Fig. 9). All the analyses here presented for the parameters that optimize character congruence, whether morphology, molecules, or combined, found paraphyly of "Palpatores," although some of the combined analyses for three suboptimal parameters found monophyly of "Palpatores" (Fig. 10). Therefore, we continue to advocate paraphyly of "Palpatores," but call attention to its parameter dependence to obtain this topology.

The Cyphophthalmi (bs $=62)$ is a well-corroborated group, both morphologically and molecularly, for which internal phylogeny agrees with the current taxonomy, with the two families here represented (Sironidae and Stylocellidae) being monophyletic. The group is also obtained throughout the entire parameter set here explored, as is the monophyly of the two species of Stylocellus.

The Phalangida, a name introduced by Bristowe (1949) that should be recovered for opilionid taxonomy, is obtained in most of the parameters here studied (Fig. 10 ), although it is only moderately supported in the combined tree $(\mathrm{bs}=14)$. This result agrees with previous analyses of Giribet et al. (1999c) and Giribet and Wheeler (1999a). Its moderate branch support shows the relative small number of characters for arachnid phylogeny that can be used for rooting the opilionid tree. In the two cases in which Phalangida is not monophyletic, the group Cyphophthalmi + Eupnoi is obtained (Fig. 10). Phalangida is nevertheless the best corroborated hypothesis, and thus the one here preferred, and can be diagnosed by the presence of an ocular tubercle (character 7), leg II longer than adjacent legs (character 70, a state also shared with Ricinulei), 

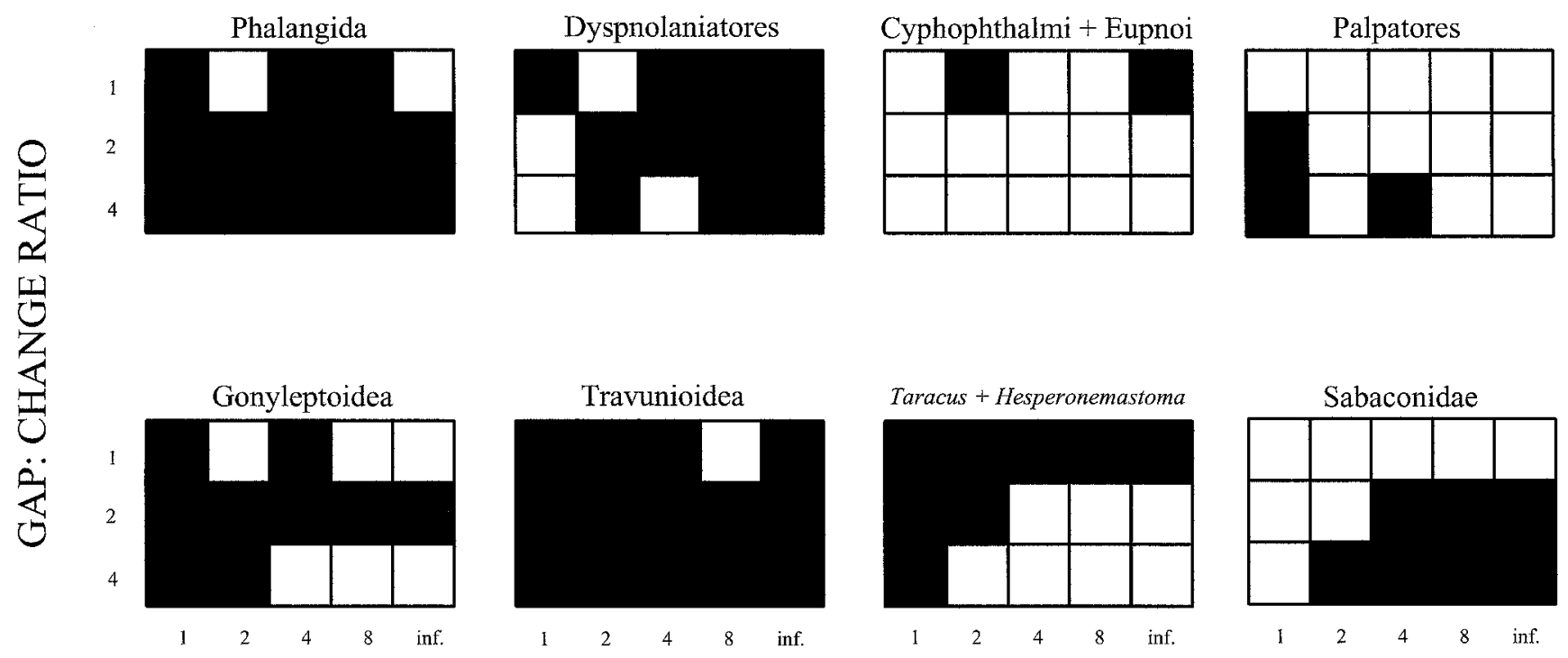

\section{TRANSVERSION:TRANSITION RATIO}

FIG. 10. Topological congruence plots of the combined analyses (extant taxa only) for several opilionid groupings throughout the parameter space of 15 variables explored here. $(\square)$ Monophyletic, $(\square)$ nonmonophyletic.

presence of tarsomeres in walking legs (character 71, although highly homoplastic), and loss of the spermatozoan axoneme (character 195).

In the best corroborated trees (morphological tree, molecular, and combined), the Phalangida is divided into Eupnoi and a clade that includes Dyspnoi + Laniatores, here named Dyspnolaniatores, as proposed previously (Giribet et al., 1999c; Giribet and Wheeler, 1999). Eupnoi is obtained across the entire parameter set ( $b s=26$ ), while Dyspnolaniatores ( $b s=7$ ) is not obtained for certain suboptimal parameters (Fig. 10). When only molecular data are considered, the branch support for Dyspnolaniatores is identical to the support for the monophyly of Phalangida (bs = 9; Fig. 7); however, a certain degree of character conflict is reflected by the slightly lesser stability of the Dyspnolaniatores compared to that of Phalangida. The new taxon Dyspnolaniatores is diagnosed by the repugnatorial glands situated below the side of the carapace, not visible from above (character 13), and by having an unjointed ovipositor (character 173).

Internal phylogeny of the Eupnoi (bs $=26$ ) shows Caddo (the only representative of the Caddoidea in the present study) as sister taxon to Phalangioidea. The phalangioids $(\mathrm{bs}=52)$ can be divided into three clades as follows: (Dalquestia (Phalangiidae + Sclerosomatidae)). The inclusion of Astrobunus within the "Leiobunidae" is supported by both morphological and molecular data and reflects the modern classification of "Leiobunidae" not being a separate family of the Sclerosomatidae (Crawford, 1992; Cokendolpher and Lee, 1993), although it disagrees with the monophyly of "Leiobuninae." These results also disagree with the inclusion of the members of the "Metopilio group" ( $D$. formosa here) within the Sclerosomatidae. The addition of more genera belonging to the different subfamilies of Sclerosomatidae and of the "Metopilio group" is necessary to establish a better classification within this problematic clade of phalangioid Opiliones.

The Dyspnoi (bs = 91) is one of the most interesting clades in this study, since its monophyly is strongly supported, but it is the clade that the "Cyphopalpatores" hypothesis splits to include the Cyphophthalmi in-between. This clade has a fairly good representation of taxa included in the analyses (all seven families represented). The two clades of Dyspnoi, Ischyropsalidoidea and Troguloidea, are well supported (bs $=29$ and 63 , respectively) and found across the entire parameter space, although the monophyly of Ischyropsalidoidea is not well supported by the morphological 
data here presented. The monophyly of the Dyspnoi is one of the best corroborated opilionid nodes of our analyses, confirming the results of Shultz (1998) and Giribet et al. (1999c) and refuting the "Cyphopalpatores" hypothesis (Martens, 1976, 1980, 1986; Martens et al., 1981).

The internal phylogeny of the Troguloidea received little attention in the literature until the studies of Martens and co-workers. In fact, the only morphological characters defining the Troguloidea pertain to the genitalia (characters 170,180, and 183), and thus it is not surprising that the group was not well characterized until the studies of Martens (1976). In our analyses, the family Nemastomatidae is monophyletic (bs = 19), showing the following structure (Ortholasma (Centetostoma + Nemastoma)), although no unambiguous morphological synapomorphies define this clade. Dicranolasmatidae (Dicranolasma) is sister to Trogulidae (Trogulus), and these two families are sister to Nemastomatidae, with Nipponopsalididae (Nipponopsalis) as the first split within the Troguloidea. The same relationship among Nemastomatidae, Trogulidae, and Dicranolasmatidae was obtained by Shultz (1998), and the hypothesis of relationships of Nipponopsalis with the Troguloidea instead of with the Ischyropsalidoidea (as noticed before by Martens and Suzuki, 1966) is here corroborated. The addition of more troguloid genera is, however, necessary before deepening the study of relationships within the group.

The cladistic relationships among the families and genera of Ischyropsalidoidea received special attention from Shear (1986), who proposed a relationship to the family level as follows: (Sabaconidae (Ischyropsalididae + Ceratolasmatidae)). Our optimal tree supports a sister group relationship between Ischyropsalis and Ceratolasma, but the ceratolasmatid Hesperonemastoma groups within the Sabaconidae. A relationship between Hesperonemastoma and Taracus is found in eight parameter sets (Fig. 10), while in most of the remaining parameter sets Hesperonemastoma is sister to the Sabaconidae, but never sister to Ceratolasma. Optimization of the morphological characters over the combined tree shows that the relationship between Hesperonemastoma and the Sabaconidae can be diagnosed by the presence of plumose palpal setae (character 52) and by the dense distribution of the palpal setae (character 53). Ceratolasma is sister taxon to Ischyropsalis in most of the parameters here studied. These results contradict the relationships proposed by Shear (1986), although we recognize that the absence of the genera Acuclavella and Crosbycus in our analyses, together with the absence of some of the internal characters for the Ischyropsalidoidea (see Shear, 1986), could be responsible. The addition of these taxa in future analyses should help to establish a hypothesis of relationships within the Ischyropsalidoidea, but the conflicting position of Hesperonemastoma could still reflect some of the conflicts that existed for a long time within the Ischyropsalidoidea.

The Laniatores is the best supported opilionid clade (bs $=88$ ). The optimal trees (with and without fossils) yield a topology in which the three superfamilies, Travunioidea, Oncopodoidea, and Gonyleptoidea, are monophyletic (Figs. 5 and 6) and where Travunioidea is sister group to the other Laniatores. This relationship was also proposed by other authors (Martens, 1976, 1980, 1986; Martens et al., 1981; Giribet et al., 1999c). Shultz (1998) also proposed a sister group relationship between the Travunioidea and the remaining Laniatores, with no resolution within the GonyleptoideaOncopodoidea (Fig. 9). Alternative suboptimal topologies for the laniatorid relationships (while all the other ordinal relationships were stable) have also been reported (Giribet and Wheeler, 1999), showing that although the Laniatores is a well-corroborated group, its internal relationships are parameter dependent. In the present analysis the triaenonychids are sister group to the remaining Laniatores, although triaenonychid monophyly is not obtained under certain parameter sets (Fig. 10). Only in two cases is nonmonophyly of the Grassatores (Oncopodoidea + Gonyleptoidea) obtained. The two oncopodids are monophyletic across the entire parameter space, but not the Gonyleptoidea, which under certain parameters include the oncopodids. Therefore, and even though the monophyly of both groups is obtained in the best corroborated tree, we will adopt the name Grassatores for this group, as informally proposed by Kury, although without any implications of the internal relationships of the grassatorid families, until more data on all the families are available. A paraphyletic Gonyleptoidea including the Oncopodoidea is a possibility suggested by the data for some suboptimal parameters; in the best corroborated 
tree, support for the Gonyleptoidea (bs $=9$ ) is less than the support for the Oncopodidae ( $b s=21)$. Further testing of these alternative hypotheses, as well as the study of the relationships among the families of Travunioidea and Gonyleptoidea, will require a more extensive taxon sampling within the laniatorid Opiliones.

\section{FINAL REMARKS}

The relationships among the chelicerate orders are, in general, not well supported by any of the independent

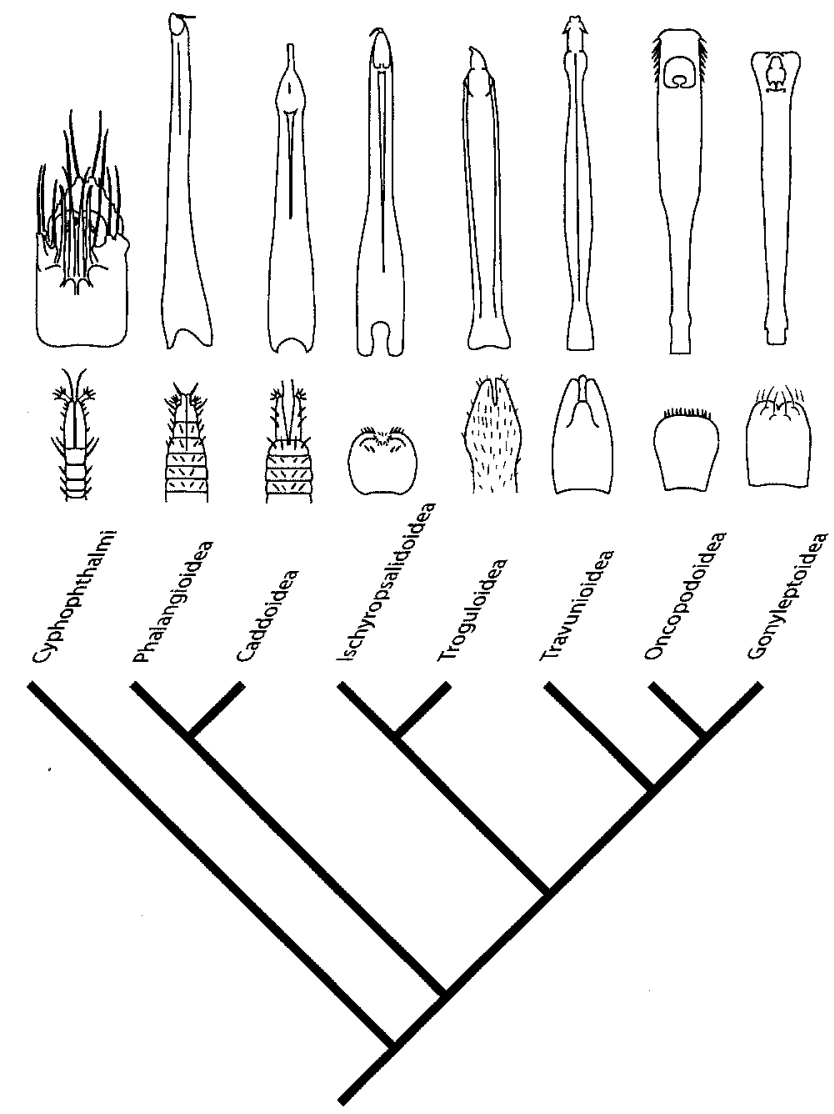

FIG. 11. Summary tree of the phylogenetic relationships of the superfamilies of Opiliones derived from the combined analysis here presented. Genitalic characters: penis (above) and ovipositor (below) are mapped. Penis morphology is divided into two main classes: short, membranous, and undivided (Cyphophthalmi) or long, chitinous, and divided into trunk and glans (the remaining opiliones). Ovipositor morphology is also divided into two types: jointed (Cyphophthalmi, Phalangioidea, and Caddoidea) or unjointed (the remaining superfamilies). Drawings are modified from Martens (1980) and Martens et al. (1981) (reproduced by permission of the publisher). data sets or by the combination of them since results are unstable under different parameter sets (with the exception of the clades Tetrapulmonata, Pedipalpi, and Camarostomata). This seems to be due to character conflict, notably between the Dromopoda (in particular scorpions) and the "merostomes" and between pycnogonids and trilobites. The morphological data here presented could be refined in future studies by adding more taxa, and perhaps some new fossils, but the level of informative characters for chelicerate studies seems to have been densely sampled. Therefore, to resolve some of the more contentious issues it will be easier to rely on new data from other molecular markers (e.g., elongation factor- $1 \alpha$ and RNA polymerase II, J. Shultz, work in progress), which might shed new light on arachnid ordinal relationships.

Outgroup relationships for Opiliones have remained obscure in the past. Certain putative sister groups such as Acari or Ricinulei can be discarded as a result of the data here presented. However, the monophyly of Dromopoda, and whether Haplocnemata is the sister group of Opiliones, as suggested by some parameter sets, should be tested by new data sources.

Concerning the internal phylogeny of the Opiliones, the results presented here are consistent with the hypothesis of paraphyly of "Palpatores," as proposed earlier (Giribet et al., 1999c; Giribet and Wheeler, 1999), and do not support the "Cyphopalpatores" hypothesis (Martens, 1976, 1980, 1986; Martens et al., 1981) or the hypothesis of monophyly of the "Palpatores" (Shultz, 1998). The hypothesis presented here is the most congruent hypothesis among three data sets (two ribosomal genes and a morphological data set), constitutes the most inclusive analysis performed so far, and is stable to parameter choice. Thus, the hypothesis here presented allows us to establish a new system of classification for the Opiliones (summarized in Fig. 11):

Opiliones Sundevall, 1833

Cyphophthalmi Simon, 1879

Phalangida Bristowe, 1949

Eupnoi Hansen and Sørensen, 1904

Caddoidea Banks, 1892

Phalangioidea Thorell 1876

Dyspnolaniatores nov.

Dyspnoi Hansen and Sørensen, 1904

Troguloidea Simon, 1872

Ischyropsalidoidea Simon, 1879 
Laniatores Thorell, 1876

Travunioidea Absolon and Kratochvil, 1932 Grassatores Kury ${ }^{2}$

Oncopodoidea Thorell, 1890

Gonyleptoidea Sundevall, 1833

Relationships within Cyphophthalmi, Phalangioidea, Troguloidea, Ischyropsalidoidea, Travunioidea, and Grassatores require data on more genera before proposing new hypotheses of relationships among the different opilionid families, but the data already suggest that conflict with the current classification system occurs in many groups of Opiliones (e.g., families Sclerosomatidae, Ceratolasmatidae, Sabaconidae, and Triaenonychidae).

\section{APPENDIX 1: MORPHOLOGICAL CHARACTERS}

\section{Cephalothorax}

1. Median eyes $[0=$ present; $1=$ absent] (Paulus, 1979; Shultz, 1990; Giribet et al., 1999c). All groups of chelicerates except Pseudoscorpiones, Schizomida, Ricinulei, and Palpigradi have a pair of median eyes. In some Acari, this pair is fused into one. Median eyes are present in all the Opiliones except for the Cyphophthalmi and some troglobitic species, such as Maiorerus ${ }^{3}$ (Rambla, 1993) and Hoplobunus (pers. obs.). Median eyes are also absent in the troglobitic scorpion Belisarius.

2. Number of median eyes [0 $=\mathrm{two} ; 1=$ four $]$ (Paulus, 1979; Weygoldt and Paulus, 1979a,b; Wheeler and Hayashi, 1998). Pycnogonids have four median eyes, while all the remaining chelicerates have two. Comparison with nonchelicerate arthropods (e.g., Crustacea, Collembola) indicates that four median eyes is a more general condition (Paulus, 1979).

\footnotetext{
${ }^{2}$ The name Grassatores was proposed informally by Kury in 1996 in a congress abstract, but we have decided to keep this nomen nudum since it is introduced in a catalog of the Laniatores by Kury (work in progress). An online reference can be found at http:/ /acd.ufrj.br/ mndi/laniatores.htm.

${ }^{3}$ Unless indicated, references to genera refer to the specific species from Table 2.
}

3. Type of median eyes $[0=$ retinulae with closed isolated rhabdoms; 1 = retina composed of a network of rhabdomeres as in the lateral eyes; $2=$ sensory cells with an irregular arrangement of their rhabdomeres; 3 = inverse retina] (Paulus, 1979). Retinulae with closed isolated rhabdoms are distributed in Scorpiones, Uropygi, Amblypygi, and Opiliones, whereas the retina in the Solifugae and Araneae is composed of a network of rhabdomeres as in the lateral eyes. Pycnogonids have median eyes with an inverse retina. This character is coded as a ground plan.

4. Lateral eyes $[0=$ present; $1=$ absent] (Paulus, 1979; Giribet et al., 1999c). Chelicerata have either lateral facetted eyes (Xiphosura, Eurypterida, fossil Scorpiones) or lateral simple-lens eyes, ocelli (Arachnida). Lateral facetted eyes are always absent in extant Arachnida. Lateral eyes are absent in Pycnogonida and present in all the remaining chelicerate groups except in Palpigradi. Lateral eyes are also generally absent in Opiliones, but the eyes of the stylocellids are in a lateral position instead of central. These eyes appear almost completely transparent, and a reflective tapetum can easily be seen (Shear, 1993a). Tapeta are characteristic of arachnid lateral eyes, but not of median eyes. However, pycnogonids have tapeta in their ocelli, which are otherwise considered to be median eyes (based on their style of protocerebal innervation) (Hess et al., 1996). The eyes of all other opilionids are median eyes, presumed to be homologous with the ancestral median ocelli; a tapetum is lacking, and their rhabdoms face the lens (Martens, 1978; Selden et al., 1991). Therefore, according to Shear, the presence of a tapetum suggests that the laterally placed stylocellid eyes are not derived from median ocelli which migrated to the edges of the carapace, though such migration is known in some other opilionids. Other investigators have reported the existence of "probable eyespots" at the base of the ozophores in Pettalus sp. (Gruber, pers. comm.). Shear (1993b) mentioned that the stylocellid lateral eyes are thought to be homologous to the "lateral eyes" of Ricinulei, although "lateral eyes" of extant Ricinulei are coated with cuticular projections, like the rest of the prosoma, and cannot function as lenses (Platnick and Shabad, 1976). Fossil Ricinulei have a pair of lateral eyes on each side of the head in the position of the paired clear patches in extant Ricinulei (Selden, 1992). We have thus coded for presence of lateral eyes in Ricinulei. Lateral eyes are absent for the troglobitic 
scorpion Belisarius xambeui and in Opilioacarus texanus (see discussion of character 5). Despite the existence of Trigonotarbida that lack lateral eyes (Dunlop, 1996a), the group has been coded as having lateral eyes following Shear et al. (1987) and Dunlop (1997), undoubtedly the plesiomorphic state.

5. Lateral eyes $[0=$ facetted; $1=$ five pairs; $2=$ three pairs; $3=$ two pairs; $4=$ one pair] (Paulus, 1979; Shultz, 1990; Wheeler and Hayashi, 1998). Compound lateral eyes are found in Xiphosura, Eurypterida, and fossil Scorpiones [all taxa except the Neoscorpionina sensu (Jeram, 1994b)]. Five groups of lateral eyes are found in Androctonus; three pairs of lateral eyes are found in Araneae, Amblypygi, Uropygi, and the fossil group Phalangiotarbida; two pairs of lateral eyes are found in Solifugae, some Pseudoscorpiones, and some Acari; vestigial lateral eyes are found in Schizomida. Ricinulei has been coded as state 3 based on the presence of lateral eyes in fossils (see character 4). This character has been coded as "?" in Stylocellus. The inapplicability to Palpigradi and the remaining Opiliones is related to the absence of lateral eyes (character 3). Trigonotarbids have variable numbers of major lenses and several minor lenses in the lateral eyes (Shear et al., 1987), have only minor lenses (Dunlop, 1997), or lack lateral eyes altogether (Dunlop, 1996a). Three major lenses are present in several species described by Shear et al. (1987), though Dunlop (1997) cautioned that some of these may belong to other tetrapulmonate groups, therefore we have coded this as "?". Opilioacarus has two pairs of eyes situated in a lateral position (van der Hammen, 1986), although other opilioacarids may have three pairs. Two pairs are also found in the few argasid ticks that have eyes. Binnington (1972) found that a variety of ticks, most of which lack eyes, or at least lack lenses, had the innervation for three pairs of lateral eyes. Lindquist (1984) suggested that the primitive set-up for mites would be three pairs of lateral and one pair of median eyes, although no extant mite has that set. A median eye or set of eyes is found in some Acariformes but not in Parasitiformes. Opilioacarid eyes are probably lateral eyes (Klompen, pers. comm.). All other parasitiform eyes or photoreceptor regions seem to fit lateral eyes.
6. Lateral eye rhabdoms [0 $=$ star-shaped; $1=$ quadratic network] (Weygoldt and Paulus, 1979a,b; Dunlop and Webster, 1999). Star-shaped lateral eye rhabdoms are found in xiphosurans and scorpions (citations found in Paulus, 1979). They are quadratic in all other arachnids bearing lateral eyes for which this character has been investigated [Solifugae, Araneae, Acari, Pseudoscorpiones, Uropygi, and Amblypygi (citations found in Paulus, 1979)] (Dunlop and Webster, 1999) and are arranged to form a "network" (Paulus, 1979). Lateral eyes have not been investigated in stylocellids. Rhabdom structure cannot be determined in Ricinulei. The star shape may be a symplesiomorphy, being present in nonchelicerate arthropods (e.g., Zygentoma and Chilopoda).

7. Ocular tubercle $[0=$ absent; $1=$ present] (Giribet et al., 1999c). Generally, the Opiliones present two central eyes situated on an ocular tubercle or ocularium (Figs. 12A and $12 \mathrm{C}, \mathrm{Oc}$ ). The ocular prominence can be lacking, or the eyes can be situated on separate tubercles. The ocular tubercle is absent in Cyphophthalmi (which lack median eyes), although it is present in some opilionid taxa that have secondarily lost their median eyes (e.g., Maiorerus and Hoplobunus). Thus, these two characters are coded as independent characters. An ocularium was erroneously coded as absent in Dicranolasma by Giribet et al. (1999c). An ocular tubercle similar to that of the Opiliones is found in Pycnogonida. Various Paleozoic chelicerates possess a median eye tubercle to some degree (e.g., scorpions; KjellsvigWaering, 1986), leading Dunlop (1997, 1999) to consider it a potential autapomorphy for Chelicerata. The character coded here is a more pronounced development than the low mound observed in many chelicerates.

8. Shape of the ocularium $[0=$ rounded; $1=$ with anteriorly projecting bilobed hood equipment with marginal fringe of cuticular projections; $2=$ with an erect medial spine] (Shultz, 1998). Hoodlike structures projecting anteriorly from the carapace and covering the feeding apparatus have apparently evolved independently in several opilionid lineages, e.g., ortholasmatine nemastomatids (Shear and Gruber, 1983) and Ceratolasma (Gruber, 1978). The hood in Dicranolasma and Trogulus is formed by bilobed processes projecting anteriorly from the eye tubercle and is fringed with cuticular projections (Roewer, 1923; Shultz, 1998). An 

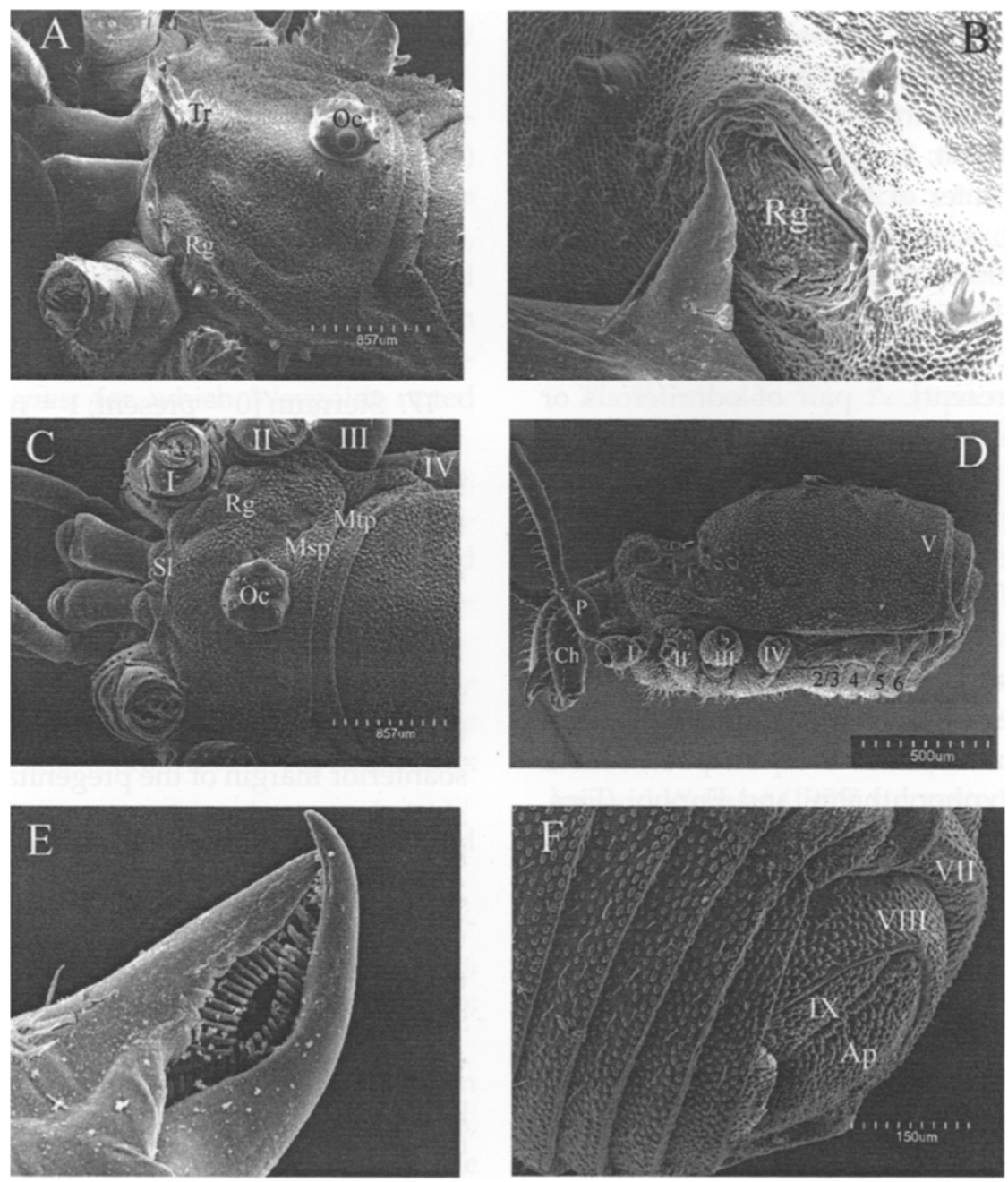

FIG. 12. (A) Odiellus troguloides (Eupnoi, Phalangiidae), dorsolateral view of the cephalothorax showing the trident (Tr), repugnatorial gland $(\mathrm{Rg})$, and ocularium bearing the median eyes (Oc). (B) Opilio parietinus (Eupnoi, Phalangiidae), detail of the repugnatorial gland (Rg). (C) Leiobunum sp., New York (Eupnoi, Leiobunidae). Dorsal view of the cephalothorax showing the disposition of the appendages [cheliceres, palps, walking legs (I to IV), supracheliceral lamellae (Sl), repugnatorial gland, ocularium bearing the median eyes, mesopeltidium (Msp), and metapeltidium (Mtp). (D) Hesperonemastoma modestum (Dyspnoi, Ceratolasmatidae). Lateral view showing the scutum parvum (abdominal tergites up to $\mathrm{V}$ fused), abdominal sternites ( $2 / 3$ to 6), and disposition of the appendages [cheliceres (Ch), palps (P), and walking legs (I to IV)I. (E) Nemastoma bimaculatum (Dyspnoi, Nemastomatidae), diaphanous cheliceral teeth. (F) Hesperonemastoma modestum, showing the abdominal tergite 9 divided dorsally (IX) and situated laterally to the anal plate (Ap).

erect medial spine is found in Triaenonychidae: Equitius and Triaenobunus (pers. obs.) and Zuma (Goodnight and Goodnight, 1942). The genus Hoplobunus was described originally as having a spine on the ocular tubercle (Banks, 1900), but the species included here does not present such a spine. Coding is restricted to Opiliones with an ocularium.

9. Ocularium $[0=$ smooth; $1=$ with two rows of denticles]. An ocularium with two rows of denticles is characteristic of the Phalangioidea and is present in Dalquestia, Odiellus (Fig. 12A), Phalangium, Opilio, Astrobunus, Nelima, Leiobunum (Fig. 12C), and Hadrobunus (pers. obs.). Coding is restricted to Opiliones with an ocularium.

10. Denticles of the ocularium $[0=$ small; $1=$ well developed]. Well-developed denticles in the ocularium 
are found in Odiellus (Fig. 12A), Phalangium, and Opilio (pers. obs.). Coding is restricted to these Opiliones with two rows of denticles (character 9).

11. Trident $[0=$ absent; $1=$ present $]$. A close group of tubercles in the center of the anterior edge of the carapace, the trident, is characteristic of the Phalangiidae (Hillyard and Sankey, 1989). A trident is found in Odiellus (Fig. 12A), Phalangium, and Opilio (pers. obs.).

12. Pair of repugnatorial glands in the carapace $[0=$ absent; $1=$ present $]$. A pair of odoriferous or repugnatorial glands (ozopores) is found in a more or less lateral position on the carapace of all Opiliones (Figs. 12A, 12B, and 12C), but not in any other group of chelicerates. Absence in fossils is coded based on a lack of ozopores.

13. Repugnatorial glands $[0=$ on the side of the carapace, visible from above; $1=$ below the side of the carapace, not visible from above]. The repugnatorial glands are located on the side of the carapace, visible from above in the Cyphophthalmi and Eupnoi (Figs. $12 \mathrm{~A}$ and $12 \mathrm{C}$ ). Coding is restricted to the Opiliones.

14. Ozophores [0 $=$ absent; $1=$ present] (Giribet $e t$ al., 1999c). The ozophores are cone-like structures that bear the repugnatorial glands (ozopores) in the cyphophthalmids: S. rubens (van der Hammen, 1985), $P$. coiffaiti (Juberthie, 1956), and Stylocellus spp. (pers. obs.). Coding is restricted to the Opiliones.

15. Metapeltidial sensory cones $[0=$ absent; $1=$ present] (Shear, 1986; Shultz, 1998; Giribet et al., 1999c). Metapeltidial sensory cones are small projections that occur on the dorsal surface of the metapeltidium of certain "Palpatores." They are found in Ischyropsalis (Roewer, 1923; Shear, 1986; Shultz, 1998; Giribet et al., 1999c), Ceratolasma (Shear, 1986), Sabacon (Roewer, 1923; Juberthie et al., 1981; Shear, 1986; Martens, 1988; Shultz, 1998), Taracus (Shear, 1986), and C. agilis (Shultz, 1998). Shear (1986) considered the presence of metapeltidial sensory cones to be a synapomorphy for the Ischyropsalidoidea, which is refuted by the presence of metapeltidial cones in Caddo (Shultz, 1998). Shear (1986) described a pair of depressions on either side of the midline of the metapeltidium in H. modestum and hypothesized that these represented reduced sensory cones; however, Shultz (1998) could not observe the presence of such structures. Since actual sensory cones are not observed in Hesperonemastoma, we have coded them as absent.

16. Number of metapeltidial sensory cones $[0=$ one;
$1=$ two; 2 = more than two] (Shear, 1986). A pair of metapeltidial cones is present in Sabacon (Roewer, 1923; Juberthie et al., 1981; Shear, 1986; Shultz, 1998), Ceratolasma (Shear, 1986), and C. agilis (Shultz, 1998). In Taracus the number of metapeltidial sensory cones is reduced to 1 (Shear, 1986), and in most Ischyropsalis spp., multiple cones occur (Roewer, 1923; Shear, 1986; Shultz, 1998). Coding is restricted to the taxa with metapeltidial sensory cones.

17. Sternum [0 = present; $1=$ not apparent] (Savory, 1971; Yoshikura, 1975; Shultz, 1998). The ventral surface of the prosoma in Opiliones can be divided into three basic regions, namely, the labium, sternum (prosomal intercoxal sternal region according to Shultz, 1998), and arculi genitales (Hansen and Sørensen, 1904). The labium, if present, represents the sternite of segment III (Winkler, 1957), which is associated with the coxae of leg I. The arculi genitales forms the dorsoanterior margin of the pregenital chamber and probably corresponds to the sternite of the first opisthosomal somite (Hansen and Sørensen, 1904). The sternum does not appear to be a distinct sternite, but is a region with different degrees of development and sclerotization in different lineages (Pocock, 1902; Hansen and Sørensen, 1904; Shultz, 1998). The sternum is well developed in Xiphosura and is flexibly attached to the pedal coxae by soft cuticle. According to Shultz (1998), the sternum of scorpions may represent the first opisthosomal sternite (Pocock, 1902; van der Hammen, 1986) and would correspond to the arculi genitals (but see character 143 for the possibility that the scorpion sternum is appendage-derived). The sternum is absent (or not apparent) in Siro and Parasiro (Hansen and Sørensen, 1904), but is present in Stylocellus (Hansen and Sørensen, 1904). It is also present in the remaining opilionid groups. Among the other chelicerates, a sternum is present in Xiphosura, Scorpiones, Trigonotarbida, Araneae, Amblypygi, Palpigradi, Uropygi, Schizomida, Ricinulei, and Opilioacarus. It is absent in Pseudoscorpiones, Solifugae, and the rest of Acari here represented. Character 22 from Giribet et al. (1999c) has been modified and split into characters 18 and 20 .

18. Sternum $[0=$ undivided; $1=$ with distinct sclerites] (Shultz, 1990, 1999). The posthypostomal cephalic sternum in Trilobita was poorly sclerotized and is unknown. The most closely related arachnates preserving details of sternal morphology are naraoiids, which 
have segmental posthypostomal sternites (Chen et al., 1997).

19. Labium (= tritosternum) $[0=$ absent; $1=$ present] (Shultz, 1990). Shear et al. (1987; character 16) coded a labium as absent in trigonotarbids, but Dunlop (1996b; character 6) indicated its presence (see Dunlop, 1994, Figs. 4, 11, and 12). Weygoldt (1998) interpreted the Silurian scorpion Proscorpius as possessing a labium like that of amblypygids, though this structure is absent in Allopalaeophonus, for which Weygoldt noted similarity of the coxosternum to that of eurypterids.

20. Rostrum [0 = absent; $1=$ present $]$ (Shultz, 1990). The labrum in Solifugae and Pseudoscorpiones projects anteriorly between the bases of the chelicerae and forms a unique beak-like structure, the rostrum (epistomolabral plate sensu Dunlop, 2000).

21. Fusion of head and thorax $[0=$ absent; $1=$ present]. All chelicerates, but not the pycnogonids, have fused the head and the thorax into a cephalothorax (or prosoma).

22. Cucullus $[0=$ absent; $1=$ present $]$ (Pittard and Mitchell, 1972).

23. Enlarged proboscis with terminal, inverted $Y$ shaped mouth $[0=$ absent; $1=$ present] (Snodgrass, 1938; King, 1973; Weygoldt and Paulus, 1979a,b; Wheeler and Hayashi, 1998).

24. Prosoma-opisthosoma coupling mechanism [0 = absent; $1=$ present] (Weygoldt and Paulus, 1979a,b; Shultz, 1990). Shear et al. (1987) dismissed the shared presence of a locking device between the prosoma and the opisthosoma in Ricinulei and Trigonotarbida as nonhomologous, though arguments against this homology were not presented. Dunlop (1996b) regarded a dorsal locking ridge in trigonotarbids and ricinuleids as a homologous expression of opisthosomal tergite 1 . Both groups express the coupling mechanism ventrally by lateral recesses in the opisthosoma that accommodate the coxae of leg 4 (Dunlop, 1996b).

25. Prosomal stigmata $[0=$ absent; $1=$ present $]$ (Roewer, 1934; Shultz, 1990). Prosomal stigmata of the respiratory apparatus are located between the coxae of the second and third walking legs in Solifugae (Roewer, 1934).

26. Supracheliceral lamellae [0 $=$ absent; $1=$ present] (Rambla, 1975; Giribet et al., 1999c). These structures are present in most of the "Palpatores" (Rambla, 1975). They are absent in Dalquestia (Cokendolpher, 1984a), Ischyropsalis (Rambla, 1975), Hesperonemastoma (pers. obs.), and Caddo, Taracus, Nipponopsalis, and Trogulus (N. Tsurusaki, pers. comm.). They are present in Odiellus (Rambla, 1973); Phalangium (Hillyard and Sankey, 1989); Opilio (pers. obs. contra Bishop, 1949); Nelima, Leiobunum (Fig. 12C), Hadrobunus, Sabacon, and Ortholasma (pers. obs.); Astrobunus (Rambla, 1976; pers. obs.); Nemastoma (Rambla, 1975); and Dicranolasma (Rambla, 1975; Gruber, 1996). Ceratolasma is coded as "?".

27. Poorly developed carapace pleural margin $[0=$ absent; 1 = present] (Shultz, 1990; Dunlop and Webster, 1999). Weygoldt and Paulus $(1979 a, b)$ cited a reduced carapace pleural margin as a synapomorphy for Eurypterida + Arachnida, whereas Shultz (1990) judged the pleural margin of eurypterids to be "well-developed." The reduction cited by Weygoldt and Paulus for eurypterids is by comparison to Xiphosura and Trilobita and is descriptively accurate, though the pleural margin is even less developed in scorpions and arachnids. Dunlop and Webster (1999) suggested that the suppression of the pleural margin is obligately coupled with the shift from gnathobasic feeding. The carapace outline in the Devonian scorpion Palaeoscorpius, which has been regarded as having fully gnathobasic feeding (Jeram, 1998), is too poorly known (Kjellsvig-Waering, 1986) to test Dunlop and Webster's proposal. The coding used here, which recognizes a reduction in the pleural margin in eurypterids, does not covary with the loss of gnathobases (character 78).

28. Anteroventrally directed mouth $[0=$ absent; 1 = present] (Shultz, 1990). Ontogenetic as well as outgroup evidence suggests that an anteroventral (as opposed to posterior) orientation of the mouth is apomorphic for arachnids (Shultz, 1990; character 9). Dunlop and Webster (1999) speculated that this state in scorpions could have been convergently acquired as a result of terrestrialization. Their argument would have more force were a posterior mouth orientation (as is suggested in the case of eurypterids) known for fossil scorpions; the state is currently uncertain for eurypterids and fossil scorpions. Dunlop (1997) inferred the mouth of trigonotarbids to be anteroventrally oriented, though less so than in other tetrapulmonates. The opening of the mouth on the proboscis in pycnogonids is not plausibly homologized with its opening to the preoral chamber in arachnids.

29. Carapace $[0=$ undivided; $1=$ with transverse segmental furrows; 2 = divided] (Shultz, 1990). The 
cephalothorax in Xiphosura and Eurypterida shows little evidence of segmentation; this is also generally the case for the cheek region of the trilobite cephalon. An unsegmented carapace is found in Araneae, Amblypygi, Uropygi, and Ricinulei. External evidence of segmentation is present in some arachnid taxa in the form of one or two transverse furrows, such as in many Eupnoi and Dyspnoi (Figs. 12A and 12C), Pseudoscorpiones, and Scorpiones (Shultz, 1990). The carapace of adult Palpigradi, Schizomida, and Solifugae is divided into at least three sclerites (propeltidium, mesopeltidium, and metapeltidium). The same nomenclature is applied to the three regions by opilionid taxonomists. Within the Opiliones the three regions can remain distinct, as seen in Phalangiidae. The propeltidium and mesopeltidium can be fused in certain taxa, leaving only a free metapeltidium: Ortholasma (Shear and Gruber, 1983; pers. obs.), Ceratolasma (Gruber, 1978), Sabacon (Shear, 1975b), Ischyropsalis, Taracus, and Nipponopsalis (pers. obs.). In other cases, all three regions can be fused, as occurs in the Cyphophthalmi, the Laniatores, and certain Dyspnoi: Hesperonemastoma, Dicranolasma, Centetostoma, Nemastoma, and Trogulus (pers. obs.).

30. Opilionid cephalothorax $[0=$ with differentiated propeltidium, mesopeltidium, and metapeltidium; 1 = propeltidium and mesopeltidium fused]. Coding is applied to Opiliones with a transverse segmental furrow (see Figs. 12A and 12C, Msp, Mtp).

31. Epipharyngeal sclerite $[0=$ embedded in intercheliceral membrane; 1 = firm attachment to epistome] (Shultz, 1999). Dunlop (1994, Fig. 11) tentatively identified the epipharyngeal sclerite in Trigonotarbida.

32. Epipharyngeal sclerite $[0=$ small, without significant posterior projection; $1=$ large, projecting posteriorly to anterior surface of brain] (Shultz, 1999).

33. Ventroposterior wall of preoral chamber $[0=$ formed by "sternite" (tritosternum or labium); 1 = formed by palpal coxae] (Shultz, 1999).

34. Endosternum [0 = absent; $1=$ present] (Boudreaux, 1979). In Euchelicerata except Solifugae (Firstman, 1973; Selden, 1981), the ventral tendons of the prosoma are consolidated into a plate, the endosternum, which is suspended by the dorsoventral muscles (Boudreaux, 1979). Firstman (1973) considered fusion of perineural vascular membrane to be an additional component of the endosternum. Whether or not homology between Dohrn's membrane in pycnogonids and the endosternum is endorsed (Firstman, 1973), pycnogonids do not possess the plate-like endosternum of Euchelicerata. In trilobitomorphs, the cephalic intersegmental tendons resemble those of the trunk, being preserved between segmental sternites (see Chen et al., 1997, for naraoiids), and we infer the endosternum to be absent.

35. Fenestrate endosternite $[0=$ absent; $1=$ present $]$ (Shultz, 1990). Coding is restricted to Euchelicerata (dependent on presence of endosternite).

36. Epistomolabral plate covering mouth dorsally, pair of subcapitular, bilobate lateral lips flanking mouth ventrolaterally $[0=$ absent; $1=$ present $]$ (Lindquist, 1984; Dunlop, 2000).

37. Movable gnathosoma/subcapitulum of the palpal coxae [0 = absent; $1=$ present] (Lindquist, 1984; Shultz 1990).

38. Three-branched epistomal skeleton supporting the pharyngeal dilator muscles $[0=$ absent; $1=$ present] (Shultz, 2000). According to Shultz (2000), Opiliones and Scorpiones appear to share a unique system for supporting the extrinsic pharyngeal muscles. An epistome has three processes, one median and two lateral, which serve as the skeletal framework to which the pharyngeal dilator muscles attach. This character has been coded for those taxa for which muscular data are well known (Shultz, 1993, 1999, 2000).

39. Subcapitular rutella [0 = absent; $1=$ present $]$ (Lindquist, 1984).

\section{Appendages}

40. Ovigers [0 $=$ absent; $1=$ present] (King, 1973; Arnaud and Bamber, 1987). A pair of "appendages" attached to the ventral surface of the body, posteriorly situated in relation to the palps, is present at least in the males of all the pycnogonid species here analyzed.

\section{Chelicerae}

41. Chelifores/chelicerae [ $0=$ absent; $1=$ present $]$.

42. Opilionid male cheliceral glands $[0=$ absent; $1=$ present] (Martens and Schawaller, 1977; Shear, 1986; Shultz, 1998; Giribet et al., 1999c). Male cheliceral glands are epidermal glandular organs situated in the proximal joint on the basal cheliceral article in males of the Ischyropsalidoidea and Troguloidea. This organ was described by Martens and Schawaller (1977) for 
the following species: D. scabrum, N. lugubre, I. hellwigi, I. carli, and Sabacon jiriense. For the species studied here, the male cheliceral glands are found in N. bimaculatum (Hillyard and Sankey, 1989), C. tricantha (Gruber, 1978), N. abei (Suzuki, 1940), S. cavicolens (Shear, 1975b), and D. soerenseni, I. luteipes, and C. dubium (Giribet et al., 1999c). The glands are absent in Taracus (Shear, 1975b, 1986), Hesperonemastoma (Shear, 1986), and Trogulus (Shultz, 1998). The genus Ortholasma is polymorphic for this character, and since the specimen that we used for the molecular analysis was not identified to the species level, we have coded it as "?".

43. Diaphanous cheliceral teeth $[0=$ absent; $1=$ present] (Shultz, 1998; Giribet et al., 1999c). The opposing margins of the cheliceral fingers are emarginate and lined with diaphanous to subdiaphanous teeth in several species of Dyspnoi: Sabacon (Roewer, 1923; Suzuki, 1965; Shultz, 1998), Ischyropsalis (Roewer, 1923; Eisenbeis and Wichard, 1985; Shultz, 1998; Giribet et al., 1999c), Hesperonemastoma (Shultz, 1998), Dicranolasma (Shultz, 1998), Centetostoma (Giribet et al., 1999c), Nemastoma (Fig. 12E), Ortholasma (Shear and Gruber, 1983), Ceratolasma (Gruber, 1978), Nipponopsalis (Suzuki, 1940), Trogulus (Eisenbeis and Wichard, 1985; Shultz, 1998), and Taracus (Nobuo Tsurusaki, pers. obs.). Oncopus was coded as having state " 2 " by Giribet et al. (1999c), obviously a misprint, since there was no state " 2 " in the character description.

44. Chelicerae formed by $[0=$ three segments, the last two forming a chela; 1 = two segments, subchelate; 2 = two segments, chelate, articulating at a ventral or ventrolateral joint] (Shultz, 1990). Dunlop (1996b) was unable to distinguish between the two-segmented "clasp-knife" type chelicerae in extant tetrapulmonates and trigonotarbids (Shear et al., 1987) and the cheliceral segmentation of ricinuleids. Ricinuleids are thus coded as state 1 .

45. Chelicerocarapacal articulation $[0=$ absent; $1=$ present] (Shultz, 1990).

46. Cheliceral venom glands $[0=$ absent; $1=$ present] (Shultz, 1990).

47. Cheliceral silk glands [0 $=$ absent; $1=$ present $]$ (Shultz, 1990).

48. Cheliceral flagellae in males $[0=$ absent; $1=$ present]. This structure is present in Solifugae.

49. Plagula ventralis $[0=$ absent; $1=$ present $]$ (Shear et al., 1987). Homann (1985) claimed that a small sclerite in the articular membrane between the fang and the basis of the chelicera (the plagula ventralis) is unique to Tetrapulmonata. Shear et al. (1987, Fig. 7) showed its presence in Trigonotarbida. It is not present in all Araneae (Dunlop, 1996b).

50. Cheliceral gland of spiders [ $0=$ absent; $1=$ present] (Forster and Platnick, 1984; Selden et al., 1991).

51. Chelicera $[0=$ paraxial; $1=$ diaxial] (Platnick and Gertsch, 1976). Coding is restricted to Tetrapulmonata, as well as recording the paraxial state in trigonotarbids (Dunlop, 1997).

\section{Palps}

52. Palpal setae $[0=$ simple (Fig. $13 \mathrm{~A}$ ); $1=$ "plumose," with distal clusters of microtrichia (Fig. 13B); 2 = "clavate," mace-shaped] (Shear, 1986; Shultz, 1998; Giribet et al., 1999c). It is not known for certain whether the plumose setae are glandular. Plumose palpal setae are present in Caddo (Gruber, 1974, Fig. 20a), Taracus (Fig. 13B), Hesperonemastoma, and Sabacon (Shear, 1986, Figs. 7-9). Clavate setae are known in Ortholasma (Shear and Grüber, 1983), juvenile Dicranolasma (Gruber, 1978), and Nipponopsalis (Miyosi, 1942; Gruber, 1978). Adult Ceratolasma and Ischyropsalis (Shear, 1986, Figs. 3 and 4), Dalquestia, Astrobunus, Nelima, Leiobunum, Hadrobunus, Odiellus, Phalangium, Opilio, Nemastoma, and Centetostoma (pers. obs.) have simple palpal setae. Phalangium was reported to have plumose palpal setae by Shultz (1998), but this was a miscoding (J. W. Shultz, pers. comm.). Opilioacarus presents different types of palpal setae (van der Hammen, 1966) and has been coded as "?". Juveniles of certain species of Eupnoi and Laniatores also might present plumose setae (W. A. Shear, pers. comm.). Mace-shaped setae are also found in some Phalangioidea such as Ballarrinae (Hunt and Cokendolpher, 1991).

53. Dense distribution of palpal setae $[0=$ absent; $1=$ present] (Shear, 1986). A very dense distribution of plumose setae on palpi (tibia and tarsus) occurs in Sabacon (Shear, 1975b; Gruber, 1978; Martens, 1983) and Taracus and is considered by Shear (1986) to be a synapomorphy for Sabaconidae. However, a dense distribution of palpal setae also occurs in Hesperonemastoma (pers. obs.). Shear (1986) also mentioned two other synapomorphies for the Sabaconidae, a swollen tibia and tarsus, and the tarsus reflexed on the mesal surface 

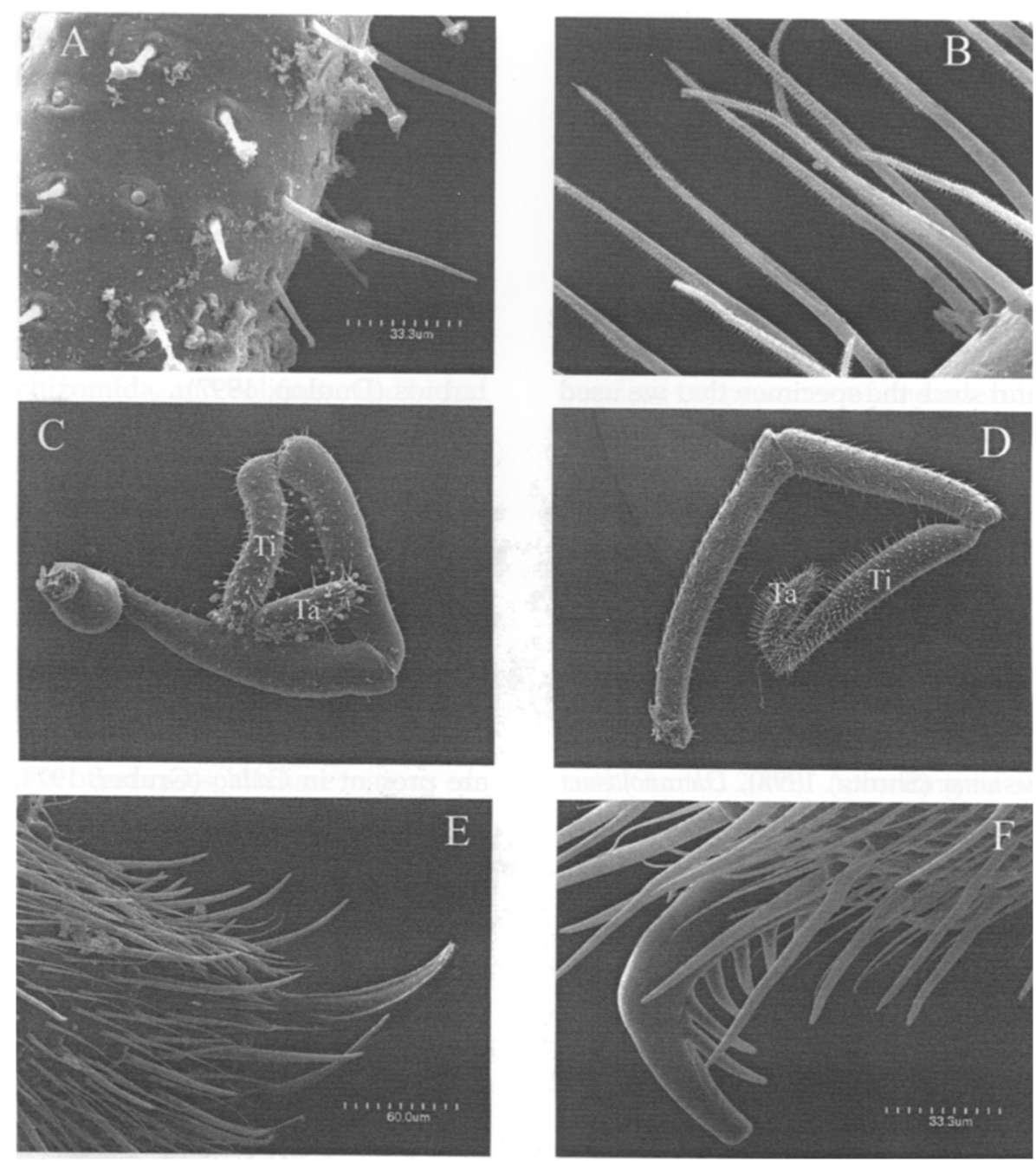

FIG. 13. SEM photographs of palpal characters: (A) Nemastoma bimaculatum (Dyspnoi, Nemastomatidae), simple setae on palpal tibia. (B) Taracus sp. (Dyspnoi, Sabaconidae), plumose setae on palpal tibia. (C) Nem. bimaculatum, palp. (D) Taracus sp., palp with the tarsus reflexed on the mesal surface of the tibia. (E) Odiellus troguloides (Eupnoi, Phalangiidae), smooth palpal claw. (F) Astrobunus grallator (Eupnoi, Sclerosomatidae), pectinate palpal claw.

of the tibia, but he considered that these three characters were dependent and coded them as a single character.

54. Tarsus reflexed on the mesal surface of the tibia $[0=$ absent (Fig. 13C); 1 = present (Fig. 13D)] (Shear, 1986). A tarsus reflexed on the mesal surface of the tibia is present in Sabacon and Taracus (Gruber, 1978; Martens, 1983; Shear, 1986).

55. Palpal tarsal claw $[0=$ present; $1=$ absent $]$ (Shultz, 1998; Giribet et al., 1999c; see Barrows, 1925).
According to Shultz (1998), the opilionid palp is primitively equipped with a terminal apotelic claw, a condition retained in all Eupnoi, Laniatores, and Cyphophthalmi (pers. obs.): Dalquestia (Cokendolpher, 1984), Odiellus (Rambla, 1973, 1985; Gruber, 1978; Martens, 1983), Phalangium (Gruber, 1978; Martens, 1983; Edgar, 1990; Shultz, 1998), Opilio (Hillyard and Sankey, 1989), Astrobunus (Rambla, 1976), Nelima (Hillyard and Sankey, 1989), Leiobunum, Hadrobunus (Bishop, 1949), Caddo (Gruber, 1974; Shear, 1975a; Shultz, 1998), Scotolemon 
(van der Hammen, 1985), Oncopus (Bristowe, 1976; Schwendinger, 1992; Martens and Schwendinger, 1998), Gnomulus (Martens and Schwendinger, 1998), Maiorerus (Rambla, 1993), Equitius, Triaenobunus, Zuma, Bishopella, Gnidia, Pachyloides, Hoplobunus (pers. obs.), and the Cyphophthalmi (e.g., Shear, 1980, 1985, 1993a,b,c; van der Hammen, 1985; Eisenbeis and Wichard, 1985; Rambla, 1991; Shear and Gruber, 1996; Shultz, 1998; pers. obs.). According to Shear (1986), the palpal claw of all ischyropsalidoids has been reduced to a small nubbin or entirely lost. It is absent in Sabacon (Shear, 1975b; Martens, 1983; Shultz, 1998; pers. obs.), Taracus (pers. obs.), Ischyropsalis, Hesperonemastoma, Dicranolasma, and Trogulus (Shultz, 1998; Giribet et al., 1999c; pers. obs.), Ortholasma (Shear and Gruber, 1983; pers. obs.), Nemastoma (Hillyard and Sankey, 1989), Ceratolasma (Gruber, 1978; pers. obs.), Nipponopsalis (Suzuki, 1940; pers. obs.), and Centetostoma (pers. obs.).

56. Palpal tarsal claw $[0=$ not prehensile; $1=$ prehensile] (Giribet et al., 1999c; Shultz, 1990). All the Laniatores exhibit a special type of palpal claw that is prehensile, similar to the cheliceral fang of mygalomorph spiders (Rambla, 1975). Caddo has a movable palpal claw (Gruber, 1974; Shear, 1975a) but it is not prehensile like that of Laniatores.

57. Opilionid palpal tarsal claw $[0=$ well developed; 1 = rudimentary] (Shultz, 1998; Giribet et al., 1999c). The palpal claw is greatly reduced in the Cyphophthalmi (e.g., Shear, 1980, 1985, 1993a,b; Eisenbeis and Wichard, 1985; van der Hammen, 1985; Rambla, 1991; Shear and Gruber, 1996; Shultz, 1998; pers. obs.).

58. Opilionid palpal tarsal claw $[0=$ smooth (Fig. 13E); 1 = pectinate or toothed (Fig. 13F)]. Palpal claws are smooth in Phalangiidae and pectinate in "Leiobunidae" (Hillyard and Sankey, 1989; but see Cokendolpher, 1984b). They are smooth in Dalquestia (Cokendolpher, 1984), Odiellus (Rambla, 1973, 1985), Caddo (Gruber, 1974), Phalangium, Opilio, Laniatores, and Cyphophthalmi (pers. obs.). They are pectinate in Astrobunus (Fig. 13F) (Rambla, 1976), Hadrobunus (pers. obs.), Nelima (Hillyard and Sankey, 1989), and Leiobunum (pers. obs.).

59. Opilionid palps [ $0=$ thin; $1=$ robust] (Giribet et al., 1999c). Palpi are either sensory or prehensile appendages, depending on the opilionid groups. We consider "thin" palpi those of tactile function and that are thinner or similar to the walking legs, while "robust" palpi are thicker than the walking legs, as in Scotolemon, Maiorerus, Bishopella, Pachyloides, Gnidia, Hoplobunus, Triaenobunus, Equitius, and Caddo (pers. obs.). Caddo was erroneously coded as "thin" by Giribet et al. (1999). Coding is restricted to Opiliones.

60. Tibia and tarsus of the palpi with two rows of long-spined tubercles ("grasping hand") $[0=$ absent; $1=$ present; 2 = spines fused into a lateral flap]. This character corresponds to character 7 of Giribet et al. (1999c), although the character has been redefined. The Laniatores (Equitius, Triaenobunus, Zuma, Scotolemon, Maiorerus, Bishopella, Pachyloides, and Hoplobunus, pers. obs. and citations above) have two rows of long-spined tubercles at each side of the tibial and tarsal segments of the palpi. These tubercles can extend to the patella and femur in some species. The oncopodids have smooth palpi, without spines (Schwendinger, 1992; Martens and Schwendinger, 1998; pers. obs.). The cosmetids, including Gnidia, have a modified flattened palp without the spines (pers. obs.). This state is not present in any of the nonlaniatorid Opiliones and seems to be a modification of state " 1 ", and thus we have considered this character as ordered. Caddo presents a single row of long spines at the ventral side of the femur and a row of short spines in the ventral side of the tarsus and tibia (Gruber, 1974; Shear, 1975a). This is also observed in other "spiny-palped" "Palpatores" [e.g., Dicranolasma nymphs, Platybunus spp. (J. Gruber, pers. comm.)] that have the spines restricted to the proximal articles, mainly the femur. Coding is restricted to Opiliones. ORDERED.

61. Ratio between the tarsus and the tibia of opilionid palp $[0=$ subequal; 1 = tarsus shorter than tibia; $2=$ tarsus longer than tibia]. The tarsus is longer than the tibia in Dalquestia (Cokendolpher, 1984), Odiellus (Rambla, 1973), Phalangium (Hillyard and Sankey, 1989), Opilio (Hillyard and Sankey, 1989), Astrobunus (Rambla, 1976), Nelima (Hillyard and Sankey, 1989), Leiobunum (Hillyard and Sankey, 1989), Caddo (Shear, 1975a), Nipponopsalis (Suzuki, 1940), Trogulus (Eisenbeis and Wichard, 1985), Oncopus (Schwendinger, 1992), and Hadrobunus (Bishop, 1949). The tarsus is shorter than the tibia in Nemastoma (Hillyard and Sankey, 1989), Sabacon (Shear, 1975b), Ortholasma (Shear and Gruber, 1983), Ischyropsalis, Hesperonemastoma, 
Taracus, Centetostoma, Dicranolasma, Gnidia, and Bishopella (pers. obs.). Both segments are almost equal in length in the Sironidae, Ceratolasma (Gruber, 1978), Equitius, Triaenobunus, Zuma, Maiorerus, Hoplobunus, and Pachyloides (pers. obs.). Coding is restricted to Opiliones.

62. Scorpionid palpal chelae $[0=$ absent; $1=$ present] (Barrows, 1925; Shultz, 1990).

63. Palpal coxae $[0=$ free; $1=$ fused medially $]$ (Shultz, 1990). The palpal coxae of trigonotarbids are unfused, and Dunlop (1996b) considered them likely to have been mobile.

64. Palpal poison glands $[0=$ absent; $1=$ present $]$ (Yoshikura, 1975). Roncus has a venom apparatus only in the fixed chelal finger, while Americhernes has it only in the movable chelal finger (Harvey, 1992).

65. Coxal gland orifice on palps $[0=$ absent; $1=$ present] (Shultz, 1990).

66. Adhesive palpal organ (terminal sucker) $[0=$ absent; 1 = present] (Barrows, 1925; Savory, 1971).

67. Copulatory organ on male palp $[0=$ absent; $1=$ present] (Barrows, 1925; Shultz, 1990).

68. Palpal chelae with the movable finger supplied with internal musculature $[0=$ absent; $1=$ present $]$ (Barrows, 1925; Shultz, 1990).

69. Palpal apotele $[0=$ differentiated from tarsus; $1=$ not differentiated from tarsus] (Shultz, 1999).

\section{Walking Legs ${ }^{4}$}

70. Leg II longer than adjacent legs and modified as a feeler $[0=$ absent; $1=$ present $]$. This character accommodates character 14 from Giribet et al. (1999c), character 9 from Shultz (1998), and character 4 from Dunlop (1996b). Leg II is typically longer than adjacent legs in nonsironoid opilions, including Scotolemon (Roewer, 1923; Berland, 1949), Maiorerus (Rambla, 1993), Oncopus (Bristowe, 1976; Schwendinger, 1992), Gnomulus (Martens and Schwendinger, 1998), Dalquestia (Cokendolpher, 1984), Phalangium (Berland, 1949; Shultz, 1998), Caddo (Shear, 1975; Shultz, 1998), Ischyropsalis (Berland, 1949, Shultz, 1998), Ceratolasma (Gruber,

\footnotetext{
${ }^{4}$ Coding of skeletomuscular leg characters for spiders is based on the description of the fourth leg of Liphistius sumatranus by Shultz (1989), and, unless indicated, this has been used as a ground plan for the entire order Araneae since its appendicular morphology does not differ substantially from that of other spiders. Others are also based on leg IV of representative species (Shultz, 1989).
}

1978), Sabacon (Shear, 1975b; Shultz, 1998), Hesperonemastoma (Shultz, 1998), Dicranolasma (Gruber, 1993; Shultz, 1998), Ortholasma (Shear and Gruber, 1983), Nipponopsalis (Suzuki, 1940; Martens and Suzuki, 1966), and Trogulus (Berland, 1949; Shultz, 1998). Leg II is shorter or not notably longer than adjacent legs in Siro and other sironoids (Hansen and Sørensen, 1904; Shultz, 1998). Dunlop (1996b) coded the elongation of leg II and its function as a feeler as shared by Opiliones and Ricinulei.

71. Tarsal segments (tarsomeres) in walking legs [0 = absent; 1 = present] (Shultz, 1989, 1998, 1999; Giribet et al., 1999c). Telotarsi are undivided in most chelicerates, but they are typically subdivided into numerous tarsomeres in the Opiliones. Among the $\mathrm{Cy}$ phophthalmi, most species have undivided tarsi, but the fourth tarsus of the males of certain species of sironids are divided (Shear, 1980). S. rubens (van der Hammen, 1985), P. coiffaiti (pers. obs.), Stylocellus spp. (pers. obs.), and Oncopus (Roewer, 1923; Bristowe, 1976; Schwendinger, 1992; Martens and Schwendinger, 1998) have undivided tarsi. Trogulus is polymorphic for the character (Hansen and Sørensen, 1904; Roewer, 1923), but $T$. nepaeformis, the species here studied, has divided tarsi (Eisenbeis and Wichard, 1985). The remaining taxa have more than one tarsal segment (pers. obs. and citations above). Extant Xiphosura, Scorpiones, Pseudoscorpiones, Araneae, and Acari lack tarsal segments as defined above with reference to Opiliones. However, the Devonian xiphosuran Weinbergina is interpreted as having a bipartite tarsus (Stürmer and Bergström, 1981). Solifugae, Ricinulei, Palpigradi, Amblypygi, Uropygi, and Schizomida have tarsal segments.

72. Walking leg claws [0 = all (or at least II, III, and IV) similar; 1 = III and IV differing from I and II] (Giribet et al., 1999c). Generally, the tarsi of legs I and II of the Laniatores have a single claw, while tarsi from legs III and IV have more complex claws (Rambla, 1975): Scotolemon (van der Hammen, 1985), Oncopus (Schwendinger, 1992), Gnomulus (Martens and Schwendinger, 1998), Equitius, Triaenobunus, Zuma, Maiorerus, Bishopella, Gnidia, Pachyloides, and Hoplobunus (pers. obs.). All the "Palpatores" have a single claw similar in all four pairs of legs (Rambla, 1975). The Cyphophthalmi also have similar single claws in all four pairs of walking legs: Siro (Eisenbeis and Wichard, 1985), Parasiro (Juberthie, 1956), and Stylocellus 
(Rambla, 1991; pers. obs.). The remaining arachnids have a similar claw in all walking legs, except for some taxa that present a modified leg I (Amblypygi, Uropygi, Schizomida, and Solifugae) lacking a claw.

73. Claws from legs III and IV [0= a single triramous or multiramous claw; $1=$ two claws; 2 = one claw] (Giribet et al., 1999c). Two claws are observed in Oncopus (Schwendinger, 1992) and Gnomulus (Martens and Schwendinger, 1998), as well as in the Gonyleptoidea (pers. obs.) and most other arachnids. The triaenonychids have a single triramous claw (pers. obs). The telotarsal spurs of eurypterids and "Protoscorpiones" (Jeram, 1998, character 19) are coded as state 0.

74. Opilionid tarsal process $[0=$ absent; $1=$ present $]$ (Giribet $e t$ al., 1999c). The tarsal process was called a pseudonychium by Roewer (nomenclature followed in Giribet et al., 1999c), based on the supposition that this structure corresponded to the structure described by Sørensen in juveniles (Muñoz-Cuevas, 1971). The tarsal process is a chitinous prolongation of the tarsus located dorsal to the claws from legs III and IV in certain groups of Laniatores of the families Cosmetidae and Gonyleptidae. Since tarsal processes of different types are present in many other groups of Arachnida, we have restricted the coding of this particular type of tarsal process to the opilionid taxa.

75. Coxapophysis $\Pi[0=$ absent; $1=$ present $]$ (Shultz, 1998). Coxapophyses (gnathocoxae in Giribet et al., 1999c) are projections occurring on the medial surface of the palpal and certain pedal coxae (especially legs I and II) in extant scorpions and many Opiliones, where they assist in forming a preoral chamber, the stomotheca (Hansen and Sørensen, 1904; Shultz, 1998, 2000). The gnathocoxae are frequently reduced or lost on the posterior legs in Opiliones, but are present in all the legs of the Cyphophthalmi (Shear, 1980; van der Hammen, 1985; Rambla, 1991; pers. obs.) and Ceratolasma (Gruber, 1978). Stomothecae are lacking in basal fossil scorpions (Jeram, 1998; Weygoldt, 1998; Dunlop and Webster, 1999). Coxapophyses are present on leg II in Siro (Shear, 1980; Shultz, 1998), Phalangium (Shultz, 1998; pers. obs.), Dalquestia, Odiellus, Nelima, Hadrobunus, Astrobunus, Leiobunum (pers. obs.), Caddo (Roewer, 1923; Shultz, 1998), Ischyropsalis (Pocock, 1902; Martens and Suzuki, 1996; Shultz, 1998), Hesperonemastoma (Shultz, 1998), Nipponopsalis (pers. obs.), Ceratolasma (Gruber, 1978), Triaenonychidae (pers. obs.), Oncopus
(Roewer, 1923; Schwendinger, 1992; pers. obs.), Gnomulus (Martens and Schwendinger, 1998; pers. obs.), Scotolemon (van der Hammen, 1985), Maiorerus, Hoplobunus, and Bishopella (pers. obs.). Coxapophyses are absent on leg II in Dicranolasma (Pocock, 1902; Shultz, 1998), Nemastoma (pers. obs.), Trogulus (Pocock, 1992; Roewer, 1923; Shultz, 1998), Sabacon species (Hansen and Sørensen, 1904; Shultz, 1998; pers. obs.), Taracus (pers. obs.), Cosmetidae, and Gonyleptidae (Kury, 1993; pers. obs.). Shultz (1998) suggested that coxapophyses more closely resemble immovable coxal processes of Limulus than the endites of that taxon. We infer these "coxal processes" to mean the triangular projection on the last leg of Limulus. We cannot, however, identify a convincing homologue of coxapophyses on legs II-IV of Xiphosura (or Eurypterida) and code characters 75-77 as absences.

76. Coxapophysis III $[0=$ absent; $1=$ present $]$. Coxapophyses on leg III are present in Cyphophthalmi (Shear, 1980; van der Hammen, 1985; Rambla, 1991), Ceratolasma (Gruber, 1978), triaenonychids (pers. obs.), Gnomulus (Martens and Schwendinger, 1998; pers. obs.), and Bishopella (pers. obs.).

77. Coxapophysis IV $[0=$ absent; $1=$ present $]$. Coxapophyses on leg IV are present in Cyphophthalmi (Shear, 1980; van der Hammen, 1985; Rambla, 1991; pers. obs.), Dalquestia, Odiellus, Hadrobunus, Astrobunus, Leiobunum (pers. obs.), and Ceratolasma (Gruber, 1978)

78. Toothed gnathobases on coxae II-VI $[0=$ absent; $1=$ present] (Selden, 1981; Selden et al., 1991).

79. Coxae of walking legs $[0=$ all free; $1=$ pair $I$ and sometimes pair II free (tending to fuse with pairs III and IV); 2 = all fused] (Giribet et al., 1999c; Shultz, 1990). Some Cyphophthalmi present different degrees of fusion among the coxae. Trogulus, Dicranolasma, Ortholasma, and Nemastoma have all the coxae fused (pers. obs.). The Eupnoi have free coxae, as do Taracus, Sabacon, Hesperonemastoma, Centetostoma, Ischyropsalis, Nipponopsalis, Oncopus, and Gnomulus (pers. obs.).

80. Coxae $[0=$ smooth; $1=$ with a row of denticles at each side]. Two rows of denticles are observed in the coxae of Astrobunus, Leiobunum, Hadrobunus, and Nemastoma (pers. obs.). Coding is restricted to Opiliones.

81. Coxae IV $[0=$ normal; 1 = extraordinarily developed, surpassing the carapace, and forming a wide angle with the other coxae]. Extraordinarily developed 
coxae IV are found in Pachyloides, Gnidia, and Hoplobunus (pers. obs.).

82. Tracheal system with accessory stigmata in the tibia of the walking legs [0 = absent; $1=$ present] (Giribet et al., 1999c). This is found in all members of the Phalangioidea (Hansen and Sørensen, 1904). Coding is restricted to chelicerates with a tracheal system.

83. Adenostyle in male tarsus IV [0= absent; $1=$ present]. The Cyphophthalmi have an adenostyle [apophysis of the tarsal gland (Juberthie, 1967); telotarsal organ (van der Hammen, 1985)] in the tarsus of leg IV (Shear, 1980).

84. Leg I $[0=$ unmodified, ambulatory; $1=$ elongate, tactile] (Shultz, 1989, 1990, 1999).

85. Coxotrochanteral joint $[0=$ simple; $1=$ complex $]$ (Shultz, 1989, 1990). The nonpreservation of intrinsic musculature in trilobite legs renders the homology of podomeres with those in Chelicerata uncertain. Still, classic (Størmer, 1944) and modern (Shultz, 1989) work has identified probable correspondences between the basis, six podomeres, and pretarsus of trilobites and an eight-segmented leg in chelicerates. This and other characters involving hinges/condyles between podomeres (characters 87 and 92) are coded for trilobites based on Bruton and Haas (1999).

86. Femur of legs III and IV divided [0 = absent; 1 = present] (Shultz, 1989, 1990; Dunlop, 1996b).

87. Femorpatellar joint $[0=$ transverse dorsal hinge articulation; 1 = transverse bicondylar articulation; $2=$ anterodorsal monocondylar articulation] (Shultz, 1989, 1990). Coding for a transverse bicondylar articulation in trigonotarbids (see also character 92) is based on the reconstruction by Shear et al. (1987, Fig. 51).

88. Tibial trichobothria with 2-2-1-1 distribution [0 = absent; 1 = present] (Shultz, 1990). Coding is restricted to arachnids with trichobothria (character 213).

89. Coxal gland orifice, leg III $[0=$ present; $1=$ absent] (Shultz, 1990).

90. Coxal gland orifice, leg $\mathrm{I}[0=$ present; $1=$ absent $]$ (Shultz, 1990).

91. Trochanterofemoral joint of walking legs $[0=$ transverse bicondylar; $1=$ dorsal hinge; $2=$ vertical bicondylar] (Shultz, 1989, 1990).

92. Patellotibial joint of walking legs $[0=$ dorsal monocondylar; 1 = dorsal hinge; $2=$ simple bicondylar; 3 = vertical bicondylar] (Shultz, 1989, 1990).
93. Enlarged femur on leg IV [0 = absent; $1=$ present] (Hansen and Sørensen, 1905; Shultz, 1990).

94. Male copulatory organ on leg III $[0=$ absent; $1=$ present] (Weygoldt and Paulus, 1979a,b; Shultz, 1990).

95. Empodium [0 = absent; $1=$ present] (Shultz, 1990).

96. Malleoli or racket organs $[0=$ absent; $1=$ present] (Shultz, 1990).

97. Palp [0 = leglike; 1 = raptorial] (Shear et al., 1987; Shultz, 1990, 1999).

98. Cleaning organ on palpal tarsus $[0=$ absent; $1=$ present] (Delle Cave, 1975; Shear et al., 1987; Selden et al., 1991). Shear et al. (1987) identified a complex cleaning organ as an autapomorphy of Amblypygi.

99. Compression zone $Y$ in patellotibial joint of walking legs [ 0 = absent; $1=$ present] (Manton, 1977; Selden et al., 1991). "Compression zone $Y$ " refers to a posterior emargination in the patellotibial joint that provides complex mobility to this joint in Araneae (Selden et al., 1991).

100. Tarsal organ $[0=$ absent; $1=$ present $]$ (Forster, 1980; Selden et al., 1991). Selden et al. (1991) claimed that the tarsal organ of spiders (Blumenthal, 1935) is present in Amblypygi, Uropygi, and Schizomida but is unknown in Trigonotarbida. They disputed homology with similar tarsal structures in scorpions and ticks based on ultrastructural differences.

101. Apotelic claw of leg I [0 = differentiated from tarsus; 1 = not differentiated from tarsus] (Shultz, 1999). Amblypygi, Uropygi, Schizomida, and Solifugae lack a claw on walking leg I.

102. Telotarsus of legs II-IV with three tarsomeres [0 = absent; 1 = present] (Shultz, 1999).

103. Patella-tibia joint with auxiliary posterior articulation [0 = absent; 1 = present] (Shultz, 1999).

104. Sternocoxal articulation, leg I [0 = absent; $1=$ present] (Shultz, 1999).

105. Coxae IV and sternite VII [0 = separate; $1=$ fused] (Shultz, 1999).

106. Coxa of walking leg IV with an invagination at the posteromedian corner $[0=$ absent; $1=$ present $]$ (Platnick and Gertsch, 1976).

107. Elastic arthrodial sclerites spanning the tibiatarsus joints $[0=$ absent; $1=$ present $]$ (Shultz, 2000).

108. Laterally compressed podomeres $[0=$ femur and patella cylindrical; 1 = femur and patella laterally compressed] (Jeram, 1998). Codings follow Jeram. (1998, character 14). 
109. Coxae grouped around sternum [0 = absent; 1 = present] (Jeram, 1994b, 1998). Palaeoscorpiones and Scorpiones (sensu Stockwell, 1989) share the coxae of leg II abutting the anterior edge of the sternum (Jeram, 1998, character 21). In Allopalaeophonus the coxa of leg $\Pi$ is anterior to the sternum.

110. Exopod on last prosomal walking leg $[0=$ present; 1 = absent]. The flabellum of Xiphosura has long been interpreted as a vestigial exopod, homologous with those of trilobitomorphs (e.g., Størmer, 1944). Exopods are lacking on limb VI in eurypterids and arachnids. Coding is restricted to taxa that possess exopods / exopodal derivatives (e.g., book gills, book lungs) on any trunk limb.

\section{Abdomen}

111. Abdominal sternite $9[0=$ present, well developed; 1 = very small or apparently absent] (Shultz, 1998). Abdominal sternite 9 is present in Siro (Roewer, 1923; Shultz, 1998), Parasiro (Juberthie, 1956; Selden et al., 1991), Stylocellus (pers. obs.), Scotolemon (van der Hammen, 1985), Oncopus (Roewer, 1923), and Laniatores in general (pers. obs.), although it is generally fused with sternite 8 . It is greatly reduced or absent in Phalangium, Caddo, Sabacon, Ischyropsalis, Hesperonemastoma, Dicranolasma, Trogulus (Shultz, 1998), Nemastoma (Hansen and Sørensen, 1904), Nelima, Hadrobunus, Centetostoma, Taracus, and Nipponopsalis (pers. obs.). Coding is restricted to Opiliones.

112. Abdominal tergite $9[0=$ undivided; $1=\mathrm{di}$ vided dorsally] (Shultz, 1998). According to Hansen and Sørensen (1904), the dorsal surface of the opilionid abdomen is generally regarded as having nine tergites and an anal operculum. Tergite 9 is modified in certain Opiliones in association with specialization of the anal complex. It is undivided in Siro and other sironids, whether distinct or consolidated in various ways with adjacent tergites and sternites (Hansen and Sørensen, 1904; Roewer, 1923; Shear, 1980; Shultz, 1998). It is also undivided in Scotolemon (van der Hammen, 1985), and other Laniatores, but is generally fused to tergite 8 . In contrast, tergite 9 in most other Opiliones is divided dorsally, with the two parts widely separated by the anal operculum and, in some cases, by tergite 8 . This condition is present in Phalangium, Caddo, Sabacon, Ischyropsalis, Hesperonemastoma (Fig. 12F), Dicranolasma, and Trogulus (Shultz, 1998) and the rest of Eupnoi and Dyspnoi.

113. Male exocrine glands in the anal region $[0=$ absent; 1 = present] (Giribet et al., 1999c). Juberthie (1967) described a complex of glands found in the anal region of males of certain species of sironids. These glands might involve modifications of the posterior end of the body, especially the anal plate and the eighth and ninth tergites (Shear, 1980). This structure is supposed to generate a pheromone. These glands and their associated modifications are lacking in most Stylocellidae, Ogoveidae, and Neogoveidae (Shear, 1980; Rambla, 1991; Selden et al., 1991). Siro (Eisenbeis and Wichard, 1985) and Parasiro (pers. obs.) are the only terminal taxa here examined that have the male exocrine glands in the anal region.

114. Fusion of all opisthosomal tergites behind the opercular tergite into a thoracetron $[0=$ absent; $1=$ present]. The fusion of all opisthosomal tergites behind the opercular tergite into a thoracetron is regarded as an apomorphy for Xiphosurida (Anderson and Selden, 1997), whereas the Paleozoic synziphosurine grade have free opisthosomal tergites.

115. Abdominal tergites $[0=$ not fused or not forming a scutum; $1=$ at least tergites 6 to 8 always free (scutum parvum); 2 = fusion of tergites 1 to 8 (scutum magnum)] (Giribet et al., 1999c). Fusion of the eight abdominal tergites occurs in the Cyphophthalmi (Juberthie, 1956; Eisenbeis and Wichard, 1985; Rambla, 1975, 1991), Oncopodidae (Martens and Schwendinger, 1998), and some Troguloidea, which are likewise slowmoving, soil-dwelling opilionids (Martens and Schwendinger, 1998). In the Cyphophthalmi, although there is fusion of the abdominal tergites, the primitive segmentation is visible in the transverse furrows. A scutum parvum is found in Sabacon (Shear, 1975b); Ortholasma (Shear and Gruber, 1983); Nelima, Caddo, Centetostoma, Dicranolasma, and Ischyropsalis (Giribet et al., 1999c); Astrobunus (Rambla, 1976); Ceratolasma (Gruber, 1978); Hesperonemastoma, Leiobunum, Hadrobunus, Dalquestia, Taracus, Nipponopsalis, and all the Laniatores except the Oncopodoidea (pers. obs.). Some species, such as the exemplars of Nelima and Caddo used here, differ in the fusion of abdominal tergites in males and females. This was considered by Giribet et al. (1999c) as another character, but here we have decided to consider only the maximum degree of fusion in the representatives of the species. 
116. Lateral edge $[0=$ absent; $1=$ present $]$. The Laniatores have a lateral edge that unites the abdominal scutum with the cephalothorax (Rambla, 1975).

117. Transverse row of spines on the abdominal tergites [ $0=$ absent; $1=$ present]. This is found in Dalquestia, Odiellus, Phalangium, Opilio, and Nipponopsalis (pers. obs.). Other Opiliones present different kinds of spination in the abdominal tergites, but we refer here to a single row of spines per tergite.

118. Cuticular appendages (paired or unpaired) on the carapace and the first abdominal tergite, respectively, form a small "bridge" [0 = absent; $1=$ present $]$ (Šilhavý, 1961; Martens and Schwendinger, 1998). This character has been reported as a putative synapomorphy for the Oncopodidae (Martens and Schwendinger, 1998).

119. Saddle [ $0=$ absent; $1=$ present]. Most of the species in the Phalangiidae and Leiobuninae are decorated by a dorsal pattern of markings known as the saddle, which usually forms a dark central band that may cover the anterior two-thirds of the entire length of the abdomen (Hillyard and Sankey, 1989). A saddle is found in Odiellus, Phalangium, Opilio, Nelima, Leiobunum, and Hadrobunus (pers. obs.).

120. Pectines $[0=$ absent; $1=$ present $]$.

121. Stinging apparatus derived from the telson and bearing a sharp aculeus [ $0=$ absent; $1=$ present $]$.

122. Opisthosomal (pygidial) repugnatorial glands $[0=$ absent; $1=$ present $]$ (Shultz, 1990).

123. Spinnerets $[0=$ absent; $1=$ present].

124. Number of spinnerets $[0=$ eight; $1=$ six or less] (Platnick and Gertsch, 1976).

125. Position of the spinnerets $[0=$ far forward on the abdomen, just behind the second lung plate and far from the anus; 1 = at the end of the abdomen, near the anus] (Platnick and Gertsch, 1976).

126. Width of prosoma-opisthosoma junction $[0=$ broad; 1 = narrow] (Shultz, 1990). Shultz (1990, character 40) coded a pedicel as a narrow first opisthosomal segment. Previous workers (Weygoldt and Paulus, $1979 a, b)$ had applied a stricter definition of a pedicel (e.g., restricted to Araneae and Amblypygi), though even this homology has been disputed (Shear et al., 1987). Selden et al. (1991) considered the narrowing of segment 7 to adequately code for an apomorphy of tetrapulmonates. Dunlop (1996b, character 7) coded a pedicel as present in Ricinulei, Palpigradi, and Tetrapulmonata, a usage similar to that of Shultz (1990) and the one that we follow here.

127. Postgenital appendages [0 $=$ opercular and/or lamellar; 1 = poorly sclerotized or eversible; $2=$ absent] (Shultz, 1990).

128. Pygidium of three segments [0 = absent; $1=$ present] (Shultz, 1990). Basal Xiphosura ("Synziphosurina") have a three-segmented postabdomen (Anderson and Selden, 1997). Weygoldt (1998) cited these fossils, along with embryological evidence from extant Xiphosura (Scholl, 1977), as evidence that a three-segmented "pygidium" is a plesiomorphy for Micrura. We accept Shultz's (1990) coding of a pygidium because the segments are distinctively shortened relative to the remainder of the opisthosomal segments, whereas the postabdominal segments of Synziphosurina are not shortened.

129. Pygidial flagellum $[0=$ absent; $1=$ present $]$ (Shultz, 1990).

130. Pygidial ommatoids [ $0=$ absent; $1=$ present] (Hansen, 1893; Shultz, 1990).

131. Specialized pygidial flagellum in the male $[0=$ absent; 1 = present] (Shultz, 1990).

132. Lamellate respiratory organs $[0=$ absent; $1=$ present]. This character codes for homology of imbricated lamellae setae (Bergström, 1979) on the appendages of fossil Arachnata (including trilobites) and the lamellate respiratory oragns of chelicerates.

133. Lamellate respiratory organs derived from posterior wall of opisthosomal limb buds $[0=$ absent; $1=$ present] (Anderson, 1973; Dunlop, 1998). This character recognizes the embryological evidence for homology between xiphosurid book gills and arachnid book lungs. Fossil taxa with obvious book gills (Eurypterida) or book lungs (Trigonotarbida) are scored with an assumption that the development of these organs is the same as for extant taxa. This character differs from the preceding one, which codes for a more general homology between the exopods of trilobites and the book gills/lungs of chelicerates.

134. Type of lamellate respiratory organs $[0=$ exopod lamellar setae; 1 = book gills; $2=$ book lungs]. The status of book gills in fossil scorpions has not been conclusively established (see discussion in Dunlop and Webster, 1999). Shultz (1990) did not code the book lungs of extant Scorpiones as homologous with those of Tetrapulmonata. Dunlop and Webster (1999) likewise 
rejected homology because the book lungs of tetrapulmonates (and trigonotarbids; Shear et al., 1987) are restricted to opisthosomal segments 2-3, whereas those of scorpions are on segments 4-7 (fide Dunlop and Webster; segments 3-6 in traditional interpretation). Coding is restricted to taxa with lamellate respiratory organs.

135. Position of lamellate respiratory organs $[0=$ on all postantennal exopods; $1=$ on opisthosomal segments $3-7 ; 2=$ on opisthosomal segments $4-7 ; 3=$ on opisthosomal segments 2-3] (Braddy et al., 1999). The precise correspondence in the distribution of respiratory organs in eurypterids and scorpions is independent of whether these organs are book gills or book lungs. The four pairs of book gills in eurypterids (Braddy et al., 1999) are on segments 4-7, as are the book lungs of extant scorpions (Dunlop and Webster, 1999, Fig. 1). Xiphosurans have five pairs of book gills. Coding is restricted to taxa with lamellate respiratory organs.

136. Lamellate respiratory organs comprising $[0=$ horizontally oriented lamellae; $1=$ vertically oriented lamellae] (Braddy et al., 1999). The book lungs of extant scorpions are composed of 140-150 vertically oriented lamellae; similar structure is known from mesoscorpions as early as the Devonian (Shear et al., 1996). Braddy et al. (1999) showed that eurypterids share a vertical arrangement of the gill lamellae. Book lungs in tetrapulmonates (e.g., Araneae) include vertical, oblique, or nearly horizontal lamellae, though they are perpendicular to the spiracle or its remnants (Snodgrass, 1952; see Claridge and Lyon, 1961, Fig. 1 for lamellae in Trigonotarbida). The lamellae in Xiphosura are horizontal. Trilobites have flattened setae splaying from the exopod shaft, imbricated with partial overlap. They are not readily coded as horizontal, and the state is left unassigned.

137. Respiratory organ on genital segment $[0=$ present; 1 = absent] (Dunlop, 1998). Dunlop (1998) distinguished tetrapulmonates from other chelicerates with book gills or book lungs in having a respiratory organ on the genital (second opisthosomal) segment. Lack of these organs on this segment groups Xiphosura, Scorpiones, and Eurypterida. Polarity was determined by nonchelicerate Arachnata, such as Trilobita, which have lamellate respiratory organs (the exopod setae) on all postantennal limbs. Coding is restricted to taxa with lamellate respiratory organs.
138. Tracheal system $[0=$ absent; $1=$ present $]$ (Shultz, 1990).

139. Sternal stigmata on opisthosomal segments 3 and 4 [0 = absent; $1=$ present] (Shultz, 1990).

140. Intrasternite stigmata $[0=$ absent; $1=$ present $]$ (Jeram, 1994a,b). Crown group scorpions and some fossil Orthosterni (Palaeopisthacanthidae) share intrasternite stigmata. Jeram (1994a) rejected the alleged presence of marginal stigmata in Paleozoic scorpions.

141. Opisthosoma greatly reduced, forming a slender tube emerging from between the posteriormost legs, with a terminal anus $[0=$ absent; $1=$ present $]$ (Snodgrass, 1952; Wheeler and Hayashi, 1998).

142. Opisthosomal silk glands $[0=$ absent; $1=$ present] (Shultz, 1990).

143. Appendages of the first abdominal segment $[0=$ paired appendages absent in postembryonic development; 1 = present] (Shultz, 1990). The appendages of the first abdominal (opisthosomal) segment in Xiphosura, the chilaria, are located between the coxae of leg IV and form a part of the feeding apparatus. The corresponding segment in Eurypterida bears a plate-like structure, the metastoma, that overlaps the medial portions of the coxae of leg IV (see Shultz, 1990). The sternal versus appendicular contributions to the metastoma are uncertain (Dunlop and Webster, 1999). Jeram (1998) considered the metastoma most likely homologous with the sternum of scorpions. Dunlop and Webster (1999) raised the question whether the scorpion sternum could be derived from limb buds observed in the embryo in certain taxa, the subsequent fate of which is ambiguous. Until this homology is determined we have coded an absence of paired appendages in postembryonic stages in eurypterids, scorpions, and arachnids (following Weygoldt and Paulus, 1979a,b).

144. Five-segmented postabdomen $[0=$ absent; $1=$ present] (Dunlop, 1998; Dunlop and Webster, 1999). Dunlop (1998) stated that this might be the clearest synapomorphy for scorpions and eurypterids. Coding is restricted to chelicerates with a postabdomen (= pygidium fide Weygoldt, 1998; see character 128).

145. Opisthosomal tergites divided longitudinally into median and lateral plates [ $0=$ absent; $1=$ present $]$ (Dunlop, 1996b). Homology between the division of opisthosomal plates in Ricinulei and Trigonotarbida, otherwise lacking in arachnids, was defended by Dunlop (1996b). 
146. Fusion of opisthosomal tergites 2 and 3 into a diplotergite [0 = absent; $1=$ present] (Dunlop, 1996b).

147. Styliform postanal telson $[0=$ absent; $1=$ present] (Bergström et al., 1980).

148. Opisthosomal pleural membrane $[0=$ without distinct longitudinal folds; $1=$ with two or more distinct longitudinal folds] (Shultz, 1999).

149. Sternite of first abdominal segment $[0=$ retained as a small, round sclerite on the pedicel, near the posterior pair of coxae; 1 = absent] (Platnick and Gertsch, 1976).

150. Third abdominal segment distinct sclerite ventrally $[0=$ present; $1=$ absent $]$ (Platnick and Gertsch, 1976).

\section{Internal Anatomy}

151. Midgut caeca of prosoma $[0=$ simple; $1=$ branched] (Yoshikura, 1975; Wheeler and Hayashi, 1998). Trilobites are potentially coded based on their cephalic caeca. Some trilobite-allied arachnates (naraoiids; see Chen et al., 1997) have branching cephalic midgut caeca comparable to those of chelicerates, though these organs are not shared by Trilobita s. str. [see Chatterton et al. (1994) for evidence that the "genal caeca" of many trilobites are probably circulatory rather than digestive]. Wheeler and Hayashi (1998) coded this as "?" in Limulus although it should be coded as state " 1 ", as illustrated by Størmer (1944, Fig. 13.9).

152. Pairs of midgut diverticula $[0=$ four; $1=$ three $]$ (Dumitrescu, 1975a,b; Shultz, 1998; Giribet et al., 1999c). Midgut diverticula are found in many arachnids, although, according to Shultz (1998), those of Opiliones appear to have a unique arrangement or are not readily homologized with those of the outgroups. They have thus been coded as inapplicable for the outgroups. Dumitrescu (1975a,b) conducted a comparative survey of these structures in Opiliones. Four pairs of midgut diverticula are present in Cyphophthalmi, Eupnoi, and Dyspnoi (Loman, 1903; Berland, 1949; Dumitrescu, 1975a,b). All the Laniatores examined by Dumitrescu (a cladonychiid, a phalangodid, a cosmetid, and a gonyleptid) had three pairs of midgut diverticula, as well as the oncopodid Gnomulus (Loman, 1903). Consequently, we have assumed that all Laniatores (Travunioidea, Oncopodoidea, and Gonyleptoidea) present this state.
153. Endodermal Malpighian tubules [0 = absent; 1 = present] (Weygoldt and Paulus, 1979a,b; Shultz, 1990). Malpighian tubules are endodermal extensions of the gut found in most arachnids, but not in palpigrades, opilionids, and pseudoscorpions (Shultz, 1990). They are not present in xiphosurans and presence or absence is unknown in eurypterids (Dunlop and Webster, 1999).

154. Postcerebral pharynx $[0=$ absent or poorly developed; $1=$ present] (Weygoldt and Paulus, 1979a,b; Shultz, 1990). Coding for trigonotarbids accepts Shultz's (1990) rejection of medial carapacal depressions as evidence for the state of the pharynx (Shear et al., 1987, character 9).

155. Perineural membrane enveloping arterial sinus [0 = present; $1=$ absent] (Firstman, 1973; Wheeler and Hayashi, 1998).

156. Two pairs of ostia [0 = absent; $1=$ present $]$ (Weygoldt, 1986; Wheeler and Hayashi, 1998).

157. Pharynx with $X$-shaped lumen $[0=$ absent; $1=$ present] (Clarke, 1979; Wheeler and Hayashi, 1998).

158. Gonads $[0=$ reticulum of fine tubules; $1=$ ladder type; 2 = saccular type] (Clarke, 1979; Wheeler and Hayashi, 1998).

159. Palate plate $[0=$ absent; $1=$ present $]$ (Bartels, 1930; Foelix, 1982; Dunlop, 1994). A palate plate in Araneae is formed by rows of microscopic platelets, which trap particles of food.

\section{Genitalia}

160. Gonostome [0 = open, with a rudimentary operculum; 1 = fully closed by a well-developed operculum] (Giribet et al., 1999c). A similar character was coded by Shultz (1998). Our state " 0 " corresponds to his state "genital operculum small, not forming complete floor to pre-genital chamber"; our state " 1 " corresponds to his state "genital operculum well developed, forming complete floor to pre-genital chamber".

The structure of the genital operculum in Opiliones is apparently unique and cannot be homologized with genital features in other arachnids (Shultz, 1998; Giribet et al., 1999c). The genital operculum in most Opiliones is an oblong plate or dorsoventrally flattened process that projects anteriorly from the sternite of postoral somite IX and forms the floor to the genital 
opening or, more precisely, the opening to the pregenital chamber. A similar situation is present in Siro (Eisenbeis and Wichard, 1985), Parasiro (pers. obs.), and Stylocellus (Rambla, 1991), but the operculum itself is much shorter and covers only the extreme posterior part of the pregenital opening, leaving an open gonostome (Hansen and Sørensen, 1904; Eisenbeis and Wichard, 1985; Rambla, 1991; Shultz, 1998). Some authors do not regard Siro as having a genital operculum (e.g., Shear, 1982; van der Hammen, 1985; Hennig, 1986).

161. Genital operculum $[0=$ unjointed; $1=$ with a suture (partially jointed); $2=$ jointed] (Giribet $e t$ al., 1999c). Shear (1986) considered the presence of a genital operculum with a suture ("partially jointed") as apomorphic for the families Ischyropsalididae + Ceratolasmatidae: Ischyropsalis, Dicranolasma, Centetostoma, Nipponopsalis, and Ceratolasma (pers. obs.). A fully jointed genital operculum is found in the Laniatores. Coding is restricted to Opiliones with a genital operculum.

162. Genital operculum divided, incorporated into pedicel [0 = absent; $1=$ present] (Shultz, 1990).

163. Genital operculum overlapping third opisthosomal sternite $[0=$ absent; 1 = present] (Shultz, 1990; Dunlop, 1999). Trigonotarbids share a "megoperculum" with Tetrapulmonata (Dunlop, 1996b, Fig. 4, 1999).

164. Gonopore on second opisthosomal segment $[0=$ absent; $1=$ present $]$. The position of the gonopore in Trilobita is not known but, unlike Chelicerata s. str. no genital modification occurs on an anterior thoracic segment in trilobites (e.g., genital operculum or genital appendage).

165. Anteriorly located gonopore $[0=$ absent; $1=$ present] (Weygoldt and Paulus, 1979a,b; Dunlop, 1996b). In the apomorphic state, opisthosomal somite 2 has migrated forward such that the gonopore comes to lie topologically in front of its usual position.

166. Small, bilobed genital operculum $[0=$ absent; 1 = present] (Weygoldt, 1998). Proscorpius shares a bilobed genital operculum with extant scorpions. Jeram (1998, character 26) noted that some Devonian and Carboniferous scorpions lack a median suture on the operculum. The state in palaeophonids is unknown, but Palaeoscorpius has a bilobed operculum (KjellsvigWaering, 1986, text-Fig. 19), which supports this state being general for scorpions.

\section{Penis 5}

167. Penis (spermatopositor) $[0=$ absent; $1=$ present]. A penis is present in all the Opiliones, and certain Acari, but absent in the remaining chelicerate taxa. A penis/aedeagus is absent in the Opilioacarida and the other Parasitiformes. An aedeagus has apparently evolved at least four times in Acariformes (Cunaxidae, some genera of Tydeidae, nearly all Eleutherengona, and Astigmata), but it is absent in the most primitive groups, the "Endeostigmata," oribatid mites, and most early derivative Prostigmata (Kethley, 1990). It has as such been coded as absent in all the Acari groups represented in the analyses.

168. Penis morphology $[0=$ (short) membranous and undivided; $1=$ (long) chitinous and divided into shaft and glans] (Giribet et al., 1999c).

169. Penis musculature [0 = present; $1=$ absent $]$ (Giribet et al., 1999c). Penis musculature is present in Cyphophthalmi, Troguloidea, Ischyropsalidoidea, Phalangioidea, and Travunioidea, but is absent in Gonyleptoidea and Oncopodoidea, which operate the glans hydraulically.

170. Number of penis muscles [0 $=$ three; $1=$ two; 2 = onel (Martens, 1986; Shultz, 1998; Giribet et al., 1999c). Three muscles are found in Cyphophthalmi. Two muscles are found in the Troguloidea. A single muscle is found in Ischyropsalidoidea, Phalangioidea, and Travunioidea.

171. Glans penis $[0=$ symmetrical glans structures not interconnected that can be moved independent of each other; 1 = with lateral sclerites fused by an intermediate (median) plate] (Martens, 1986; Martens and Schwendinger, 1998). Martens and Schwendinger (1998) reported the presence of a glans penis with lateral sclerites fused by an intermediate plate as a putative synapomorphy for the Oncopodidae.

\footnotetext{
${ }^{5}$ The coding of the penis characters is based on literature sources, specifically: Cyphophthalmi, S. rubens (van der Hammen, 1985), $P$. coiffaiti (Juberthie, 1956), Stylocellus silhavyi (Rambla, 1991), Stylocellus spp. (Shear, 1993); Eupnoi, A. grallator (Rambla, 1976), O. troguloides (Rambla, 1973), D. formosa (Cokendolpher, 1984), Caddo (Gruber, 1974); Dyspnoi, I. luteipes (Martens, 1969), C. tricantha (Gruber, 1978), S. cavicolens (Shear, 1975b), Ortholasma spp. (Shear and Gruber, 1983); Laniatores, E. doriae (Hunt, 1985), Oncopus (Schwendinger, 1992; Martens and Schwendinger, 1998), Gnomulus (Martens and Schwendinger, 1998), M. randoi (Rambla, 1993), P. thorellii (Acosta, 1996), $S$. lespesi (van der Hammen, 1985). See also Martens (1986) for a general discussion on the "groundplan" of each family.
} 


\section{Ovipositor $^{6}$}

172. Ovipositor [ $0=$ absent; $1=$ present] (Shultz, 1990). An ovipositor organ is present in Opiliones and many Acari. Opilioacarids have an ovipositor, but it is absent in the other three suborders of Parasitiformes; an ovipositor is present in nearly all basal groups of Acariformes and is assumed to be primitive for the Acariformes (H. Klompen, pers. com.). An ovipositor organ is present in Allonothrus, but the ovipositor is lost in Acarus and all other Astigmata (Grandjean, 1956).

173. Ovipositor morphology $[0=$ segmented (jointed type); 1 = unsegmented (unjointed type)] (Martens et al., 1981; Shultz, 1998; Giribet et al., 1999c). Intermediate forms may be seen in acropsopilionins (see Gruber, 1974, p. 249 for Tasmanopilio fucus), although they do not occur in any of the species here studied.

174. Terminal sensory organs in the ovipositor organ [0 = absent; 1 = present] (Martens et al., 1981; Shultz, 1998; Giribet et al., 1999c).

175. Jointed ovipositor $[0=$ only the apical ring split; $1=$ two or three apical rings split] (Martens et al., 1981; Giribet et al., 1999c).

176. Ovipositor [0 = bilaterally symmetrical; with noncruciform vagina; $1=$ radially symmetrical with cruciform vagina] (Martens et al., 1981; Giribet et al., 1999c).

177. Number of apical lobes on ovipositor $[0=$ two; 1 = four] (Martens et al., 1981; Shultz, 1998; Giribet et al., 1999c). This character was used by Giribet et al. (1999c) and by Shultz (1998). Giribet et al. (1999c) coded Equitius as having an ovipositor with four apical lobes, based on the description for Holoscotolemon given by Martens et al. (1981). However, the triaenonychid ovipositor typically has a fleshy, sometimes sclerotized,

\footnotetext{
${ }^{6}$ The codings of the ovipositor are based on literature sources, specifically, Cyphophthalmi, S. rubens (Martens et al., 1981; van der Hammen, 1985), P. coiffaiti (Juberthie, 1956), S. silhavyi (Rambla, 1991); Eupnoi, A. grallator (Rambla, 1976), O. troguloides (Rambla, 1973), Ph. opilio (Martens et al., 1981; Eisenbeis and Wichard, 1985), O. parietinus (Martens et al., 1981), C. agilis (Gruber, 1974; Shear, 1975a; Martens et al., 1981); Dyspnoi, I. luteipes (Martens et al., 1981), $H$. kepharti (Martens et al., 1981), C. tricantha (Gruber, 1978), S. cavicolens (Shear, 1975b), S. viscayanum (Martens et al., 1981), D. scabrum (Martens et al., 1981), T. nepaeiformis (Martens et al., 1981); Laniatores, O. acanthochelis (Martens et al., 1981), P. clavigera (Martens et al., 1981), S. lespesi (Martens et al., 1981; van der Hammen, 1985), B. laciniosa (Martens et al., 1981).
}

lobe on each side where simple setae are inserted (Hunt and Hickman, 1993).

178. External morphology of ovipositor [0 = setae along shaft; 1 = few or no setae along shaft] (Martens et al., 1981; Shultz, 1998).

179. Inner sheath of ovipositor lined with cuticular hooks [0 = absent; $1=$ present] (Martens et al., 1981; Shultz, 1998).

180. Vaginal glands in ovipositor $[0=$ aciniform glands; 1 = aggregate glands; 2 = glands opening without ducts via vaginal pore fields; $3=$ compact] (Martens et al., 1981; Shultz, 1998). Martens et al. (1981) noted small glands draining into the vaginal lumen via small ducts (aciniform glands) in Dicranolasma and Trogulus. Similar glands were drained collectively by larger ducts (aggregate glands) in Siro, Phalangium, Caddo, Ischyropsalis, Hesperonemastoma, and Sabacon. The glands were found to empty directly into the vaginal lumen via pore fields in the vaginal wall in Scotolemon, Vonones, and one gonyleptid species. The condition in Oncopus appears to be intermediate between the aciniform and the pore field conditions and is coded here as polymorphic. Travunioidea have a type called compact glands.

181. Seminal receptacles in vaginal lumen of ovipositor $[0=$ simple blind sacs or diverticula; $1=$ encased within structure protruding into vaginal lumen] (Martens et al., 1981; Shultz, 1998).

182. Outer longitudinal muscles of ovipositor $[0=$ with segmental pattern of insertion; 1 = without segmental pattern of insertion] (Martens et al., 1981; Shultz, 1998).

183. Outer circular muscles of ovipositor $[0=a b-$ sent; 1 = present] (Martens et al., 1981; Shultz, 1998; Giribet et al., 1999c).

184. Inner longitudinal muscles of ovipositor [0 absent; 1 = present] (Martens et al., 1981; Shultz, 1998). Martens et al. (1981) found longitudinal muscles immediately external to the vagina and internal to the circumvaginal muscles in Scotolemon, Vonones, Oncopus, and a gonyleptid. They noted that the muscles were absent in Peltonychia and Holoscotolemon, and their figures indicated that inner longitudinal muscles were absent in Phalangium, Caddo, Ischyropsalis, Hesperonemastoma, Sabacon, Dicranolasma, and Trogulus. Martens et al. (1981) did not report the condition in Siro, but observations of the ovipositor of $S$. acaroides indicated 
that the inner longitudinal muscles are absent (Shultz, 1998).

185. Ovipositor laterally compressed, not dorsoventrally flattened or circular in cross section $[0=$ absent; 1 = present] (Martens et al., 1981; Martens and Schwendinger, 1998). This character was described for Oncopus (Martens et al., 1981) and subsequently also found in all the other genera of Oncopodidae: Gnomulus, Biantoncopus, Palaeoncopus, and Coenoncopus (Martens and Schwendinger, 1998).

\section{Reproduction/Development}

186. Hexapodal instar, followed by three octopod nymphal instars $[0=$ absent; $1=$ present $]$ (Weygoldt and Paulus, 1979a,b; Lindquist, 1984; Shultz, 1990; Dunlop, 1996b). Dunlop (2000) noted that anamerism in pycnogonids could imply that the hexapodal state is a symplesiomorphy. The precise correspondence of hexapod and octopod nymphs, however, suggests homology between the states observed in Ricinulei and Acari.

187. Prenymph and four postnymphal instars $[0=$ absent; 1 = present] (Weygoldt and Paulus, 1979a,b).

188. Female grasps male opisthosoma during mating [0 = absent; $1=$ present] (Weygoldt and Paulus, 1979a,b; Shultz, 1990).

189. Egg teeth on the dorsal side of the palpal coxae [0 = present; 1 = absent] (Yoshikura, 1975; Wheeler and Hayashi, 1998).

190. Embryonic number of opisthosomal segments $[0=10 ; 1=11 ; 2=12 ; 3=13]$ (Yoshikura, 1975; Wheeler and Hayashi, 1998). Yoshikura (1975, Table 11) synthesized data on the arachnid orders. Within the spiders we have coded Liphistius based on Heptathela, and within the Acari we have coded Opilioacarus based on the data on Notostigmata (Yoshikura, 1975).

191. Egg structure $[0=$ isolecithical or telolecithical; 1 = centrolecithical] (Yoshikura, 1975; Wheeler and Hayashi, 1998).

192. Embryological development $[0=$ with a growth zone giving rise to both the prosoma and the opisthosoma; 1 = with a growth zone giving rise to the opisthosomal (Anderson, 1973; Dunlop and Webster, 1999). A growth zone giving rise to the ambulatory segments of the prosoma and the opisthosoma is found in scorpions and xiphosurans, while in all other arachnids this growth zone gives rise to the opisthosoma only, the prosoma developing directly from the blastoderm. A ground-plan coding has been adopted for this character.

\section{Sperm Morphology ${ }^{7}$}

193. Spermatozoan nucleus with a manchette of microtubules [ $0=$ absent; $1=$ present $]$ (Alberti and Palacios-Vargas, 1987; Shultz, 1990; Alberti, 1995). A manchette of microtubules (or microtubule array, according to Shultz, 1990) is observed in the flagellate spermatozoa of Uropygi, Schizomida, Amblypygi, Araneae, and Ricinulei. No manchette is found in Scorpiones, Pseudoscorpiones, Palpigradi, Acari, and Xiphosura (Alberti and Palacios-Vargas, 1987). The Laniatores (only gonyleptoids studied) are the only group of Opiliones that have a manchette of microtubules (Juberthie and Manier, 1978; Jones and Cokendolpher, 1985). The

\footnotetext{
${ }^{7}$ Spermatozoa of several chelicerate groups are known from only one or a few species (in such instances, the relevant species is indicated in the following list): Pycnogonida (van Deurs, 1973, 1974a,b; El-Hawawi and King, 1978; King and El-Hawawi, 1978), Xiphosura (e.g., Yamamichi and Sekiguchi, 1982; Alberti and Janssen, 1986; Fahrenbach, 1999), Solifugae [Eusimonia mirabilis (Alberti, 1980), only mature spermatozoa are known], Ricinulei [Cryptocellus boneti (Alberti and Palacios-Vargas, 1984)], Palpigradi [Prokoenenia wheeleri (Alberti, 1979)], Uropygi [Mastigoproctus giganteus (Philipps, 1976; Jespersen, 1978)], Schizomida [Schizomus palaciosi (Alberti and Palacios-Vargas, 1987)I, Amblypygi [Tarantula sp. (Jespersen, 1978), Admetus pomilio (Tripepi and Saita, 1985)], Scorpiones (see Baccetti, 1979; Alberti, 1983), Araneae Mesothelae based on Heptatela kimurai (Osaki, 1969), Araneae Mygalomorphae based on Eurypelma californicum (Alberti et al., 1986), Araneae Araneomorphae (see Alberti and Weinmann, 1985; Alberti, 1990; Alberti and Coyle, 1991), Acari (see Alberti, 1991), Pseudoscorpiones (Legg, 1973; Alberti, 1995). The coding of the sperm characters for these groups is based on ground plans of the species available in the literature. The sperm characters have been coded as "?" for the fossil taxa. Within the Opiliones, cyphophthalmid sperm has been studied in two species, S. rubens (Juberthie and Manier, 1978) and S. duricorius (Alberti, 1995). A comparative study of opilionid spermatozoa was developed by Juberthie and Manier (1978), including several of the species included in our data set: $S$. rubens, $T$. nepaeformis, I. luteipes, $N$. bimaculatum, O. troguloides ( $=0$. gallicus), Leiobunum sp., and S. lespesi. Tripepi (1983) studied the spermiogenesis of Ph. opilio, Reger (1969) studied spermiogenesis of Leiobunum sp., and Jones and Cokendolpher (1985) studied the cosmetid $V$. sayi. We have thus coded the sperm characters for these opilionids at the species level. Since several species of Gonyleptoidea (belonging to the families Cosmetidae, Erebomastridae, Gonyleptidae, and Phalangodidae) show uniformity in sperm ultrastructure (Juberthie and Manier, 1978; Jones and Cokendolpher, 1985), we have used a Gonyleptoidea groundplan coding.
} 
condition in pycnogonids is polymorphic (van Deurs, 1974a,b), and since spermatozoa of none of the species used for the molecular analysis have been studied, the character is coded as "?".

194. Acrosomal complex [0 = present; $1=$ absent $]$ (Juberthie and Manier, 1978; Alberti and Palacios-Vargas, 1987; Alberti, 1995). An acrosomal complex ${ }^{8}$ is primitively present in all arachnid orders, except Palpigradi, in which no acrosomal filament (= perforatorium) is found (Alberti, 1979, 1995). Certain groups of Opiliones and Acari have also lost the acrosomal filament or completely lack an acrosomal complex. Sometimes this occurs in the same genus: S. rubens (with all the acrosomal components) (Juberthie et al., 1976) and S. duricorius without acrosomal complex (Alberti, 1995). Subacrosomal material spreads between the nuclear envelope and the plasmalemma in Nem. lugubre (Alberti, 1995).

195. Spermatozoan axoneme $[0=$ present; $1=a b-$ sent] (Alberti and Palacios-Vargas, 1987; Shultz, 1990; Juberthie and Manier, 1978; Alberti, 1995). Flagellate spermatozoa are found in Xiphosura, certain pycnogonids, Scorpiones, Pseudoscorpiones, Uropygi, Schizomida, Amblypygi, Araneae, and Ricinulei (Alberti, 1995). Ultrastructural studies have shown that flagellar elements in the spermatozoa of the Opiliones are absent, except in the Cyphophthalmi (S. rubens), which retain a nonmotile axoneme (Juberthie and Manier, 1978; Tripepi, 1983; Shultz, 1998) with a $9+0$ microtubule arrangement (Shultz, 1990). Pycnogonida are coded as "?".

196. Coiling of flagellate spermatids $[0=$ absent; $1=$ present] (Alberti and Palacios-Vargas, 1987). Coiled-flagellate spermatozoa are found in. Pseudoscorpiones, Uropygi, Schizomida, Amblypygi, Araneae, and Ricinulei (Alberti, 1995). A reduced coiling process was observed for $S$. rubens (Juberthie et al., 1976; Alberti and Palacios-Vargas, 1987). Coding is applied to chelicerates that possess an axoneme.

197. Pair of coaxial centrioles in axoneme $[0=a b-$ sent; 1 = present] (Wirth, 1984). According to Wirth, a pair of coaxial centrioles is shared by Xiphosura, Scorpiones, Uropygi, Amblypygi, Araneae, and

\footnotetext{
${ }^{8}$ The acrosomal complex typically is composed of an acrosomal vesicle (vacuole) and an acrosomal filament (perforatorium). The acrosomal filament is part of the subacrosomal material containing actin filaments, which are highly ordered.
}

Pseudoscorpiones. This arrangement is unique within Arthropoda. The nearly orthogonal arrangement of the centrioles in the mature spermatozoa of Theraphosidae is a derived condition acquired through ontogeny (Alberti, 1995). Pycnogonids with a flagellate sperm (Nymphon spp.) lack the proximal centriole. The spermatid of $S$. rubens likewise has a single centriole. Coding is restricted to chelicerates with flagellate spermatozoa.

198. Microtubule arrangement in spermatozoan axoneme $[0=9+2 ; 1=9+3 ; 2=9+0]$ (Baccetti, 1979; Shultz, 1990; Alberti, 1995). This varies between the two xiphosurids: Limulus has $9+2$, and the Asian horseshoe crabs have $9+0$ (Alberti, 1995). Araneae, Uropygi, Schizomida, and Amblypygi have a $9+3$ axoneme. However, certain spiders (Linyphiidae) have a $9+0$ axoneme, as in Carcinoscorpius, Siro, and many scorpions. Within the variable scorpions, the $9+2$ pattern is found in Euscorpius, while other genera such as Hadrurus or Centruroides have a $9+1$ axoneme, and others such as Tityus, Vaejovis, Anuroctonus, and Uroctonus have a $9+0$ pattern (references in Baccetti, 1979). Androctonus has been coded with a $9+0$ pattern, according to familial ground plan, but Belisarius has been coded as "?". The condition in pycnogonids is also variable, and does not correspond to any of the described states, so we have coded them as "?".

199. Acrosomal vesicle [0 $=$ filled with dense material; $1=$ globular; 2 = acrosome almost reduced to the acrosomal vesicle] (Juberthie and Manier, 1978).

200. Implantation fossa $[0=$ shallow, funnel shaped; $1=$ deep]. The implantation fossa is a posterior region of the nucleus which usually contains the centrioles or their derivatives (Alberti, 1995). The fossa may be a shallow, funnel-shaped indentation as in scorpions of the families Buthidae (coding adopted for Androctonus) and Vaejovidae, and in Uropygi, Amblypygi, Mesothelae, and Pseudoscorpiones. In Schizomida and many spiders, the implantation fossa is deep, sometimes making the sperm almost a hollow tube (see references in Alberti, 1995). A groundplan ordinal coding has been adopted. A very shallow implantation fossa is observable in Siro.

201. Postcentriolar elongation of the nucleus $[0=$ absent; 1 = present]. Alberti (1995) regarded the presence of a postcentriolar elongation of the nucleus as a putative synapomorphy for Amblypygi and Araneae.

202. Nuclear envelope that disappears at the end of spermiogenesis $[0=$ absent; $1=$ present $]$. A nuclear 
envelope that disappears at the end of spermiogenesis is found in Xiphosura, Solifugae, and Acari (Actinotrichida; coding adopted for Acarus and Allonothrus) (Alberti, 1995).

203. Persisting flagellar tunnel surrounding the axoneme $[0=$ absent; $1=$ present]. A permanent flagellar tunnel surrounding the axoneme is present in scorpions and pseudoscorpions. A flagellar tunnel is observed during spermiogenesis of Uropygi, Amblypygi, Araneae, and Ricinulei but disappears later, and a tunnel appears in connection with the transient flagellum of Siro (Alberti, 1995). The flagellar tunnel may be derived from the cytoplasmic collar around the flagellar basis in xiphosuran sperm (coded as "?") (Alberti, 1995).

204. Helical appearance of nucleus $[0=$ absent; $1=$ present $;=$ corkscrew shape] (Alberti, 1995). The nucleus of certain scorpions (Androctonus coded according to Buthus; Belisarius coded as "?"), Uropygi, and Schizomida exhibits a helical shape, becoming corkscrew shaped in most Araneae and Amblypygi. Alberti (1995) distinguished a corkscrew-shaped nuclear region in Pseudoscorpiones as derived from the acrosomal vesicle rather than from the nucleus so it is not coded as homologous. ORDERED.

205. Vacuolated type of sperm $[0=$ absent; $1=$ present]. A vacuolated type of sperm is present in Opilioacarida and Anactinotrichida (= Parasitiformes) (Alberti, 1995).

206. Sperm aggregates $[0=$ absent; $1=$ present $]$. Sperm aggregates are found in Scorpiones, Solifugae, and the cyphophthalmid Siro (Alberti, 1995). In Siro, the aggregates include dimorphic spermatozoa (Juberthie et al., 1976; Alberti, 1995).

207. Midpiece $[0=$ present; $1=$ absent $]$ (Alberti and Palacios-Vargas, 1987; Alberti, 1995).

208. Gonoporal brood sac [ $0=$ absent; $1=$ present $]$ (Shultz, 1990, 1999).

\section{Nervous System/Sense Organs}

209. Slit sensillae $[0=$ absent; $1=$ present (Weygoldt and Paulus, 1979a,b; Shultz, 1990). Slit sensillae have been described for Trigonotarbida (Shear et al., 1987). The homology of larger slit-like structures at certain prosomal joints in a eurypterid (Dunlop and Braddy, 1997) is uncertain, and we are reluctant to interpret them as slit sensillae.
210. Opisthosomal ganglia $[0=$ free/fused and remaining in the opisthosoma; $1=$ some free but restricted to the cephalothorax; $2=$ all are incorporated with the subesophageal nerve mass] (Yoshikura, 1975; Shear et al., 1987; Wegerhoff and Breidbach, 1995). The coding of this character was reversed in Wheeler and Hayashi (1998). Scorpions have seven free abdominal ganglia; Xiphosura (Limulus) has four; Solifugae and Uropygi have one free abdominal ganglion (Babu, 1985). In most other Arachnida, all ventral nerve cord ganglia are fused to form a condensed subesophageal ganglion or preserve free abdominal ganglia, but not in the opisthosoma. In amblypygids and spiders [only Mygalomorphae have one free abdominal ganglion (Hanström, 1928)], free abdominal ganglia are absent, having migrated forward and fused with the subesophageal ganglia (Kaestner, 1935; Babu, 1985). Opiliones [Phalangium opilio, Nemastoma sp., Acrographinotus sp. (Gonyleptidae), and Mermerus beccari (Assamiidae)] (Kaestner, 1935) have a subesophageal nerve mass originating from the fusion of five pairs of prosomal ganglia and the abdominal ones (Juberthie, 1964), although Juberthie also reported the case of T. nepaeformis, with four free pairs of abdominal ganglia. This seems to fit with the Opilionid CNS model reported by Yoshikura (1975), who stated that Opiliones have free abdominal ganglia, although they are located in the prosoma. ORDERED.

211. Lateral organ $[0=$ absent; $1=$ present $]$ (Yoshikura, 1975). Lateral organs are a pair of transient embryonic organs situated on or between the coxae of the second (and sometimes first) prosomal walking leg. Codings for presence at the ordinal level follow Yoshikura (1975, Table 15).

212. Pair of anteromedial sensory organs $[0=a b$ sent; 1 = present] (Shultz, 1990).

213. Trichobothria $[0=$ absent; $1=$ present $]$ (Selden et al., 1991; Dunlop, 1996b). Coding presence of trichobothria as apomorphic for extant Tetrapulmonata (but not Trigonotarbida), Palpigradi follows Dunlop (1996b, character 16); Acari follows Lindquist (1984). Selden et al. (1991, character 38) recorded trichobothria in extant scorpions, pseudoscorpions, and mites as well and cited their absence in solifuges, ricinuleids, and opilionids. Trichobothria are lacking in early fossil scorpions (Jeram, 1998), first appearing in relatively crownward taxa such as the Carboniferous Palaeopisthacanthus and Compsoscorpius. 
214. Trichobothria on the dorsal surface of the distal leg segments with a base consisting of a rounded dome covered by flattened plates $[0=$ absent; $1=$ present $]$ (Platnick and Gertsch, 1976).

215. Number of flattened plates covering the dome of the base of the trichobothria [0= one; $1=$ two] (Platnick and Gertsch, 1976).

216. Number of neuromeres of the subesophageal ganglia [0 = 17; $1=12]$ (Hanström, 1928; Millot, 1933, 1949; Platnick and Gertsch, 1976).

\section{Ecology/Behavior}

217. Soil crypsis by glandular adhesion of particles [0 = absent; 1 = present] (Shultz, 1998). Several litteror soil-dwelling Opiliones have evolved chemical and/ or mechanical specializations for covering their bodies with soil or detritus. Dicranolasma and Trogulus are the only terminal taxa that use a gland-produced adhesive for coating their bodies with soil particles. Marine animals have been coded as inapplicable.

218. Extraintestinal digestion $[0=$ absent; $1=$ present] (Snodgrass, 1948; Weygoldt and Paulus, 1979a,b; Lindquist, 1984; Shultz, 1990). Although this character cannot be directly observed in fossils, several factors suggest the absence of extraintestinal digestion in basal scorpions. Palaeoscorpius in particular has a mobile complement of prosomal coxae (as in Xiphosura), in some early scorpions at least some coxae are known to be gnathobasic, and the absence of stomothecae in early scorpions implies that an oral tube for liquid feeding was not developed (Jeram, 1998). Accordingly we have coded extraintestinal digestion as absent in Proscorpius (Kjellsvig-Waering, 1986, 48) and palaeophonid scorpions. The same inference is made for Trilobita and Eurypterida based on their gnathobasic structure.

219. Protection of the eggs with a secretion from abdominal glands $[0=$ absent; $1=$ present] (Shear et al., 1987). Shear et al. (1987, character 10) considered protection of the eggs with a secretion from abdominal glands to be apomorphic for Tetrapulmonata. This involves silk in Araneae and a fibrous mucoid material from genital glands in the other tetrapulmonates.

\section{Musculature $^{9}$}

220. Trochanterofemoral depressor muscle in walking legs [ $0=$ present; $1=$ absent] (Shultz, 1990).

221. Patellotibial extensor muscle [0 = absent; $1=$ present] (Shultz, 1990).

222. Anterior transpatellar muscle $[0=$ present; $1=$ absent] (Shultz, 1989, 1990). Transpatellar muscles are absent in Cyphophthalmi (Shultz, 1989), Schizomida, and Ricinulei.

223. Anterior transpatellar muscle, insertion on tibia [0 = anterior; 1 = ventral] (Shultz, 1989, 1990). Coding is restricted to chelicerates with an anterior transpatellar muscle.

224. Paired muscle arising from posterior margin of anterior carapacal doublure and inserting on carapace [0 = absent; 1 = present] (Shultz, 1999).

225. Anterior endosternal horn $[0=$ terminating in muscular attachment to labrum; $1=$ terminating in muscular attachment to palpal coxa] (Shultz, 1999).

226. Lateral extrinsic precerebral pharyngeal muscle $[0=$ arising from anterior endosternal horns; $1=$ arising from medial surface of palpal coxa] (Shultz, 1999).

227. Ventral extrinsic precerebral pharyngeal muscle [0 = present; $1=$ absent] (Shultz, 1999).

228. Tergopharyngeal muscle of precerebral pharynx [0 = present; 1 = absent] (Shultz, 1999).

229. Dorsal endosternal suspensor muscle of postoral somite V [0 = present; 1 = absent] (Shultz, 1999).

230. Lateral tergocheliceral muscles $[0=$ one head; $1=$ three heads] (Shultz, 1999).

231. Palpal posteromedial tergocoxal muscle $[0=$ present; 1 = absent] (Shultz, 1999).

232. Palpal posteromedial endosternocoxal muscle [0 = originating on endosternite, inserting on coxa; $1=$ originating and inserting on coxal (Shultz, 1999).

233. Palpal apotele levator muscle $[0=$ present; $1=$ absent] (Shultz, 1999).

\footnotetext{
${ }^{9}$ Muscular characters are difficult to homologize among different groups of chelicerates. Here we have followed the codings of Shultz (1993) for Mastigoproctus giganteus (Uropygi), Shultz (1999) for Phrynus longipes (Amblypygi; used as a ground plan for the group), Shultz (2000) for Leiobunum aldrichi (Opiliones, Eupnoi) and have coded some of the characters for the rest of taxa based on Shultz (1990), Tetrapulmonata based on Shultz (1999), and some characters for Scorpiones based on Shultz (2000).
} 
234. Pedal anterior femur-patella muscle [0 = inserting primarily on patellar margin; $1=$ inserting primarily on patellar plagula] (Shultz, 1999).

235. Pedal posterior femorpatella-tibia muscle $[0=$ present; $1=$ absent] (Shultz, 1999).

236. Pedal patellotibia-tarsus muscle $[0=$ present; $1=$ absent] (Shultz, 1999).

237. Intracoxal muscle [0 = absent; $1=$ present $]$ (Shultz, 1999).

238. Insertion process of anteromedial tergocoxal muscle [0 = weakly developed; 1 = large, well developed] (Shultz, 1999).

239. Ventral endosternal suspensor muscles $[0=$ attaching primarily to sternum; 1 = attaching primarily to coxa of appendage of anteriorly adjacent somite] (Shultz, 1999).

240. Opisthosomal pleural muscle $[0=$ forming continuous dorsoventral sheet; 1 = divided into three components] (Shultz, 1999).

241. Dorsal endosternal suspensor of fourth postoral segment with anterolateral carapacal insertion $00=$ absent; 1 =-present] (Shultz, 1990).

242. Musculi laterales $[0=$ absent; $1=$ present $]$ (Shultz, 1990). The musculi laterales is a term used by spider anatomists to define a lateral tergocoxal muscle from the walking legs that inserts on the pleural membrane adjacent to the coxa rather than on the coxa itself. This type of insertion is found in Araneae and Uropygi (Shultz, 1990).

243. Femorpatellar flexor muscles, insertion $[0=$ consisting of anterior, median, and posterior components that insert symmetrically on the ventral margin of the patella; 1 = the anterior and median components insert together on a sclerite that attaches to the anterior margin of the patella via ligaments, and the posterior component inserts broadly on the ventral margin of the patella itself] (Shultz, 1990).

244. Posterior transpatellar muscle [0 = present; $1=$ absent] (Shultz, 1989, 1990). Transpatellar muscles are absent in Cyphophthalmi (Shultz, 1989), Solifugae, Schizomida, and Ricinulei.

245. Posterior transpatellar muscle, origin [0 $=$ dorsoposterior surface of femur and/or posterior surface of patella; 1 = distal process of femur] (Shultz, 1989, 1990). Coding is restricted to taxa with a posterior transpatellar muscle.

246. Anterior patellotibial muscle $[0=$ present; $1=$ absent] (Shultz, 1990).

247. Anterior patellotibial muscle, insertion on tibia [0 = anterior; 1 = ventral] (Shultz, 1990).

248. Posterior patellotibial muscle $[0=$ present; $1=$ absent] (Shultz, 1990).

249. Claw depressor muscle, tibial head [0 = absent; $1=$ present] (Shultz, 1990).

250. Claw depressor muscle, patellar head $[0=a b-$ sent; 1 = present] (Shultz, 1990).

251. Claw depressor muscle, origin on posterior wall of patella [0 = absent; $1=$ present] (Shultz, 1990).

252. Cheliceral tergo-deutomerite muscle $[0=a b-$ sent; 1 = present] (Shultz, 2000). Coding is restricted to chelicerates with three-segmented chelicerae.

253. Intercoxal endosternal suspensor muscles $[0=$ absent; 1 = present] (Shultz, 2000).

\section{APPENDIX 2: MORPHOLOGICAL DATA MATRIX}

A dash (-) indicates inapplicability; question mark (?) indicates missing data (unknown state). Seven blocks of 10 characters each are depicted per line.

\section{Trilobita}

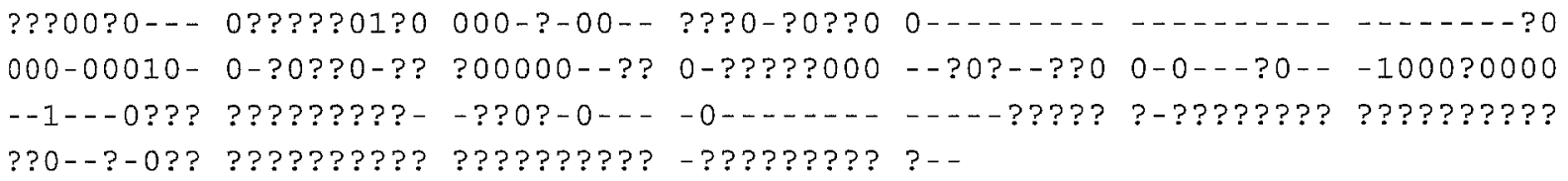




\section{Palaeoisopus}

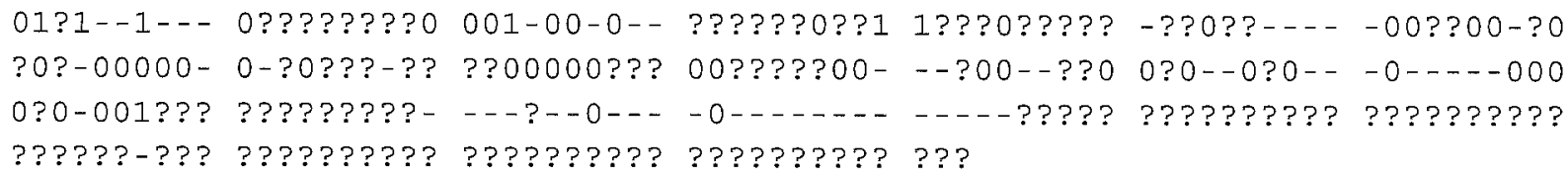

\section{Pycnogonida}

0131--1--- 00--0-???0 001-00-0-- ???0-00?01 1000000000-000??---- -000000-?0 00?-00000- 0-?001?-?? 000000000? 00????000- --0---000000--0-0-- -0----000 100--?0??? ?-000???0- --0--0-- -0------ ---000?? ?????00??? 00?000?00? ?00--?-000 ????????? ????????? -???????00 0?-

\section{Eurypterida}

00?00?0--- 00--??0000 1000001?0- ??????0??0 10000??00? -0?0??---- -00??00??0 000-00010- 0-?0010-?? 0000000000 00?????001--?00-0?0 0?0--000-- -111211000 0?01001??? ?????????- -001000-- -0----- ?? ?? ?? ?? ???? ????????? ????????? ??0--?-0?? ????????? ???????? ????????? ???

\section{Limulus}

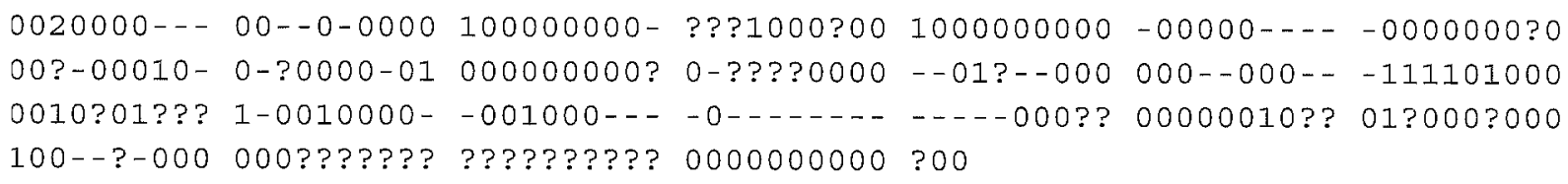

\section{Carcinoscorpius}

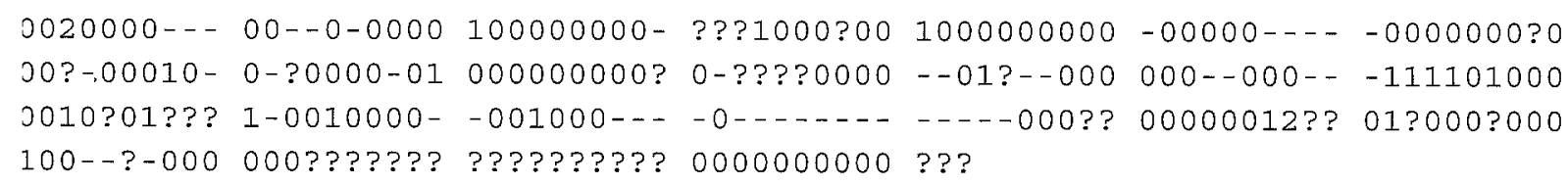

\section{Palaeophonidae}

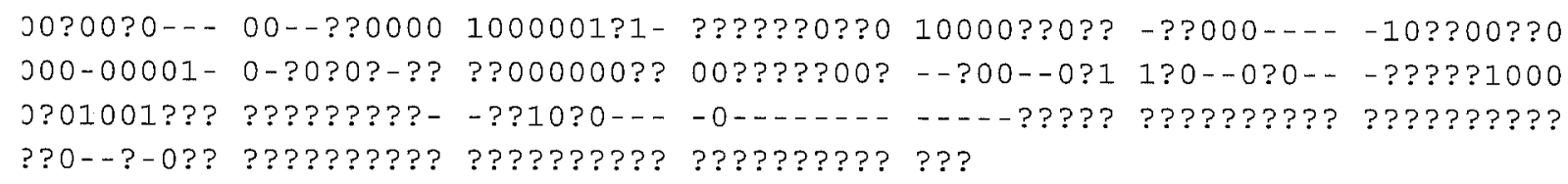

\section{Proscorpius}

ว0?00?0--- 00--??0010 1000001?1- ??????0??0 10000??00? -??000--- -10??00??0 001-00001-0-?0?0?-?? ??000000?? 00?????11?--?00--0?1 1?0--0?0-- -?????1000 ว?01001??? ?????????- -001010-- -0--_-- ?? ?? ? ? ?? ???? ????????? ????????? ??0--?-0?? ????????? ?????????? ???????? ??? 


\section{Androctonus}

0000100--- 00--0-0000 100000111-???1000100 $1000000000-00000---1000000 ? 0$

001-10001- 0-00001001 0200000000 00????1111--000--001 100--000-- -112211001

0001001??? 1-1010010- -001010-- -0-1-n - - 0000300000012 ?0 0011010010

001???0100 101?????? ????????? 0000101111 011

\section{Belisarius}

1--1--0--- 00--0-0000 100000111- ???1000100 1000000000-00000--- -1000000?0 001-10001-0-00001001 0200000000 00????1111--000--001 100--000-- -112211001 0001001??? 1-1010010- -001010-_ -0-... - - 00003 000?001??? 00??01?010 001???0100 101?????? ????????? 0000101111 011

\section{Solifugae}

0010310---00--0-1-01 100010112- ???0000?00 1002100100-0001---- -0001100-0 101-00001-0001012-11 0100110000 10????100- --000--000 000--120-- -0--1-110 000-000??? 1-1000020- -001000-- -0----- ---00001 11?01---?? 010001?010 100--?0100 001??????? ????????? 0001-01111 0-?

\section{Palpigradi}

$1--1--0--00--0-0110100000112-00010000001000000000-00000-1-000000000$ 101-00000-0-010000101000000000000000000---000--000 000--11110 00----000 00000000?? 0-00010?0- -011000-- -0-1-...---00??1 ?1011---? 000000?000 ?11???0100 00000000000000000000100000001000 ?

\section{Liphistius}

0010210-- - 00--0-0010100000110-00010000001001010011000000--- -000001000 001-00000-0-0010001000000000110000010001--000--000 00100110-- -1123?0000 010-000000 1-1110021- -111000-. -0 - - - - ---00012 11100111?01002000012 $00111001010000000000000000000011000000110-$ ?

\section{Aphonopelma}

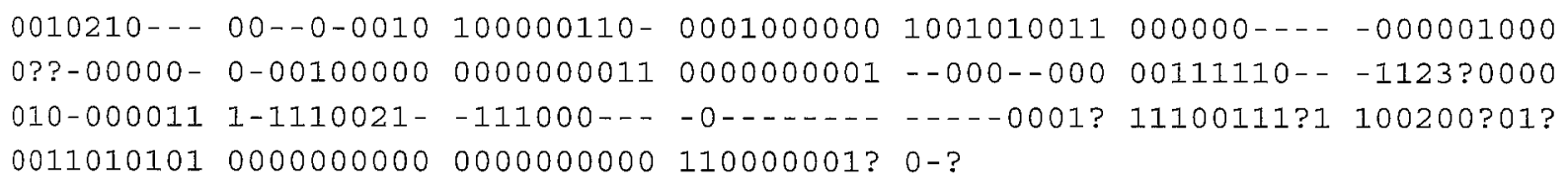

\section{Nesticus}

$0010210--00-0-0010100000110-00010000001001010011100000-\cdots-000001000$ 001-00000-00001000?0 0000000011000000000---000--000 00111110-- -0---0100 010-000011 1-1110021- -111000-- - 0-_...---0001? 11100111?1 100200?012 001101010100000000000000000000 ?10000001? 0-? 


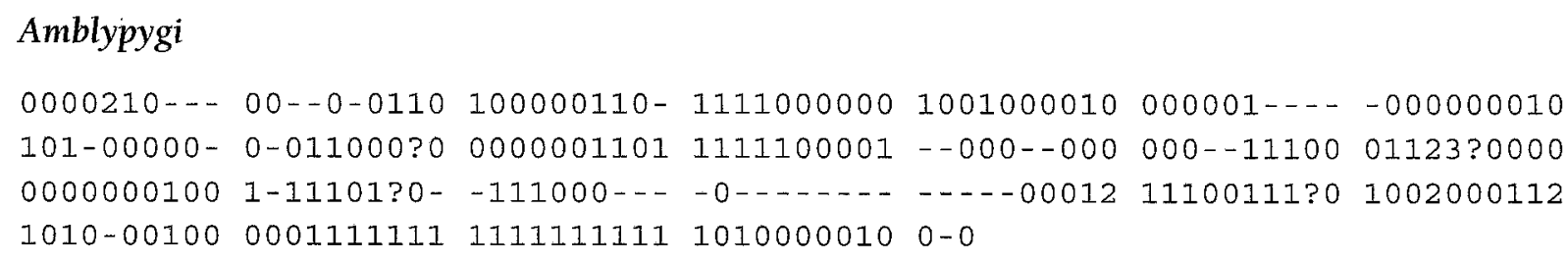

\section{Mastigoproctus}

$0000210-000-0-0110100000110-11111000001001000010000001---010000110$ 101-00000-0-011001100000001001 1111100001--000--000 010--121110112310000 00000001?0 1-1010110- -111000-. - 0 - - - - - 01102 111?0111?0 0001001110 101???0100 0001111111 1111111111 1110000011 1-0

\section{Schizomida}

1--0410---00--0-0110100000112- $11111000001001000010000001----010000010$ 101-00000-0-011001?0 0010001001 1111100001--000--000 010--1211011123?0000 00000001?? 0-1010010- -111000-- -0-.-...-0110211100111?10001001110 101???0100 01-1111111 1111111111 0011-00111 1-?

\section{Ricinulei}

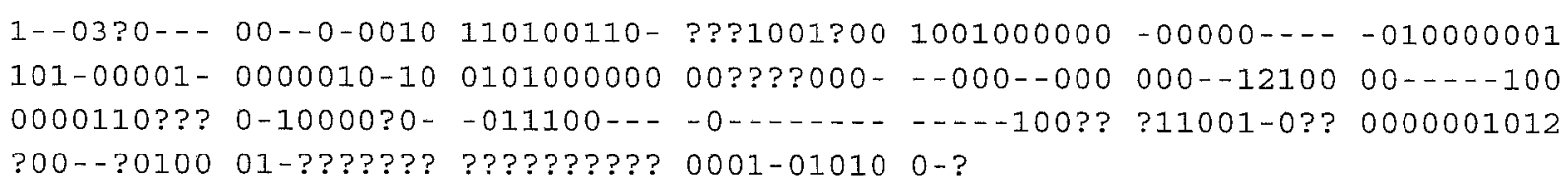

\section{Pseudoscorpiones}

1--0310--. 00--0-1-01 100000111- ???1010?00 1002101000-00000--- -1010000?0 001-00001-0000001001 0200100000 00????000- --000--000 000--020-- -0----110 000-000??? 0-0000120- -001000-_ -0_-_...--0000201000110?00010000112 001 ???0100 101??????? ????????? 000011-111 0-?

\section{Allonothrus}

1--1--0--- 00--0-1-10 10000011?- ???1011?10 1000000000-00000---- -010000000 001-00000-0000000010 010000000? 00????000---00?--000 000--010-- -0----100 000-000??? 0-1001120- -001100---1???????? ?????1000? 110?1---?? 010000?012 001???0000 000??????? ????????? 00000???10 0??

\section{Acarus}

1--1--0--- 00--0-1-10 10000011?- ???1011?10 $1000000000-00000----010000000$ 002-00000-0000000010 010000000? 00????000- --00?--000 000--010-- -0-.--100 000-000??? 0-1001120--001100-- -0--n-----1000? 110?1---?? 010000?012 001 ???0000 000?????? ?????????? 00000???10 0?? 


\section{Opilioacarus}

1--0310--- 00--0-0010 100000110-???1011?10 1000000000-?0000---- -010000000

001-00000-0001010010 010000000? 00????000- --00?--000 000--010-- -0-_--100

000-000??? 0-1001120- -001100--- -1??????? ?????100?1 ?10?1---?? 000010??12

000--?0000 000??????? ????????? 00000???10 0??

\section{Rhipicephalus}

1--1--0-- 00--0-1-10 10000011?- ???1011?10 1000000000-00000--- -010000000 001-0000?-0000000010 010000000? 00????000- --00?--000 000--010-- -0-----100 000-000??? 0-1001120- -001100-- -0--_-_ ----1000? 110?1---?? ?00010?012 000--?0000 000?????? ????????? 00000???10 0??

\section{Trigonotarbida}

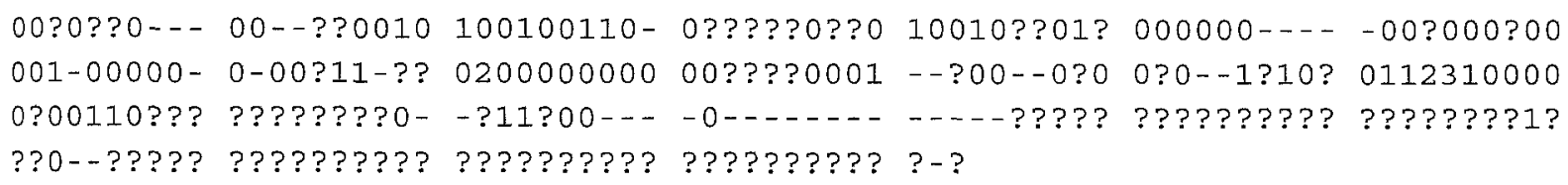

\section{Siro}

1--1--0-- 01010-1-00 100000110- ???10001001000000000-0000010000000000000 0020111000 001000?-01 2300000000 00????100-0010200000 000--020-- -0----110 000-000??? 1000010200 0001101000-10100000100000000001100010200 000001?01? 000--?0000 01-?????? ????????? 0001-00011 0??

\section{Parasiro}

1--1--0-- 01010-1-00 100000110-???1000?00 1000000000-000001000 0000000000 0020111000 001000?-01 2300000000 00????100-0010200000 000--020-- -0----110 000-000??? 1000010200 0001101000-101000001 0000000000 11???????? ??????01? 000--?0000 01-?????? ????????? 0001-00011 0??

\section{StylocellusBL}

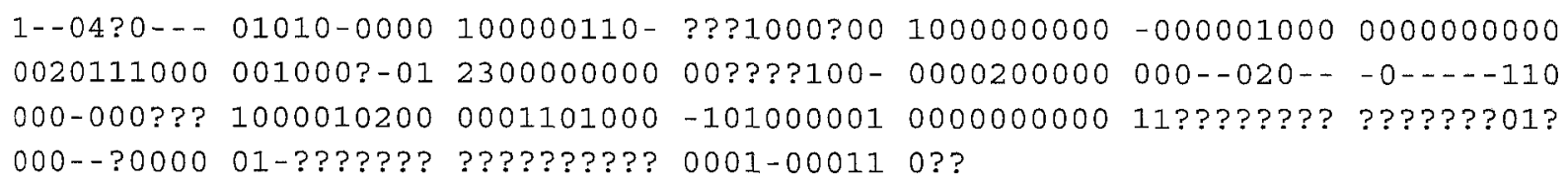

\section{StylocellusJP}

1--04?0--- 01010-0000 100000110-???1000?00 1000000000-000001000 0000000000 $0020111000001000 ?-012300000000$ 00????100-0000200000 000--020-- -0----110 000-000??? 1000010200 0001101000-101000001 0000000000 11??????? ??????01? 000--?0000 01-?????? ????????? 0001-00011 0?? 


\section{Dalquestia}

0001--1010 01000-00001000001110???1000?00 1000000000-000000000 2000000001 $10201010000100001-012300000000$ 00????100-1100101000 000--020-- -0----110 000-000??? 1000010201 ?001101102 0101100011 0000000000 11??????? ??????01? 000--?0000 000?????? ????????? 0000100011 0??

\section{Odiellus}

0001--1011 11000-00001000011110???1000?001000000000-0000000002000000001 $10201010000100001-012300000000$ 00????100-1100001010000--020-- -0--1-110 000-000??? $1000010201100110110201011000110000000000110 ? 1---2$ ? 000000?01? 000--?0000 000??????? ????????? 0000100011 0??

\section{Phalangium}

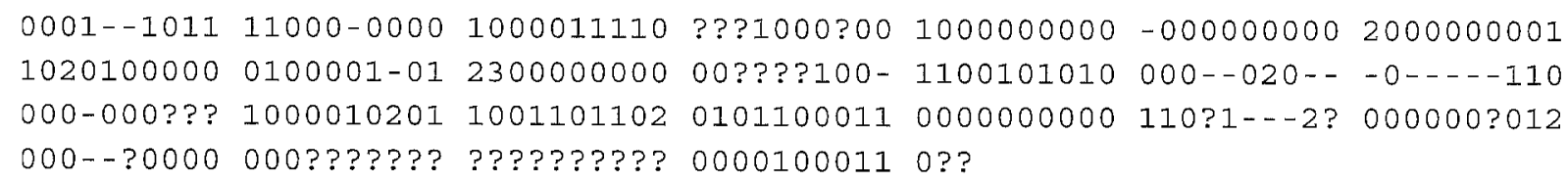

\section{Opilio}

0001--1011 11000-00001000011110???1000?00 1000000000-00000000002000000001 $10201000000100001-01230000000000 ? ? ? ? 100-1100001010000--020--10----110$ 300-000??? 1000010201100110110201011000110000000000 11???????? ???????01? J00--?0000 000??????? ????????? 00001000110 ??

\section{4strobunus}

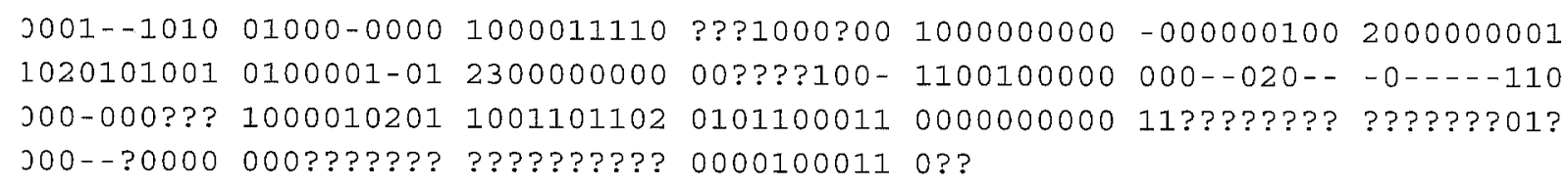

\section{Velima}

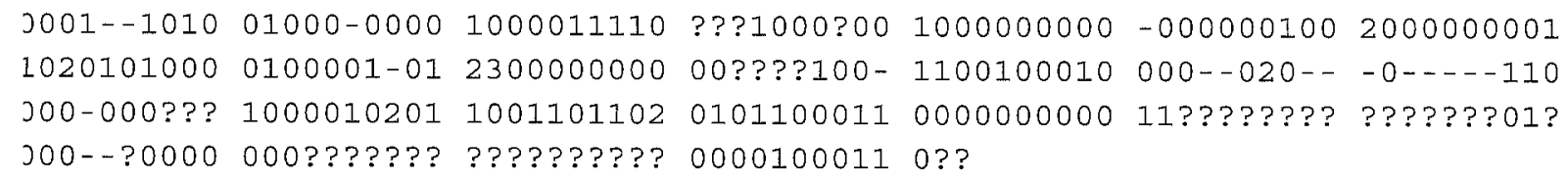

\section{Leiobunum}

3001--101001000-00001000011110 ???1000100 $1000000000-0000001002000000001$ $10201010010100001-012300000000$ 00????100-1100100010000--020-- -0----110 300-000??? $1000010201100110110201011000110000000000110 ? 1---2 ? 000000 ? 01$ ? 300--?0000 0000?????? ???????? 000010001101 ? 


\section{Hadrobunus}

0001--1010 01000-00001000011110 ???1000?00 $1000000000-0000001002000000001$

1020101001 0100001-01 2300000000 00????100-1100100010 000--020-- -0----110

000-000??? 1000010201100110110201011000110000000000 11??????? ??????01?

000--?0000 000?????? ????????? 0000100011 0??

\section{Caddo}

0001--100-01001100001000001110???1000?00 1000000000-100000010 2000000001 1020100000 0000001-01 2300000000 00????100-1100100000 000--020-- -0----110 000-000??? 1000010201 ?001101102 0101100011 0000000000 11??????? ??????01? 000--?0000 000??????? ????????? 0000100011 0??

\section{Ischyropsalis}

0001--100-0110120000 1000001111 ???1000?00 1110000000-0001--00 10000000-1 1020100000 0000001-01 2300000000 00????100-1100100000000--020-- -0-_--110 000-000??? 1000010201 1001101102 0110-00101 1100000000 110?1--0? 000000?01? 000--?0000 000?????? ????????? 0000100011 0??

\section{Hesperonemastoma}

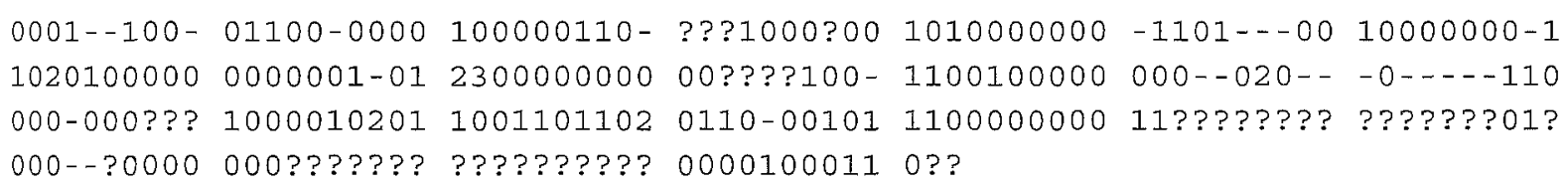

\section{Ceratolasma}

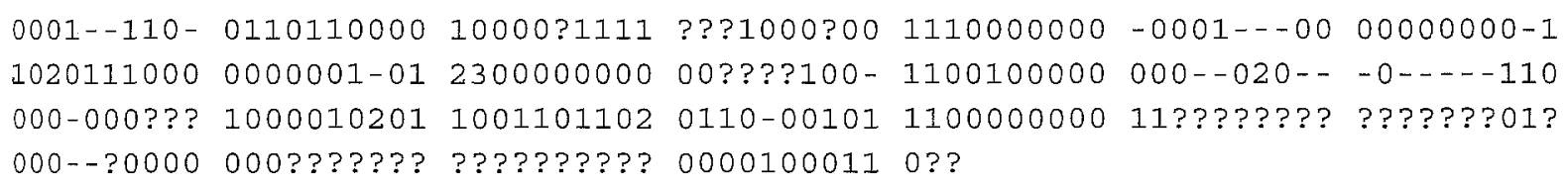

\section{Sabacon}

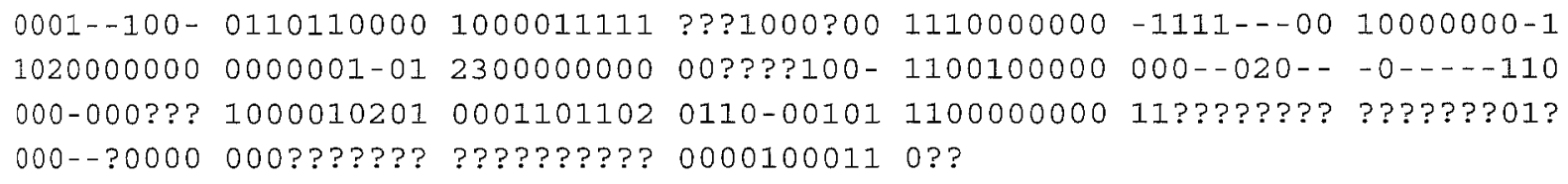

\section{Taracus}

0001--100-0110100000 1000001111 ???1000?00 1010000000 -1111--00 10000000-1 1020000000 0000001-01 2300000000 00????100-1100100000 000--020-- -0----110 000-000??? 1000010201 0001101102 0110-00101 1100000000 11??????? ??????01? 000--?0000 000??????? ????????? 0000100011 0?? 


\section{Dicranolasma}

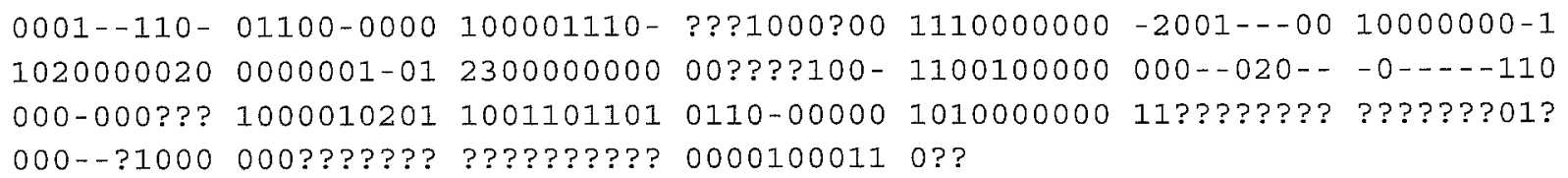

\section{Centetostoma}

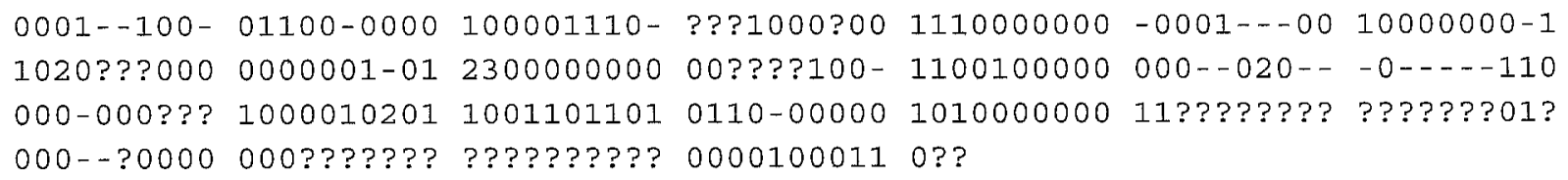

\section{Ortholasma}

0001--110-01100-0000 1000011111 ???1000?00 1?10000000-2001---00 10000000-1 $10200000200000001-012300000000$ 00????100-1100100000 000--020-- -0- - -110 000-000??? $100001020100011011010110-000001010000000$ 11???????? ??????01? 000--?0000 000??????? ???????? 0000100011 0??

\section{Nemastoma}

0001--100-01100-0000100001110-???1000?001110000000-0001---00 10000000-1 $10200000210000001-012300000000$ 00????100-1100100000 000--020-- -0----110 000-000??? $100001020100011011010110-00000101000000011001---2 ? 000000 ? 012$ 000--?0000 000??????? ???????? 0000100011 0??

\section{Nipponopsalis}

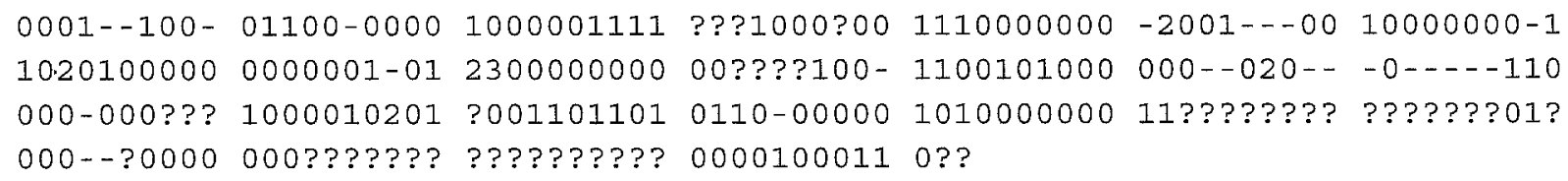

\section{Trogulus}

0001--110-01100-0000 100000110-???1000?00 1010000000-0001---00 20000000-1 10200000200000001-01 2300000000 00????100-1100200000 000--020-- -0----110 000-000??? 1000010201 1001101101 0110-000001010000000 110?1--0? 000000?011 000--?1000 000??????? ????????? 0000100011 0??

\section{Equitius}

0001--120-01100-0000 100000110-???1000?00 1000000000-0000100110000000001 $11001100100000001-012300000000$ 00????100-0000110000 000--020-- -0--1-110 000-000??? $110001020120011011020110-101030100000000$ 11??????? ??????01? 000--?0000 000??????? ????????? 0000100011 0?? 


\section{Triaenobunus}

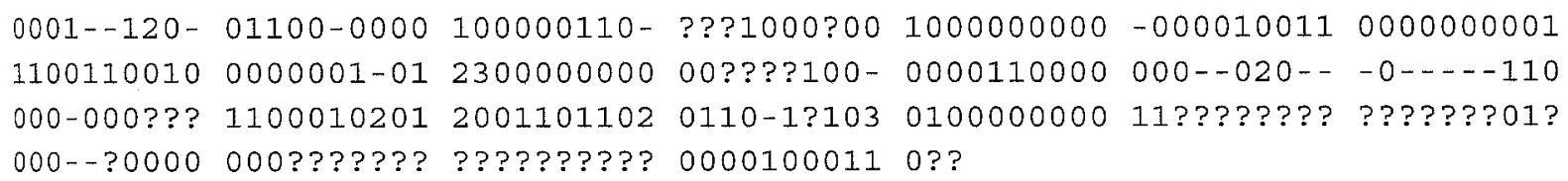

Zuma

0001--120-01100-0000 100000110- ???1000?00 1000000000-0000100110000000001 1100110010 0000001-01 2300000000 00????100-0000110000 000--020-- -0----110 000-000??? 1100010201 2001101102 0110-1?103 0100000000 11??????? ??????01? 000--?0000 000?????? ????????? 0000100011 0??

\section{Oncopus}

0001--100-01100-0000100000110-???1000?00 1000000000-000010010 2000000001 0110100000 0000001-01 2300000000 00????100-0000210100000--020-- -0----110 000-000??? 1100010201 200110111- 1110-1010(02) 0101100000 11??????? ??????01? 000--?0000 000?????? ????????? 0000100011 0??

\section{Gnomulus}

0001--100-01100-0000100000110- ???1000?00 $1000000000-0000100102000000001$ 1110110000 0000001-01 2300000000 00????100-0000210100 000--020-- -0----110 000-000??? 1100010201 $200110111-1110-1010(02) 0101100000$ 11??????? ??????01? 000--?0000 000?????? ????????? 0000100011 0??

\section{Scotolemon}

0001--100-01100-0000100000110-???1000?00 1000000000-0000100110000000001 1110100010 0000001-01 2300000000 00????100-0000110000 000--020-- -0----110 000-000??? 1100010201 200110111-0110-10102 0101000000 111?1---1? 000000?01? 000--?0000 000?????? ????????? 0000100011 0??

\section{Maiorerus}

1--1--100-01100-0000100000110-???1000?00 1000000000-0000100110000000001 1110100010 0000001-01 2300000000 00????100-0000110000000--020-- -0----110 000-000??? 1100010201 200110111-0110-10102 0101000000 111?1---1? 000000?01? 000--?0000 000?????? ????????? 0000100011 0??

\section{Bishopella}

0001--100-01100-0000100000110- ???1000?001000000000-0000100111000000001 $11101100100000001-012300000000$ 00????100-0000110000 000--020-- -0-1---110 000-000??? 1100010201 200110111-0110-10102 0101000000 111?1---1? 000000?01? 000--?0000 000??????? ????????? 0000100011 0?? 


\section{Gnidia}

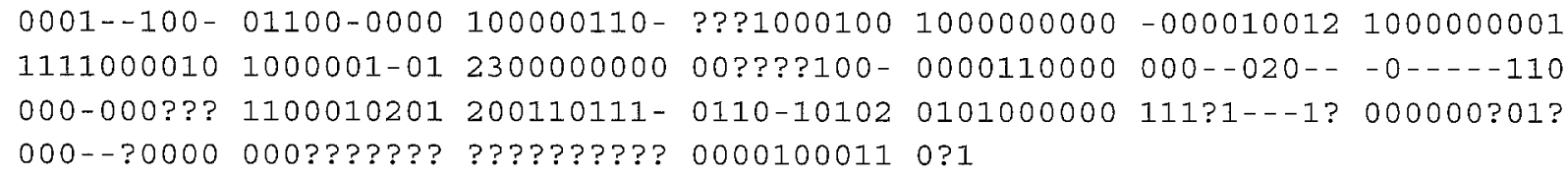

\section{Pachyloides}

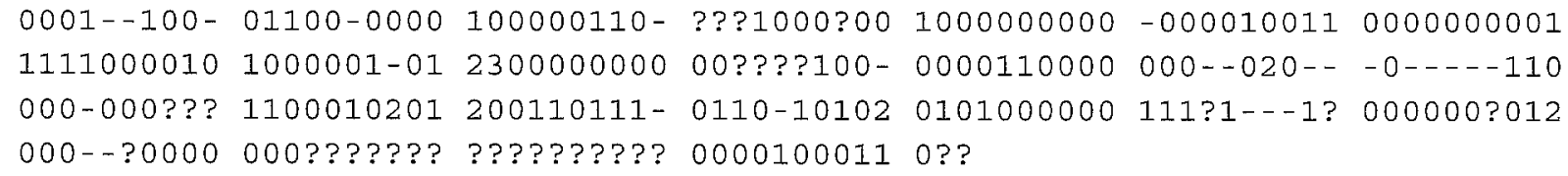

\section{Hoplobunus}

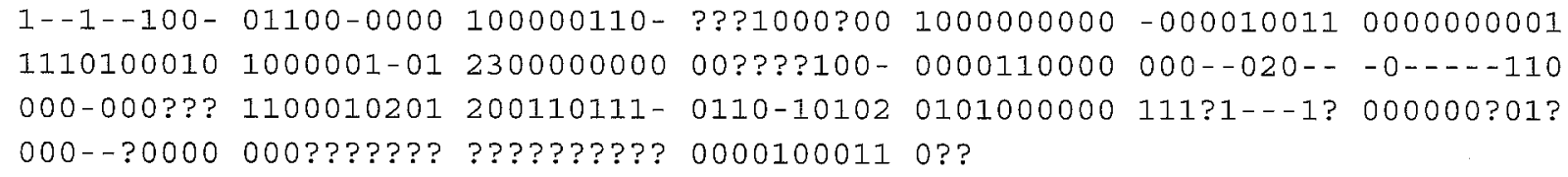

\section{APPENDIX 3}

Species List, Collection Data, and Voucher Number (MCZ DNA1XXXXX) When Available

Achelia echinata Hodge, 1864. Tossa de Mar (Girona, Spain); October 9, 1996; G. Giribet.

Callipallene sp. Tossa de Mar (Girona, Spain); October 9, 1996; G. Giribet.

Endeis laevis (Grube, 1871). Tossa de Mar (Girona, Spain); October 9, 1996; G. Giribet.

Colossendeis sp. Livingston Island (Antarctica); January 1995; Expedition BENTART'95 (MEC, Spain).

Limulus polyphemus (Linnaeus, 1758). J. W. Shultz.

Carcinoscorpius rotundicauda (Latreille, 1802). J. W. Shultz.

Belisarius xambeui Simon, 1879. La Fageda d'En Jordà (Girona, Spain); November 5, 1993; G. Giribet and C. Ribera; volcanic stone. Voucher at AMNH (Lorenzo Prendini).

Androctonus australis (Linnaeus, 1758). $18 \mathrm{~S}$ rRNA sequence from GenBank; $28 \mathrm{~S}$ rRNA sequence from $\mathrm{L}$.
Prendini; Egypt; July 1998; B. Capiz (from dealer, Chicago). Voucher at AMNH (Lorenzo Prendini).

Pseudocellus pearsei (Chamberlin and Ivie, 1938). Yucatán Peninsula (Mexico); November 6, 1993; E. Mateos.

Ricinoididae sp. No locality data.

Gluvia dorsalis Latreille, 1817. Los Monegros (Zaragoza, Spain); 1996.

Eusimonia wunderlichi Pieper, 1977. La Graciosa (Canary Islands, Spain); February 1995; M. A. Arnedo and C. Ribera.

Chanbria regalis Muma, 1951. No locality data.

Stenochrus portoricensis Chamberlin, 1922. Cueva Honda, Güimar (Tenerife, Canary Islands, Spain); November 1993; M. A. Arnedo and C. Ribera.

Hubbardia pentapeltis Cook, 1899. No locality data.

Mastigoproctus giganteus (Lucas, 1835). J. W. Shultz.

Paraphrynus sp. Yucatán Peninsula (Mexico); November 6, 1993; E. Mateos.

Amblypygi sp. No locality data.

Eukoenenia sp. South Africa; May 1999; J. Van der Schyff. MCZ DNA100456. 
Liphistius bicoloripes Ono, 1988. Ranong (Thailand); December 9, 1991; P. Schwendinger. MCZ DNA100302.

Aphonopelma sp. Sequence data from GenBank.

Nesticus cellulanus (Clerck, 1757). Collserola (Barcelona, Spain); January 4, 1995; G. Giribet, S. Carranza, and C. Ribera.

Roncus cfr. pugnax (Navas, 1925). Girona (Spain); November 1993; G. Giribet and C. Ribera (V. Mahnert, det. 1996).

Americhernes sp. No locality data.

Acarus siro Linnaeus, 1758. Sequence data from GenBank.

Allonothrus russeolus Wallwork, 1960. Sequence data from GenBank.

Opilioacarus texanus (Chamberlin and Mulaik, 1942). Kerr Co., W. Ingram, Slippery Ridge Ranch (Texas, U.S.A.); April 24, 1997; B. S. Gerdeman and H. Klompen. HK97-0424-1; AL5185.

Rhipicephalus bursa Canestrini and Fanzago, 1877. Sequence data from GenBank.

Rhipicephalus sanguineus (Latreille, 1806). Sequence data from GenBank.

Siro rubens Latreille, 1802. Mont Aigoual, Cevennes (France); April 15, 1995; G. Giribet and C. Ribera; chestnut forest litter.

Parasiro coiffaiti Juberthie, 1956. Sant Llorenç de Munt i Serra de l'Obac (Barcelona, Spain); April 16, 1994; E. Mateos.

Stylocellus sp. (BL). Bukit Larut, Taiping (Perak, Malaysia); January 7, 1996; P. Schwendinger. Voucher in P. Schwendinger collection.

Stylocellus sp. (JP). Jeram Pasu (Pasu Waterfall), $100 \mathrm{~m}$, south of Kota Baharu (Kelantan, Malaysia); January 10-11, 1999; P. Schwendinger. MCZ DNA100240.

Dalquestia formosa (Banks, 1910). Outside of Up the Creek Cave, Bexar County (Texas, USA); September 1998; J. Cokendolpher. MCZ DNA100322.

Odiellus troguloides (Roewer, 1923). Montesquiu (Barcelona, Spain); October 1993; C. Ribera. MCZ DNA100310.

Phalangium opilio Linnaeus, 1758. J. W. Shultz. MCZ DNA100307.

Opilio parietinus (DeGeer, 1778). $54^{\circ} 44^{\prime} \mathrm{N}$ $113^{\circ} 32^{\prime} \mathrm{W}$; Baptiste Lake (Alberta, Canada), $650 \mathrm{~m}$; September 1998; R. Holmberg. MCZ DNA100304.

Astrobunus grallator Simon, 1879. Serralada del
Montseny (Barcelona, Spain); October 1993; M. Rambla. MCZ DNA100311.

Nelima silvatica (Simon, 1879). Parc Natural de Collserola (Barcelona, Spain); May 1996; E. Mateos. MCZ DNA100323.

Leiobunum sp. Inwood Park, New York City (New York, USA); August 1998; L. Prendini. MCZ DNA100309.

Hadrobunus maculosus (Wood, 1868). Inwood Park, New York City (New York, U.S.A.); August 1998; L. Prendini. MCZ DNA100314.

Caddo agilis Banks, 1892. 4 miles E Coudersport, Potter Co. (Pennsylvania, U.S.A.); June 12, 1996; W. A. Shear and P. A. Selden; birch/hemlock woods. MCZ DNA100308.

Ischyropsalis luteipes Simon, 1872. Font de l'Home Mort, Núria, Queralps (Girona, Spain); July 6, 1995; G. Giribet.

Hesperonemastoma modestum (Banks, 1894). Oregon (U.S.A.); May 1996; A. Moldenke. MCZ DNA100312.

Ceratolasma tricantha Goodnight and Goodnight, 1942. J. W. Shultz. MCZ DNA100329.

Sabacon cavicolens (Packard, 1884). $35.38^{\circ} \mathrm{N}$, $83.45^{\circ} \mathrm{W}$; Scott Gap cave, Blount Co. (Tennessee, U.S.A.); November 1, 1998; W. Reeves; in organic debris. MCZ DNA100305.

Taracus sp. $15 \mathrm{~km}$ west of Philomath Woods Creek Road, Benton Co. (Oregon, U.S.A.); July 23, 1996; A. Moldenke; in leaf litter. MCZ DNA100320.

Dicranolasma soerensenii Thorell, 1876. No locality data.

Centetostoma dubium (Mello-Leitao, 1936). Serralada del Montseny (Barcelona, Spain); October 1993; M. Rambla.

Ortholasma sp. $37^{\circ} 19.5^{\prime} \mathrm{N} 122^{\circ} 11^{\prime} \mathrm{W}$; Page Mill Road at Skyline Boulevard, Santa Clara Co. (California, U.S.A.); August 14, 1998; D. Ubick.

Nemastoma bimaculatum (Fabricius, 1775). Near Heathrow Aisport (London, UK); 1998; S. Carranza.

Nipponopsalis abei (Sato and Suzuki, 1939). 3.5 $\mathrm{km}$ from Koritori, Mt. Tsurugi, Tokushima Pref. (Shikoku, Japan); 980 m; July 31, 1997; N. Tsurusaki; Cryptomeria japonica forest. MCZ DNA100306.

Trogulus nepaeformis (Scopoli, 1763). Collserola (Barcelona, Spain); May 16, 1996; G. Giribet.

Equitius doriae Simon, 1880. New South Wales (Australia); July 1995; G. S. Hunt. 
Triaenobunus sp. Australia; July 1995; G. S. Hunt. MCZ DNA100328.

Zuma acuta Goodnight and Goodnight, 1942. $37^{\circ} 19.5^{\prime} \mathrm{N} 122^{\circ} 60^{\prime} \mathrm{W}$; Sam McDonald Co. Park, 1 mile S of La Honda, San Mateo Co. (California, U.S.A.); August 14, 1998; D. Ubick.

Oncopus cfr. alticeps Pocock, 1897. Bukit Larut (= Maxwell Hill), Taiping (Malaysia); January 26, 1996; P. Schwendinger. MCZ DNA100321.

Gnomulus n. sp. Nam Tok Phliu (Waterfall and National Park), $50 \mathrm{~m}$ (Chanthaburi Province, Thailand); November 12, 1998; P. Schwendinger; Paratype deposited at the Geneva Natural History Museum.

Maiorerus randoi Rambla, 1993. Lanzarote (Canary Islands, Spain); February 1995; M. A. Arnedo.

Scotolemon lespesi Lucas, 1860. La Fageda d'En Jordà (Girona, Spain); November 5, 1993; G. Giribet and C. Ribera; volcanic stone. MCZ DNA100326.

Bishopella laciniosa (Crosby and Bishop, 1924). Sittons Cave, Dade County (Georgia, U.S.A.); August 1998; W. Reeves. MCZ DNA100324.

Gnidia holmbergi (Sørensen, 1884). Argentina; January 5, 1995; A. Muñoz-Cuevas. MCZ DNA100398.

Pachyloides thorellii Holmberg, 1878. Argentina; December 19, 1994; E. Maury. MCZ DNA100424.

Hoplobunus sp. Headquarters Cave, Bexar County (Texas, U.S.A.); September 1998; J. Cokendolpher.

\section{APPENDIX 4: STEP MATRICES USED IN THE ANALYSES}

Left column, from top to bottom, matrices 110, 111, 121, 141; middle column, matrices 210, 211, 221, 241; right column, matrices $410,411,421,441$. The gap symbol ("-") represents insertion/deletion events.

$\begin{array}{lrrrrrrrrrrrrrrr} & \mathbf{A} & \mathbf{C} & \mathbf{G} & \mathbf{T} & - & \mathbf{A} & \mathbf{C} & \mathbf{G} & \mathbf{T} & - & \mathbf{A} & \mathbf{C} & \mathbf{G} & \mathbf{T} & - \\ \mathbf{A} & 0 & 1 & 0 & 1 & 1 & 0 & 1 & 0 & 1 & 2 & 0 & 1 & 0 & 1 & 4 \\ \mathbf{C} & 1 & 0 & 1 & 0 & 1 & 1 & 0 & 1 & 0 & 2 & 1 & 0 & 1 & 0 & 4 \\ \mathbf{G} & 0 & 1 & 0 & 1 & 1 & 0 & 1 & 0 & 1 & 2 & 0 & 1 & 0 & 1 & 4 \\ \mathbf{T} & 1 & 0 & 1 & 0 & 1 & 1 & 0 & 1 & 0 & 2 & 1 & 0 & 1 & 0 & 4 \\ - & 1 & 1 & 1 & 1 & 0 & 2 & 2 & 2 & 2 & 0 & 4 & 4 & 4 & 4 & 0 \\ & & & & & & & & & & & & & & & \\ \text { A } & 0 & 1 & 1 & 1 & 1 & 0 & 1 & 1 & 1 & 2 & 0 & 1 & 1 & 1 & 4 \\ \mathbf{C} & 1 & 0 & 1 & 1 & 1 & 1 & 0 & 1 & 1 & 2 & 1 & 0 & 1 & 1 & 4 \\ \mathbf{G} & 1 & 1 & 0 & 1 & 1 & 1 & 1 & 0 & 1 & 2 & 1 & 1 & 0 & 1 & 4 \\ \text { T } & 1 & 1 & 1 & 0 & 1 & 1 & 1 & 1 & 0 & 2 & 1 & 1 & 1 & 0 & 4 \\ - & 1 & 1 & 1 & 1 & 0 & 2 & 2 & 2 & 2 & 0 & 4 & 4 & 4 & 4 & 0\end{array}$

$\begin{array}{llllllllllllllll}\mathrm{A} & 0 & 2 & 1 & 2 & 2 & 0 & 2 & 1 & 2 & 4 & 0 & 2 & 1 & 2 & 8 \\ \mathrm{C} & 2 & 0 & 2 & 1 & 2 & 2 & 0 & 2 & 1 & 4 & 2 & 0 & 2 & 1 & 8 \\ \mathrm{G} & 1 & 2 & 0 & 2 & 2 & 1 & 2 & 0 & 2 & 4 & 1 & 2 & 0 & 2 & 8 \\ \mathrm{~T} & 2 & 1 & 2 & 0 & 2 & 2 & 1 & 2 & 0 & 4 & 2 & 1 & 2 & 0 & 8 \\ - & 2 & 2 & 2 & 2 & 0 & 4 & 4 & 4 & 4 & 0 & 8 & 8 & 8 & 8 & 0\end{array}$

\begin{tabular}{|c|c|c|c|c|c|c|c|c|c|}
\hline A & $\begin{array}{llllll}0 & 4 & 1 & 4 & 4\end{array}$ & 0 & 4 & 1 & 4 & 8 & 0 & 4 & 1 \\
\hline C & $\begin{array}{lllll}4 & 0 & 4 & 1 & 4\end{array}$ & 4 & 0 & 4 & 1 & 8 & 4 & 0 & 4 \\
\hline $\mathbf{G}$ & $\begin{array}{lllll}1 & 4 & 0 & 4 & 4\end{array}$ & 1 & 4 & 0 & 4 & 8 & 1 & 4 & 0 \\
\hline & $\begin{array}{lllll}4 & 1 & 4 & 0 & 4\end{array}$ & 4 & 1 & 4 & 0 & 8 & 4 & 1 & 4 \\
\hline & $\begin{array}{lllll}4 & 4 & 4 & 4 & 0\end{array}$ & 8 & 8 & 8 & 8 & 0 & & & \\
\hline
\end{tabular}

$\begin{array}{rrrrrrrrrrrrrrrr}\mathbf{A} & 0 & 8 & 1 & 8 & 8 & 0 & 8 & 1 & 8 & 16 & 0 & 8 & 1 & 8 & 32 \\ \mathbf{C} & 8 & 0 & 8 & 1 & 8 & 8 & 0 & 8 & 1 & 16 & 8 & 0 & 8 & 1 & 32 \\ \mathbf{G} & 1 & 8 & 0 & 8 & 8 & 1 & 8 & 0 & 8 & 16 & 1 & 8 & 0 & 8 & 32 \\ \mathbf{T} & 8 & 1 & 8 & 0 & 8 & 8 & 1 & 8 & 0 & 16 & 8 & 1 & 8 & 0 & 32 \\ - & 8 & 8 & 8 & 8 & 0 & 16 & 16 & 16 & 16 & 0 & 32 & 32 & 32 & 32 & 0\end{array}$

\section{ACKNOWLEDGMENTS}

We dedicate this study to Maria Rambla, the greatest Spanish arachnologist, who inspired us to undertake this enterprise, and to the memory of Glenn Hunt. Jason Dunlop, Nikolaj Scharff, Gustavo Hormiga, Norman Platnick, Lorenzo Prendini, and Bill Shear read versions of the manuscript and provided many comments and suggestions. We thank J. C. Cokendolpher, J. Gruber, H. Klompen, N. Platnick, M. Rambla, P. J. Schwendinger, W. A. Shear, J. W. Shultz, and N. Tsurusaki for discussion on morphological characters; J. Adis, M. A. Arnedo, S. Carranza, J. C. Cokendolpher, R. Holmberg, G. S. Hunt, H. Klompen, A. Kury, E. Mateos, E. A. Maury, A. MuñozCuevas, A. Pérez-González, N. Platnick, L. Prendini, M. Rambla, W. Reeves, P. J. Schwendinger, W. A. Shear, J. W. Shultz, N. Tsurusaki, D. Ubick, J. van der Schyff, and R. van der Weele for providing specimens; M. Hahn for laboratory assistance; A. Johnston and L. Leibensperger for technical assistance. G.G. was supported by a postdoctoral Lerner Gray Research Fellowship at the AMNH, where this project was initiated.

\section{REFERENCES}

Alberti, G. (1979). Zur Feinstruktur der Spermien und Spermiocytogenese von Prokoenenia wheeleri (Rucker, 1901) (Palpigradi, Arachnida). Zoomorphology 94, 111-120.

Alberti, G. (1980). Zur Feinstruktur des Hodenepithels und der Spermien von Eusimonia mirabilis Roewer 1934 (Solifugae, Arachnida). Zool. Anz. 204, 345-352. 
Alberti, G. (1983). Fine structure of scorpion spermatozoa (Buthus occitanus; Buthidae, Scorpiones). J. Morphol. 177, $205-212$.

Alberti, G. (1990). Comparative spermatology of Araneae. Acta Zool. Fenn. 190, 17-34.

Alberti, G. (1991). Spermatology in the Acari: Systematic and functional implications. In "The Acari-Reproduction, Development and Life-History Strategies" (R. Schuster and P. W. Murphy, Eds.), pp. 77-105. Chapman \& Hall, London.

Alberti, G. (1995). Comparative spermatology of Chelicerata: Review and perspective. In "Advances in Spermatozoal Phylogeny and Taxonomy" (B. G. M. Jamieson, J. Ausió, and J.-L. Justine, Eds.), Mémoires du Musée National d'Histoire Naturelle, pp. 203-230. National Museum of Natural History, Paris.

Alberti, G., Afzelius, B. A., and Lucas, S. U. (1986). Ultrastructure of spermatozoa and spermatogenesis in bird spiders (Theraphosidae, Mygalomorphae, Araneae). J. Submicrosc. Cytol. 18, 739-753.

Alberti, G., and Coyle, F. A. (1991). Ultrastructure of the primary male genital system, spermatozoa, and spermiogenesis of Hypochilus pococki (Araneae, Hypochilidae). J. Arachnol. 19, 136-149.

Alberti, G., and Janssen, H.-H. (1986). On the fine structure of spermatozoa of Tachypleus gigas (Xiphosura, Merostomata). Int. J. Invertebr. Reprod. Dev. 9, 309-319.

Alberti, G., and Palacios-Vargas, J. G. (1984). Fine structure of spermatogenesis and mature spermatozoa of Cryptocellus boneti Bolivar and Pieltain, 1941 (Arachnida, Ricinulei). J. Ultrastruct. Res. 87, $1-12$.

Alberti, G., and Palacios-Vargas, J. G. (1987). Fine structure of spermatozoa and spermatogenesis of Schizomus palaciosi, Reddell and Cokendolpher, 1896 (Arachnida: Uropygi, Schizomida). Protoplasma 137, 1-14.

Alberti, G., and Weinmann, C. (1985). Fine structure of spermatozoa of some labidognath spiders (Filistatidae, Segestriidae, Dysderidae, Oonopidae, Scytodidae, Pholcidae; Araneae; Arachnida) with remarks on spermiogenesis. J. Morphol. 185, 1-35.

Anderson, D. T. (1973). "Embryology and Phylogeny in Annelids and Arthropods." Pergamon, Oxford.

Anderson, L. I., and Selden, P. A. (1997). Opisthosomal fusion and phylogeny of Palaeozoic Xiphosura. Lethaia 30, 19-31.

Arnaud, F, and Bamber, R. N. (1987). The biology of Pycnogonida. In "Advances in Marine Biology," pp. 1-96. Academic Press, London.

Babu, K. S. (1985). Patterns of arrangement and connectivity in the central nervous system of arachnids. In "Neurobiology of Arachnids" (F. G. Barth, Ed.), pp. 3-19. Springer-Verlag, Berlin.

Baccetti, B. (1979). Ultrastructure of sperm and its bearing on arthropod phylogeny. In "Arthropod Phylogeny" (A. P. Gupta, Ed.), pp. 609 644. Van Nostrand-Reinhold, New York.

Banks, N. (1900). New genera and species of American Phalangida. J. N. Y. Entomol. Soc. 8, 199-201.

Barrows, W. M. (1925). Modification and development of the arachnid palpal claw, with especial reference to spiders. Ann. Entomol. Soc. Am. 18, 483-516.

Bergström, J. (1979). Morphology of fossil arthropods as a guide to phylogenetic relationships. In "Arthropod Phylogeny" (A. P. Gupta, Ed.), pp. 3-56. Van Nostrand-Reinhold, New York.
Bergström, J., Stürmer, W., and Winter, G. (1980). Palaeoisopus, Palaeopantopus and Palaeothea, pycnogonid arthropods from the Lower Devonian Hünsruck Slate, West Germany. Paläontol. Z. 54, 7-54.

Berland, L. (1949). Ordre des Opilions. In "Traité de Zoologie, VI" (P.-P. Grassé, Ed.), pp. 761-793. Masson, Paris.

Binnington, K. C. (1972). The distribution and morphology of probable photoreceptors in eight species of ticks (Ixodoidea). Z. Parasitenkd. 40, 321-332.

Bishop, S. C. (1949). The Phalangida (Opiliones) of New York: With special reference to the species of The Edmund Niles Huyck Preserve, Rensselaerville, New York. Proc. Rochester Acad. Sci. 9, $159-235$.

Blumenthal, H. (1935). Untersuchungen über dar "Tarsalorgan" der Spinnen. Z. Morphol. Ökol. Tiere 29, 667.

Boudreaux, H. B. (1979). Significance of intersegmental tendon system in arthropod phylogeny and a monophyletic classification of Arthropoda. In "Arthropod Phylogeny" (A. P. Gupta, Ed.), pp. 551-586. Van Nostrand-Reinhold, New York.

Börner, C. (1902). Arachnologische Studien (II und III). Zool. Anz. 25, 433-466.

Braddy, S. J., Aldridge, R. J., Gabbott, S. E., and Theron, J. N. (1999). Lamellate book-lung in a late Ordovician eurypterid from the Soom Shale, South Africa: Support for a eurypterid-scorpion clade. Lethaia 32, $72-74$.

Bremer, K. (1988). The limits of amino acid sequence data in angiosperm phylogenetic reconstruction. Evolution 42, 795-803.

Bremer, K. (1994). Branch support and tree stability. Cladistics 10, 295-304.

Bristowe, W. S. (1949). The distribution of harvestmen (Phalangida) in Great Britain and Ireland, with notes on their names, enemies and food. J. Anim. Ecol. 18, 100-114.

Bristowe, W. S. (1976). Rare arachnids from Malaysia and Sumatra. J. Zool. London 178, 7-14.

Bruton, D. L., and Haas, W. (1999). The anatomy and functional morphology of Phacops (Trilobita) from the Hunsrück Slate (Devonian). Palaeontographica (A) 253, 29-75.

Chatterton, B. D. E., Johanson, Z., and Sutherland, G. (1994). Form of the trilobite digestive system: Alimentary structures in Pterocephalia. J. Paleontol. 69, 294-305.

Chen, J. Y., Edgecombe, G. D., and Ramsköld, L. (1997). Morphological and ecological disparity in naraoiids (Arthropoda) from the Early Cambrian Chengjiang fauna, China. Rec. Aust. Mus. 49, 1-24.

Chirgwin, J. M., Przybyla, A. E., MacDonald, R. J., and Rutter, W. J. (1979). Isolation of biologically active ribonucleic acid from sources enriched in ribonuclease. Biochemistry 18, 5294-5299.

Claridge, M. F., and Lyon, A. G. (1961). Lung-books in the Devonian Palaeocharinidae (Arachnida). Nature 191, 1190-1191.

Clarke, K. U. (1979). Visceral anatomy and arthropod phylogeny. In "Arthropod Phylogeny" (A. P. Gupta, Ed.), pp. 467-549. Van Nostrand-Reinhold, New York.

Coddington, J. A., and Scharff, N. (1994). Problems with zero-length branches. Cladistics 10, $415 \cdots 423$. 
Cokendolpher, J. C. (1984a). A new genus of North American harvestmen (Arachnida: Opiliones: Palpatores). In "Festschrift for Walter W. Dalquest in Honor of His Sixty-sixth Birthday" (N. V. Homer, Ed.), pp. 27-43. Midwestern State Univ., Wichita Falls, TX.

Cokendolpher, J. C. (1984b). Revision of the harvestman genus Leptobunus and dismantlement of the Leptobunidae (Arachnida: Opiliones: Palpatores). N. Y. Entomol. Soc. 92, 371-402.

Cokendolpher, J. C., and Lee, V. F. (1993). "Catalogue of the Cyphopalpatores and Bibliography of the Harvestmen (Arachnida, Opiliones) of Greenland, Canada, U.S.A., and Mexico." Vintage Press, Lubbock, TX

Cokendolpher, J. C., and Maury, E. A. (1990). Austropsopilio harvestmen (Opiliones, Cyphopalpatores, Caddidae) discovered in South America. Bol. Soc. Biol. Concepción 61, 59-62.

Crawford, R. L. (1992). Catalogue of the genera and type species of the harvestmen superfamily Phalangioidea (Arachnida). Burke Mus. Contrib. Anthropol. Nat. Hist. 8, 1-60.

Delle Cave, L. (1975). The "cleaning brush" in Damon diadema Simon, 1876, and Phrynichus jayakari Pocock, 1894 (Amblypygi, Arachnida). Monit. Zool. Ital. (n.s.) 9, 175-184.

Dumitrescu, D. (1975a). Contribution a l'étude morphologique de l'appareil digestif (intestin moyen) des opilions. In "Proceedings of the 6th International Arachnology Congress," Amsterdam, 1974, pp. $150-155$.

Dumitrescu, D. (1975b). Observations concernant l'appareil digestif (intestin moyen) des opilions appartenant aux familles des Sironidae, Caddidae et Neopilionidae (Arachnida). Trav. Mus. Hist. Nat. "Gr. Antipa" 16, 115-120.

Dunlop, J. A. (1994). Filtration mechanisms in the mouthparts of tetrapulmonate arachnids (Trigonotarbida, Araneae, Amblypygi, Uropygi, Schizomida). Bull. Br. Arachnol. Soc. 9, 267-273.

Dunlop, J. A. (1996a). A trigonotarbid arachnid from the Upper Silurian of Shropshire. Palaeontology 39, 605-614.

Dunlop, J. A. (1996b). Evidence for a sister group relationship between Ricinulei and Trigonotarbida. Bull. Br. Arachnol. Soc. 10, 193-204.

Dunlop, J. A. (1997). Palaeozoic arachnids and their significance for arachnid phylogeny. In "Proceedings of the 16th European Colloquium of Arachnology" (M. Zabka, Ed.), pp. 65-82. Siedlce.

Dunlop, J. A. (1998). The origins of tetrapulmonate book lungs and their significance for chelicerate phylogeny. In "Proceedings of the 17th European Colloquium of Arachnology" (P. A. Selden, Ed.), Edinburgh, 1997, pp. 9-16.

Dunlop, J. A. (1999). Pasando revista a la evolución de los quelicerados [A review of chelicerate evolution]. Bol. S. E. A. 26, 255-272.

Dunlop, J. A. (2000). The epistomo-labral plate and lateral lips in solifuges, pseudoscorpions and mites. Ekológia (Bratislava) 19, $67-78$.

Dunlop, J. A., and Selden, P. A. (1998). The early history and phylogeny of the chelicerates. In "Arthropod Relationships" (R. A. Fortey and R. H. Thomas, Eds.), pp. 221-235. Chapman \& Hall, London.

Dunlop, J. A., and Webster, M. (1999). Fossil evidence, terrestrialization, and arachnid phylogeny. J. Arachnol. 27, 86-93.

Edgar, A. L. (1990). Opiliones (Phalangida). In "Soil Biology Guide" (D. L. Dindal, Ed.), pp. 529-581. Wiley, New York.
Edgecombe, G. D., and Ramsköld, L. (1999). Relationships of Cambrian Arachnata and the systematic position of Trilobita. J. Paleontol. 73, 263-287.

Edgecombe, G. D., Wilson, G. D. F., Colgan, D. J., Gray, M. R., and Cassis, G. (2000). Arthropod cladistics: Combined analysis of histone $\mathrm{H} 3$ and $\mathrm{U} 2$ snRNA sequences and morphology. Cladistics 16, 155-203.

Eisenbeis, G., and Wichard, W. (1985). "Atlas zur Biologie der Bodenarthropoden." VCH, Stuttgart.

El-Hawawi, A. S. N., and King, P. E. (1978). Spermiogenesis in a pycnogonid Nymphon gracile (Leach). J. Submicrosc. Cytol. 10, 345-356.

Fahrenbach, W. H. (1999). Merostomata. In "Microscopic Anatomy of Invertebrates," Vol. 8A, "Chelicerate Arthropoda" (F. W. Harrison and R. F. Foelix, Eds.), pp. 21-115. Wiley-Liss, New York.

Farris, J. S., Källersjö, M., Kluge, A. G., and Bult, C. (1995). Constructing a significance test for incongruence. Syst. Biol. 44, $570-572$.

Firstman, B. (1973). The relationship of the chelicerate arterial system to the evolution of the endosternite. J. Arachnol. 1, 1-54.

Forster, R. R. (1980). Evolution of the tarsal organ, the respiratory system and the female genitalia in spiders. In "Verhandlungen der 8 Internationaler Arachnologen-Kongress, Wien" (J. Gruber, Ed.), pp. 269-284. H. Engermann, Vienna.

Forster, R. R., and Platnick, N. I. (1984). A review of the araneid spiders and their relatives, with notes on the limits of the superfamily Palpimanoidea (Arachnida, Araneae). Bull. Am. Mus. Nat. Hist. 181, 1-230.

Giribet, G. (1997). "Filogenia Molecular de Artrópodos Basada en la Secuencia de Genes Ribosomales." Univ, de Barcelona, Barcelona. [Ph.D. thesis]

Giribet, G. (1999). Ecdysozoa versus Articulata, dos hipótesis alternativas sobre la posición de los Artrópodos en el reino Animal. Bol. $S$. E. A. 26, 145-160.

Giribet, G. (2000). Catalogue of the Cyphophthalmi of the world (Arachnida, Opiliones). Rev. Ibér. Aracnol. 2, 49-76.

Giribet, G. (2001). Exploring the behavior of POY, a program for direct optimization of molecular data. Cladistics 17, S60-S70.

Giribet, G., Carranza, S., Baguñà, J., Riutort, M., and Ribera, C. (1996). First molecular evidence for the existence of a Tardigrada + Arthropoda clade. Mol. Biol. Evol. 13, 76-84.

Giribet, G., Carranza, S., Riutort, M., Baguñà, J., and Ribera, C. (1999a). Internal phylogeny of the Chilopoda (Myriapoda, Arthropoda) using complete $18 \mathrm{~S}$ rDNA and partial $28 \mathrm{~S}$ rDNA sequences. Philos. Trans. R. Soc. London B Biol. Sci. 354, 215-222.

Giribet, G., Edgecombe, G. D., and Wheeler, W. C. (1999b). Sistemática y filogenia de artrópodos: Estado de la cuestión con énfasis en análisis de datos moleculares. Bol. S. E. A. 26, 197-212.

Giribet, G., Rambla, M., Carranza, S., Baguñà, J., Riutort, M., and Ribera, C. (1999c). Phylogeny of the arachnid order Opiliones (Arthropoda) inferred from a combined approach of complete $18 \mathrm{~S}$ and partial $28 \mathrm{~S}$ ribosomal DNA sequences and morphology. Mol. Phylogenet. Evol. 11, 296-307.

Giribet, G., and Ribera, C. (1998). The position of arthropods in the 
animal kingdom: A search for a reliable outgroup for internal arthropod phylogeny. Mol. Phylogenet. Evol. 9, 481-488.

Giribet, G., and Ribera, C. (2000). A review of arthropod phylogeny: New data based on ribosomal DNA sequences and direct character optimization. Cladistics 16, 204-231.

Giribet, G., and Wheeler, W. C. (1999). On gaps. Mol. Phylogenet. Evol. 13, 132-143.

Gladstein, D. S., and Wheeler, W. C. (1997). POY: The optimization of alignment characters. Program and documentation available at ftp.amnh.org/pub/molecular.

Goloboff, P. A. (1998). Nona version 2.0. Program and documentation available at ftp.unt.edu.ar/pub/parsimony.

Goloboff, P. A. (1999). Analyzing large data sets in reasonable times: Solutions for composite optima. Cladistics 15, 415-428.

Goodnight, C. J., and Goodnight, M. L. (1942). New Phalangodidae (Phalangida) from the United States. Am. Mus. Novitates 1188, 1-18.

Grandjean, F. (1956). Caractères chitineux de l'ovipositeur, en structure normale chez les oribates (Acariens). Arch. Zool. Exp. Gén. 93, 96-106.

Grasshoff, M. (1978). A model of the evolution of the main Chelicerate groups. Symp. Zool. Soc. London 42, 273-284.

Gruber, J. (1974). Bemerkungen zur Morphologie und systematischen Stellung von Caddo, Acropsopilio und verwandter Formen (Opiliones, Arachnida). Ann. Naturhist. Mus. Wien 78, 237-259.

Gruber, J. (1978). Redescription of Ceratolasma tricantha Goodnight and Goodnight, with notes on the family Ischyropsalidae (Opiliones, Palpatores). J. Arachnol. 6, 105-124.

Gruber, J. (1996). Beobachtungen zur Ökologie und Biologie von Dicranolasma scabrum (Herbst, 1799). Teil II. Fortpflanzung, Entwicklung und Wachstum (Arachnida: Opiliones: Dicranolasmatidae). Ann. Naturhist. Mus. Wien 98, 71-110.

Hansen, H. J. (1893). Organs and characters in different orders of arachnids. Ent. Meddr. 4, 137-251.

Hansen, H. J., and Sørensen, W. (1904). "On Two Orders of Arachnida: Opiliones, Especially the Suborder Cyphophthalmi, and Ricinulei, Namely the Family Cryptostemmatoidae." Cambridge Univ. Press, Cambridge, UK

Hansen, H. J., and Sørensen, W. (1905). The Tartarides, a tribe of the order Pedipalpi. Ark. Zool. 2, 1-78.

Hanström, B. (1928). "Das Nervensystem der wirbellosen Tiere." Springer-Verlag, Berlin.

Harvey, M. S. (1992). The phylogeny and classification of the Pseudoscorpionida (Chelicerata: Arachnida). Invertebr. Taxon. 6, 13731435.

Hennig, W. (1986). "Wirbellose II: Gliedtiere." Verlag Harri Deutsch, Thun/Frankfurt.

Hess, M., Melzer, R. R., and Smola, U. (1996). The eyes of a "nobody", Anoplodactylus petiolatus (Pantopoda; Anoplodactylidae). Helgoländer Meeresunters. 50, 25-36.

Hillyard, P. D., and Sankey, J. H. P. (1989). "Harvestmen." Linnean Soc. London and The Estuarine and Brackish-Water Sci. Assoc. by E. J. Brill, Leiden.

Homman, H. (1985). Die Cheliceren der Araneaem Amblypygi und
Uropygi mit den Skleriten, den Plagulae (Chelicerata, Arachnomorpha). Zoomorphology 105, 69-75.

Hunt, G. S., and Cokendolpher, J. C. (1991). Ballarrinae, a new subfamily of harvestmen from the southern hemisphere (Arachnida, Opiliones, Neopilionidae). Rec. Aust. Mus. 43, 131-169.

Hunt, G. S., and Hickman, J. L. (1993). A revision of the genus Lomanella Pocock and its implications for family level classification in the Travunioidea (Arachnida: Opiliones: Triaenonychidae). Rec. Aust. Mus. 45, 81-119.

Janies, D., and Wheeler, W. C. (2001). Efficiency of parallel direct optimization. Cladistics 17, S71-S82.

Jeram, A. J. (1994a). Carboniferous Orthosterni and their relationship to living scorpions. Palaeontology 37, 513-550.

Jeram, A. J. (1994b). Scorpions from the Viséan of East Kirkton, West Lothian, Scotland, with a revision of the infraorder Mesoscorpionina. Trans. R. Soc. Edinburgh: Earth Sci. 84, 283-299.

Jeram, A. J. (1998). Phylogeny, classification and evolution of Silurian and Devonian scorpions. In "Proceedings of the 17th European Colloquium of Arachnology" (P. A. Selden, Ed.), Edinburgh, 1997, pp. 17-31.

Jespersen, A. (1978). The fine structure of spermiogenesis in the Amblypygi and the Uropygi (Arachnida). Zoomorphology 89, 237-250.

Jones, S. R., and Cokendolpher, J. C. (1985). Spermatogenesis in the harvestman Vonones sayi (Simon) (Opiliones: Laniatores: Cosmetidae). Bull. Br. Arachnol. Soc. 6, 403-413.

Juberthie, C. (1956). Une nouvelle espéce d'Opilions Sironidae de France et d'Espagne: Parasiro coiffaiti n. sp. Bull. Mus. 2e Sér. 28, 394-400.

Juberthie, C. (1967). Caractères sexuels secondaires des Opilions: Les glandes anales de Siro rubens. Rev. Ecol. Biol. Sol 4, 489-496.

Juberthie, C., Lopez, A., and Juberthie-Jupeau, L. (1981). Étude ultrastructurale des sensilles thoraciques dorsales et paramédianes chez Sabacon paradoxum Simon (Palpatores, Sabaconidae). Atti Soc. Tosc. Sci. Nat. Mem Ser. B 88, 27-33.

Juberthie, C., and Manier, J. F. (1978). Etude ultrastructurale comparée de la spermiogenèse des opilions et son intérêt phylétique. Symp. Zool. Soc. London 42, 407-416.

Kaestner, A. (1935). Ordnung der Arachnida: Opiliones Sundevall = Weberknechte. In "Handbuch der Zoologie. Eine Naturgeschichte der Stämme des Tierreiches" (W. Kükenthal, Ed.), pp. 300-393. de Gruyter, Berlin.

Kethley, J. (1990). Acarina: Prostigmata (Actinedida). In "Soil Biology Guide" (D. L. Dindal, Ed.), pp. 667-756. Wiley, New York.

King, P. E. (1973). "Pycnogonids." St. Martin's, New York.

King, P. E., and El-Hawawi, A. S. N. (1978). Spermiogenesis in the pycnogonid Pycnogonum litorale (Ström). Acta Zool. (Stockholm) 59, 97-103.

Kjellsvig-Waering, E. N. (1986). A restudy of the fossil Scorpionida of the world. Palaeontogr. Am. 55, 1-287.

Kury, A. B. (1993). "Análise Filogenética de Gonyleptoidea (Arachnida, Opiliones, Laniatores)." Univ. of Sao Paolo, Sao Paolo. [Ph.D. thesis] 
Lankester, E. R. (1881). Limulus, an arachnid. Q. J. Microsc. Sci. 21, 504-649.

Latreille, P. A. (1810). "Considérations Générales sur l'Ordre Naturel des Animaux Composant les Classes des Crustacés, des Arachnides, et des Insectes: Avec un Tableau Méthodique de Leurs Genres, Disposés en Familles." F. Schoell, Paris.

Lee, D.-C., and Bryant, H. N. (1999). A reconsideration of the coding of inapplicable characters: Assumptions and problems. Cladistics 15, 373-378.

Legg, G. (1973). The structure of encysted sperm of some British Pseudoscorpiones (Arachnida). J. Zool. London 170, 429-440.

Lindquist, E. E. (1984). Current theories on the evolution of major groups of Acari and on their relationship with other groups of Arachnida, with consequent implications for their classification. In "Acarology VI" (D. A. Griffiths and C. E. Bowman, Eds.), Vol. 1, pp. 28-62. Ellis Horwood, Chichester.

Loman, J. C. C. (1903). Vergleichend anatomische Untersuchungen an chilenischen und andern Opilioniden. Zool. Jb. Suppl. 6, 115-199.

Manton, S. M. (1977). "The Arthropoda: Habits, Functional Morphology, and Evolution." Clarendon, Oxford.

Martens, J. (1976). Genitalmorphologie, System und Phylogenie der Weberknechte (Arachnida, Opiliones). Entomol. Ger. 3, 51-68.

Martens, J. (1978). Weberknechte, Opiliones. Gustav Fischer Verlag, Jena, $464 \mathrm{pp}$.

Martens, J. (1980). "Versuch eines Phylogenetischen Systems der Opiliones," pp. 355-360. Proc. 8th Int. Congr. Arachnol., Vienna.

Martens, J. (1983). Europäische Arten der Gattung Sabacon Simon 1879 (Arachnida: Opiliones: Sabaconidae). Senckenbergiana Biol. 63, 265-296.

Martens, J. (1986). Die Grossgliederung der Opiliones und die Evolution der Ordnung (Arachnida). Actas X Congr. Int. Arachnol. Jaca $1,289-310$.

Martens, J. (1988). Sibirische Arten der Gattung Sabacon Simon 1879 (Arachnida: Opiliones: Sabaconidae). Senckenbergiana Biol. 69, 369-377.

Martens, J., Hoheisel, U., and Götze, M. (1981). Vergleichende Anatomie der Legeröhren der Opiliones als Beitrag zur Phylogenie der Ordnung (Arachnida). Zool. Jb. Anat. 105, 13-76,

Martens, J., and Schawaller, W. (1977). Die Cheliceren-Drüsen der Weberknechte nach rastoptischen und lichtoptischen Befunden (Arachnida; Opiliones). Zoomorphology 86, 223-270.

Martens, J., and Schwendinger, P. J. (1998). A taxonomic revision of the family Oncopodidae. I. New genera and new species of Gnomulus Thorell (Opiliones, Laniatores). Rev. Suisse Zool. 105, 499-555.

Martens, J, and Suzuki, S. (1966). Zur Systematischen Stellung ostasiatischer Ischyropsalididen-Arten (Arachnoidea, Opiliones, Ischyropsalididae). Annot. Zool. Jpn. 39, 215-221.

Mickevich, M. F., and Farris, J. S. (1981). The implications of congruence in Menidia. Syst. Zool. 27, 143-158.

Millot, J. (1933). Notes complémentaires sur l'anatomie des Liphistiides et des Hypochilides, a propos d'un travail récent de A. Petrunkevitch. Bull. Soc. Zool. Fr. 58, 217-235.

Millot, J. (1949). Classe des Arachnides (Arachnida). I. Morphologie générale et anatomie interne. In "Traite de Zoologié" (P.-P. Grassé, Ed.), pp. 261-319. Masson, Paris.

Miyosi, Y. (1942). Form changes in the development of Ischyropsalis abei Sato and Suzuki. Acta Arachnol. 7, 109-120. [In Japanese]

Munilla, T. (1999). Evolución y filogenia de los picnogónidos. Bol. S. E. A. 26, 273-279.

Muñoz-Cuevas, A. (1971). Recherches sur les opilions du Chili. II. Description d'une nouvelle espèce: Pachylus vachoni et distribution géographique du genre Pachylus. Bull. Mus. Natl. Hist. Nat. Paris 41, 1391-1397.

Nixon, K. C. (1999). The Parsimony Ratchet, a new method for rapid parsimony analysis. Cladistics $15,407-414$.

Osaki, H. (1969). Electron microscope study on the spermatozoon of the liphistiid spider, Heptathela kimurai. Acta Arachnol. Tokyo 22, 1-12.

Paulus, H. F. (1979). Eye structure and the monophyly of the Arthropoda. In "Arthropod Phylogeny" (A. P. Gupta, Ed.), pp. 299-383. Van Nostrand-Reinhold, New York.

Petrunkevitch, A. (1955). Arachnida. In "Treatise on Invertebrate Paleontology, Part P" (R. C. Moore, Ed.), pp. 299-383. Geol. Soc. Am., Univ. of Kansas Press, Lawrence.

Philipps, D. M. (1976). Nuclear shaping during spermiogenesis in the whip scorpion. J. Ultrastruct. Res. 54, 397-405.

Pittard, K., and Mitchell, R. W. (1972). Comparative morphology of the life stages of Cryptocellus pelaezi (Arachnida, Ricinulei). Grad. Stud. Texas Tech Univ. 1, 1-77.

Platnick, N. I., and Gertsch, W. J. (1976). The suborders of spiders. Am. Mus. Novitates 2607, 1-15.

Platnick, N. I., and Shabad, M. U. (1976). On Colombian Cryptocellus (Arachnida, Ricinulei). Am. Mus. Novitates 2605, 1-17.

Pocock, R. I. (1893). On some points in the morphology of the Arachnida (s.s.) with some notes on the classification of the group. Ann. Mag. Nat. Hist. Ser. 6 11, 1-19.

Pocock, R. I. (1902). Some points in the morphology and classification of the Opiliones. Ann. Mag. Nat. Hist. Ser. 7 10, 504-516.

Rambla, M. (1973). Contribución al conocimiento de los Opiliones de la Fauna Ibérica. Estudio de las especies ibéricas de los géneros Odiellus y Lacinius (Fam. Phalangiidae). Pub. Inst. Biol. Apl. 54, 5-38.

Rambla, M. (1975). Los Opiliones (Arachnida) (2a parte). Graellsia 30, 187-220.

Rambla, M. (1976). Estudio de la especie Astrobunus grallator Simon 1879 (Arachnida, Opiliones, Sclerosomatinae). Misc. Zool. 3, 53-68.

Rambla, M. (1985). Artrópodos epigeos del Macizo de San Juan de la Peña (Jaca, Huesca). IV. Opiliones. Pirineos 124, 87-169.

Rambla, M. (1991). A new Stylocellus from some caves of Borneo, Malaysia (Opiliones, Cyphophthalmi, Stylocellidae). Mém. Biospéol. 18, 227-232.

Rambla, M. (1993). Maiorerus randoi $\mathrm{n}$. gen., n. sp., the first laniatorid from a Canary Island cave (Opiliones, Phalangodidae). Mém. Biospéol. 20, 177-182.

Reger, J. F. (1969). A fine structure study on spermiogenesis in the 
Arachnida, Leiobunum sp. (Phalangida; harvestmen). J. Ultrastruct. Res. 28, 422-434.

Roewer, C. F. (1923). "Die Weberknechte der Erde. Systematische Bearbeitung der Bisher Bekannten Opiliones." VCH, Jena.

Roewer, C. F. (1934). Solifugae, Palpigradi. Bronns Klassen Ordnungen Tierreichs 4, 1-713.

Savory, T. H. (1971). "Evolution in the Arachnida." Merrow, Watford, UK.

Savory, T. H. (1977). Cyphophthalmi: The case for promotion. Biol. J. Linn. Soc. 9, 299-304.

Scholl, G. (1977). Beitrage zur Embryonalentwicklung von Limulus polyphemus L. (Chelicerata, Xiphosura). Zoomorphology 86, 99-154.

Schwendinger, P. J. (1992). New Oncopodidae (Opiliones, Laniatores) from southeast Asia. Rev. Suisse Zool. 99, 177-199.

Selden, P. A. (1981). Functional morphology of the prosoma of Baltoeurypterus tetragonophthalamus (Fischer) (Chelicerata, Eurypterida). Trans. R. Soc. Edinburgh: Earth Sci. 72, 9-42.

Selden, P. A. (1992). Revision of the fossil ricinuleids. Trans. R. Soc. Edinburgh: Earth Sci. 83, 595-634.

Selden, P. A., Shear, W. A., and Bonamo, P. M. (1991). A spider and other arachnids from the Devonian of New York, and reinterpretations of Devonian Araneae. Palaeontology 34, 241-281.

Sharov, A. G. (1966). "Basic Arthropodan Stock with Special Reference to Insects." Pergamon, Oxford.

Shear, W. A. (1975a). The opilionid family Caddidae in North America, with notes on species from other regions (Opiliones, Palpatores, Caddoidea). J. Arachnol. 2, 65-88.

Shear, W. A. (1975b). The opilionid genera Sabacon and Tomicomerus in America (Opiliones, Troguloidea, Ischyropsalidae). J. Arachnol. 3, 5-29.

Shear, W. A. (1980). A review of the Cyphophthalmi of the United States and Mexico, with a proposed reclassification of the suborder (Arachnida, Opiliones). Am. Mus. Novitates 2705, 1-34.

Shear, W. A. (1982). Opiliones. In "Synopsis and Classification of Living Organisms" (S. P. Parker, Ed.), pp. 104-110. McGraw-Hill, New York

Shear, W. A. (1985). Marwe coarctata, a remarkable new cyphophthalmid from a limestone cave in Kenya (Arachnida, Opiliones). Am. Mus. Novitates 2830, 1-6.

Shear, W. A. (1986). A cladistic analysis of the opilionid superfamily Ischyropsalidoidea, with descriptions of the new family Ceratolasmatidae, the new genus Acuclavella, and four new species. Am. Mus. Novitates 2844, 1-29.

Shear, W. A. (1993a). New species in the opilionid genus Stylocellus from Malaysia, Indonesia and the Philippines (Opiliones, Cyphophthalmi, Stylocellidae). Bull. Br. Arachnol. Soc. 9, 174-188.

Shear, W. A. (1993b). The genus Chileogovea (Opiliones, Cyphophthalmi, Petallidae). J. Arachnol. 21, 73-78.

Shear, W. A. (1993c). The genus Troglosiro and the new family Troglosironidae (Opiliones, Cyphophthalmi). J. Arachnol. 21, 81-90.

Shear, W. A. (1996). Hesperopilio mainae, a new genus and species of harvestman from Western Australia (Opiliones: Caddidac: Acropsopilioninae). Rec. West. Aust. Mus. 17, 455-460.

Shear, W. A., Gensel, P. G., and Jeram, A. J. (1996). Fossils of large terrestrial arthropods from the Lower Devonian of Canada. Nature 384, 555-557.

Shear, W. A., and Gruber, J. (1983). The opilionid subfamily Ortholasmatinae (Opiliones, Troguloidea, Nemastomatidae). Am. Mus. Novitates 2757, 1-65.

Shear, W. A., and Gruber, J. (1996). Cyphophthalmid opilionids new to Madagascar: Two new genera (Opiliones, Cyphophthalmi,?Pettalidae). Bull. Br. Arachnol. Soc. 10, 181-186.

Shear, W. A., Selden, P. A., Rolfe, W. D. I., Bonamo, P. M., and Grierson, J. D. (1987). New terrestrial arachnids from the Devonian of Gilboa, New York (Arachnida, Trigonotarbida). Am. Mus. Novitates 2901, 1-74.

Shultz, J. W. (1989). Morphology of locomotor appendages in Arachnida: Evolutionary trends and phylogenetic implications. Zool. J. Linn. Soc. 97, 1-56.

Shultz, J. W. (1990). Evolutionary morphology and phylogeny of Arachnida. Cladistics 6, 1-38.

Shultz, J. W. (1993). Muscular anatomy of the giant whipscorpion Mastigoproctus giganteus (Lucas) (Arachnida: Uropygi) and its evolutionary significance. Zool. J. Linn. Soc. 108, 335-365.

Shultz, J. W. (1998). Phylogeny of Opiliones (Arachnida): An assessment of the "Cyphopalpatores" concept. J. Arachnol. 26, 257-272.

Shultz, I. W. (1999). Muscular anatomy of a whipspider, Phrynus longipes (Pocock) (Arachnida: Amblypygi), and its evolutionary significance. Zool. J. Linn. Soc. 126, 81-116.

Shultz, J. W. (2000). Skeletomuscular anatomy of the harvestman Leiobunum aldrichi (Weed, 1893) (Arachnida: Opiliones: Palpatores) and its evolutionary significance. Zool. J. Linn. Soc. 128, 401-438.

Šilhavý, V. (1961). Die Grundsätze der modernen Weberknechtetaxonomie und Revision des Bisherigen Systems der Opilioniden. In "XIth International Congress of Entomology," Vienna, pp. 262-267.

Snodgrass, R. E. (1938). Evolution of the Annelida, Onychophora and Arthropoda. Smithsonian Misc. Collect. 97, 1-159.

Snodgrass, R. E. (1952). “A Textbook of Arthropod Anatomy." Cornell Univ. Press, Ithaca, NY.

Stockwell, S. A. (1989). "Revision of the Phylogeny and Higher Classification of Scorpions (Chelicerata)." Univ. of California, Berkeley. [Ph.D. thesis]

Størmer, L. (1944). On the relationships and phylogeny of fossil and recent Arachnomorpha. A comparative study on Arachnida, Xiphosura, Eurypterida, Trilobita, and other fossil Arthropoda. Skr. Norske Vidensk. Acad. Oslo, I. Mat.-Naturvidensk. Klasse 1944 I 5, 1-158.

Størmer, L. (1955). Merostomata. In "Treatise on Invertebrate Paleontology," Part P, "Arthropoda 2. Chelicerata with Sections on Pycnogonida and Palaeoisopus" (R. C. Moore, Ed.), pp. P4-P41. Geol. Soc. Am., Univ. of Kansas Press, Lawrence.

Strausfeld, N. J. (1998). Crustacean-insect relationships: The use of brain characters to derive phylogeny amongst segmented invertebrates. Brain Behav. Evol. 52, 186-206. 
Stürmer, W., and Bergström, J. (1981). Weinbergina, a xiphosuran arthropod from the Devonian Hunsriick Slate. Paläontol. Z. 55, 237-255.

Suzuki, S. (1940). Über das Vorkommen des Männchens von Ischyropsalis abei Sato et Suzuki (Opiliones) und seine weitere Verbreitung in Japan. J. Sci. Hiroshima Univ. Ser. B Div. 1 7, 1-11.

Suzuki, S. (1965). Three species of Ischyropsalidae (Phalangida) from Hokkaido. Annot. Zool. Jpn. 38, 39-44.

Thorell, T. (1877). Études scorpiologiques. Atti Soc. Ital. Sci. Nat. 19, 86-102.

Tripepi, S. (1983). Fine structure of spermiogenesis in Phalangium opilio L. (Opiliones, Phalangiidae). Bull. Br. Arachnol. Soc. 6, 109-114.

Tripepi, S., and Saita, A. (1985). Ultrastructural analysis of spermiogenesis in Admetus pomilio (Arachnida, Amblypygi). J. Morphol. 184, 111-120.

Turbeville, J. M., Pfeifer, D. M., Field, K. G., and Raff, R. A. (1991). The phylogenetic status of arthropods, as inferred from 18S rRNA sequences. Mol. Biol. Evol. 8, 669-686.

van der Hammen, L. (1966). Studies on Opilioacarida (Arachnida). I. Description of Opilioacarus texanus (Chamberlin \& Mulaik) and revised classification of the genera. Zool. Verhand. Leiden $\mathbf{8 6}$, $1-80$

van der Hammen, L. (1977a). A new classification of Chelicerata. Zool. Meded. Leiden 51, 307-319.

van der Hammen, L. (1977b). The evolution of the coxa in mites and other groups of Chelicerata. Acarologia 19, 12-19.

van der Hammen, L. (1979). Comparative studies in Chelicerata. I. The Cryptognomae (Ricinulei, Architarbi and Anactinotrichida). Zool. Verhand. Leiden 174, 1-62.

van der Hammen, L. (1982). Comparative studies in Chelicerata. II. Epimerata (Palpigradi and Actinotrichida). Zool. Verhand. Leiden 196, 1-78.

van der Hammen, L. (1985). Comparative studies in Chelicerata. III. Opilionida. Zool. Verhand. Leiden 220, 1-60.

van der Hammen, L. (1986). Acarological and arachnological notes. Zool. Meded. Leiden 60, 217-230.

van Deurs, B. (1973). Axonemal $12+0$ pattern in the flagellum of the motile spermatozoa of Nymphon leptocheles. J. Ultrastruct. Res. 42, 594-598.

van Deurs, B. (1974a). Pycnogonid sperm. An example of inter- and intraspecifical axonemal variation. Cell Tissue Res. 149, 105-111.

van Deurs, B. (1974b). Spermatology of some Pycnogonida (Arthropoda), with special reference to a microtubule-nuclear envelope complex. Acta Zool. (Stockholm) 55, 151-162.

Wegerhoff, R., and Breidbach, O. (1995). Comparative aspects of the chelicerate nervous system. In "The Nervous System of Invertebrates: An Evolutionary and Comparative Appproach" (O. Breidbach and W. Kutsch, Eds.), pp. 159-179. Birkhauser, Basel.

Weygoldt, P. (1986). Arthropod interrelationships-The phylogeneticsystematic approach. Z. Zool. Syst. Evol.-Forsch. 24, 19-35.
Weygoldt, P. (1998). Evolution and systematics of the Chelicerata. Exp. Appl. Acarol. 22, 63-79.

Weygoldt, P., and Paulus, H. F. (1979a). Untersuchungen zur Morphologie, Taxonomie und Phylogenie der Chelicerata. I. Morphologische Untersuchungen. Z. Zool. Syst. Evol.-Forsch. 17, 85-116.

Weygoldt, P., and Paulus, H. F. (1979b). Untersuchungen zur Morphologie, Taxonomie und Phylogenie der Chelicerata. II. Cladogramme und die Entfaltung der Chelicerata. Z. Zool. Syst. Evol.-Forsch. 17, 177-200.

Wheeler, W. C. (1990). When is an outgroup not an outgroup and how to root DNA sequence-based topologies without an outgroup. Cladistics 6, 363-367.

Wheeler, W. C. (1995). Sequence alignment, parameter sensitivity, and the phylogenetic analysis of molecular data. Syst. Biol. 44, 321-331.

Wheeler, W. C. (1996). Optimization alignment: The end of multiple sequence alignment in phylogenetics? Cladistics 12, 1-9.

Wheeler, W. C. (1998a). Molecular systematics and arthropods. In "Arthropod Fossils and Phylogeny" (G. D. Edgecombe, Ed.), pp. 9-32. Columbia Univ. Press, New York

Wheeler, W. C. (1998b). Sampling, groundplans, total evidence and the systematics of arthropods. In "Arthropod Relationships" (R. A. Fortey and R. H. Thomas, Eds.), pp. 87-96. Chapman \& Hall, London.

Wheeler, W. C. (1999). Measuring topological congruence by extending character techniques. Cladistics 15, 131-135.

Wheeler, W. C. (2000). Heuristic reconstruction of hypotheticalancestral DNA sequences: Sequence alignment vs direct optimization. In "Homology and Systematics" (R. Scotland and R. T. Pennington, Eds.), pp. 106-113. Taylor \& Francis, London.

Wheeler, W. C., Cartwright, P., and Hayashi, C. Y. (1993). Arthropod phylogeny: A combined approach. Cladistics 9, 1-39.

Wheeler, W. C., and Hayashi, C. Y. (1998). The phylogeny of extant chelicerate orders. Cladistics 14, 173-192.

Whiting, M. F., Carpenter, J. M., Wheeler, Q. D., and Wheeler, W. C. (1997). The Strepsiptera problem: Phylogeny of the holometabolous insect orders inferred from $18 \mathrm{~S}$ and $28 \mathrm{~S}$ ribosomal DNA sequences and morphology. Syst. Biol. 46, 1-68.

Winkler, D. (1957). Die Entwicklungen der äusseren Körpergestalt bei den Phalangiidae (Opiliones). Mitt. Zool. Mus. Berlin 33, 355-389.

Wirth, U. (1984). Die Struktur der Metazoen-Spermien und ihre Bedeutung für die Phylogenetik. Verh. Naturwiss. Ver. Hamburg 27, $295-362$.

Yamamichi, Y., and Sekiguchi, K. (1982). Axoneme patterns of spermatozoa of Asian horseshoe crabs. Experientia 38, 1219-1220.

Yoshikura, M. (1975). Comparative embryology and phylogeny of Arachnida. Kumamoto J. Sci. Biol. 12, 71-142.

Zrzavý, J., Hypsa, V., and Vlaskova, M. (1998). Arthropod phylogeny: Taxonomic congruence, total evidence and conditional combination approaches to morphological and molecular data sets. $I n$ "Arthropod Relationships" (R. A. Fortey and R. H. Thomas, Eds.), pp. 97-107. Chapman \& Hall, London. 